\title{
Industrial Process Heat Case Studies
}

Douglas W. Hooker

E. Kenneth May

Ronald E. West
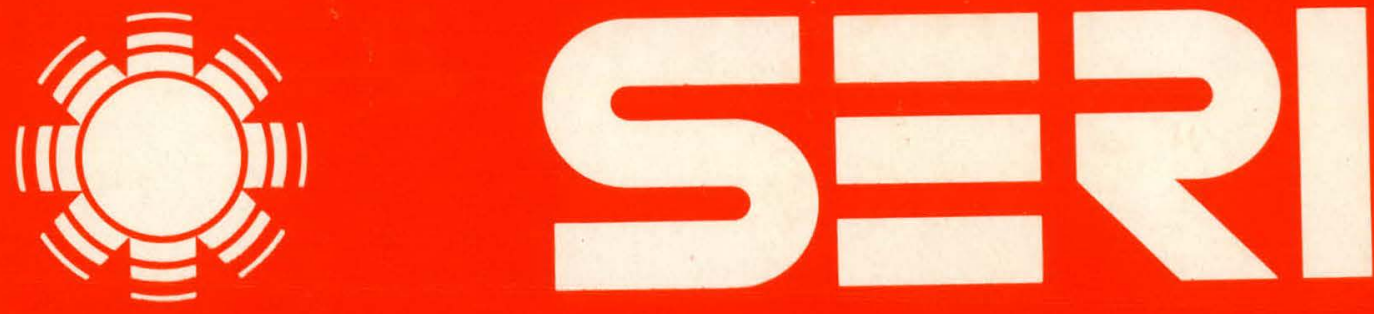

\section{Solar Energy Research Institute}

A Division of Midwest Research Institute

1617 Cole Boulevard

Golden, Colorado 80401

4

Operated for the

\section{U.S. Department of Energy} under Contract No. EG-77-C-01-4042 


\section{DISCLAIMER}

This report was prepared as an account of work sponsored by an agency of the United States Government. Neither the United States Government nor any agency Thereof, nor any of their employees, makes any warranty, express or implied, or assumes any legal liability or responsibility for the accuracy, completeness, or usefulness of any information, apparatus, product, or process disclosed, or represents that its use would not infringe privately owned rights. Reference herein to any specific commercial product, process, or service by trade name, trademark, manufacturer, or otherwise does not necessarily constitute or imply its endorsement, recommendation, or favoring by the United States Government or any agency thereof. The views and opinions of authors expressed herein do not necessarily state or reflect those of the United States Government or any agency thereof. 


\section{DISCLAIMER}

Portions of this document may be illegible in electronic image products. Images are produced from the best available original document. 
Printed in the United States of America

Available from:

National Technical Information Service

U.S. Department of Commerce

5285 Purt Royal Road

Springfield, VA 22161

Price:

\author{
Microfiche $\$ 3.00$ \\ Printed Copy $\$ 6.50$
}

\begin{abstract}
NOTICE
This report was prepared as an account of work sponsored by the United States Government. Neither the United States nor the United States Department of Energy, nor any of their employees, nor any of their contractors, subcontractors, or their employees, makes any warranty, express or implied, or assumes any legal liability or responsibility for the accuracy, completeness or usefulness of any information, apparatus, product or process disclosed, or represents that its use would not infringe privately owned rights.
\end{abstract}


SERI/TR-733-323

UC CATEGORIES: UC-58a,b,59b

INDUSTRIAL PROCESS HEAT

CASE STUDIES

DOUGLAS W. HOOKER

E. KENNETH MAY

RONALD E. WEST

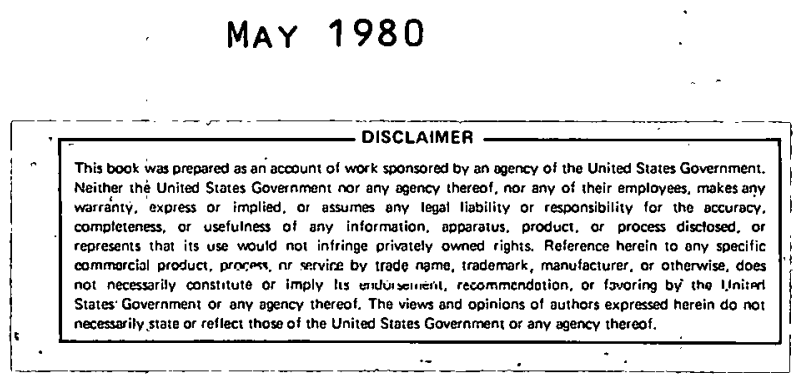

PREPARED UNDER TASK NO. 3473.20

Solar Energy Research Institute

1536 Cole Boulevard

Golden, Colorado 80401

A Division of Midwest Research Institute

Prepared for the

U.S. Department of Energy

Contract No. EG $\cdot 77 \cdot \mathrm{C} \cdot 01 \cdot 4042$ 
THIS PAGE

WAS INTENTIONALLY

LEFT BLANK 


\section{PREFACE}

This work is part of a SERI program to determine the economic and technical potential of solar energy to supply industrial process heat. The program is supported by the U.S. Department of Energy, Office of Solar Energy, Agricultural and Industrial Process Heat Branch, Task No. 3473.

The authors wish to acknowledge with appreciation the contributions of SERI staff members Kenneth C. Brown and Shirley A. Stadjuhar. Ken Brown provided valuable guidance and support throughout the course of the project. Shirley Stadjuhar assisted in the analysis and performed the software development required for the evaluation of solar industrial process heat applications.

Aouglas W Zlooker

Douglas W. Hooker

Staff Engineer

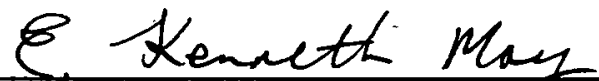

E. Kenneth May Staff Engineer

Konald $\varepsilon$. Weat toust

Ronald E. West

Consultant, University of Colorado
Approved for

SOLAR ENERGY RESEARCH INSTITUTE

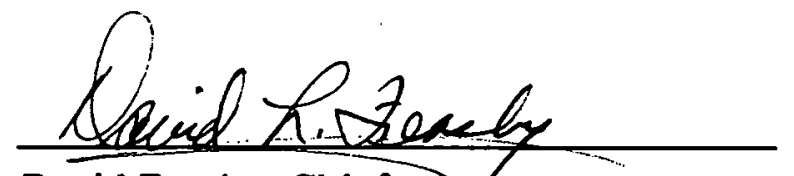

David Feasby, Chief

Incustrial Applications and

Poligy Branch

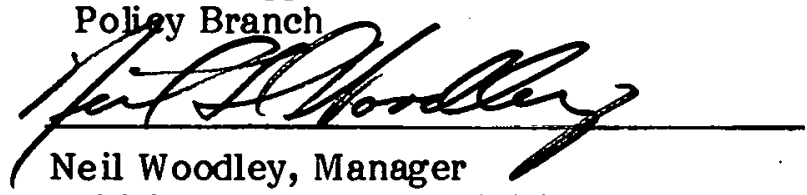

Utilities and Industry Division 
THIS PAGE

\section{WAS INTENTIONALLY \\ LEFT BLANK}




\section{SUMMARY}

The purpose of this report is to describe the results of investigations into potential solar industrial process heat (IPH) applications. IPH is the thermal energy used in the preparation and treatment of manuf actured goods. Since industry is the largest consumer of energy in the United States today, it represents a large market with significant potential for solar energy penetration. Due to the high capital cost of solar systems and the dependence of collector efficiency on operating temperature, the characteristics of manufacturing processes that require heat must be closely matched to the most suitable solar technology in order to achieve the maximum economic benefit. The IPH case study program at SERI has been formulated to provide the detailed information needed for an accurate assessment of solar IPH potential in selected industries. Several factors are considered in the studies, such as energy conservation options, reconfiguration of the industrial process for energy conservation and/or enhancement of solar applications, land availability, the capability of supplying solar energy to each process stream at the required temperature, solar preheat for one or more process energy streams, etc. Thus, the overall objectives of the IPH case study program are the following: to determine the near-term feasibility of solar IPH in selected industries with currently available solar collectors and systems; to identify energy conservation measures and energy-saving process modifications; to identify features of IPH systems that affect the potential use of solar energy; to test SERIs IPH analysis sof tware, PROSYS/ ECONMAT; to disseminate solar information to the industrial community; and to provide input and guidance to the SERI research program.

The results of seven IPH case studies are presented in this report. Individual plants in the following industries were studied: crude oil production (dewatering), aluminum container manufacturing, corn wet milling, polymeric resin manufacture (paint production), fluid milk processing, baking (bread and buns), and meat processing. For each process that was examined, the PROSYS software was used to simulate the average annual performance of the solar system most suited for the application. The ECONMAT sof tware then determined the cost effectiveness of the solar system compared to the conventionai fuel source currently being used in the process.

For the seven plants studied, few solar applications were found that are economical in the near term. The few potentially attractive solar applications that were identified resulted from unusual circumstances in the individual IPH applications, such as very expensive or inefficiently used conventional fuel sources, or from solar system designs that were able to displace more fossil fuel gross energy value than actually supplied by the solar system. For example, the crude oil dewatering system that was studied used relatively expensive propane as the primary fuel source in a very inefficient system that was not easily modified to conserve energy. Solar energy was able to economically compete in this application by supplying energy efficiently through an additional heat exchanger. In the aluminum container manufacturing plant, a solar system was postulated that could displace more fuel than it supplied through the use of air preheat and recycle in a directfired furnace application. In this_case, the solar system approached cost effectiveness.

As a result of these case studies, factors have been identified that favor the application of solar IPH systems. These factors can be grouped into four categories: environmental, process, economic, and company-related. Table S-1 lists the major factors in each category. A solar IPH application with most of the favorable features described in Table S-1 is potentially an ceonomical application that could approsch or meet current industry investment criteria. 


\section{Table S-1. FACTORS FAVORING THE APPLICATION OF SOLAR IPH SYSTEMS}

Environmental Paetors

- High insolation levels-either total or direct, depending on the solar technology proposed

- High ambient temperatures-to reduce thermal losses (partirilarly for non= concentrating collectors) and to allow the use of water as a heat transf er fluid

- A pollution-free microclimate-so as not to dirty or corrode collector surfaces

- A polluted macroclimate or area with strict air pollution regulations-where no additional air pollution emissions are allowed and where such controls are a restraint on levels of production

\section{Process Mactors}

- Low-temperature process-so that the cheapest type of collector, operating at a high efficiency, can be employed

- Continuous, steady operations ( $24 \mathrm{~h} /$ day, 7 days/week) where exact temperature control is not critical

- Liquid heating application as apposed to air or steam heating

- Built-in process storage-which helps even out fluctuations in the thermal output of the collectors, and which can act as a reservoir of heat produced by the solar system (during the weekend, or long summcr evenings)

- Easy retrofit of the the solar system-so as to minimize costs

- Inefficient fuel usage, not easily rectified-so that energy delivered from the solar system replaces more than the equivalent Btu content of fossil fuel

\section{Roonomic Pueturs}

- High and rapidly escalating fuel costs

- Uncertainties regarding fuel supplies-such as interruptible natural gas contracts

- Sufficient capital to finance investments in a solar energy system

- Long paybuck periods or demand for low rates of return on energy investments

- High federal, state, or local tax incentives for solar investments

- Energy-intensive industrial operation and energy costs representing a large fraom tion of value added

- All economical energy conservation measures already incorporated

- Cheap land or a strong roof available close to the delivery point of the required energy; salt available at little or no cost, if a salt pond is a solar option

- Low labor costs - because solar installations are labor intensive.

- New plant-allowing a solar system to be incorporated from the beginning

\section{Company Pactors}

- Desire to install a solar system and an enthusiastic work force from top management down

- A skilled maintenance and engineering work force--so that the solar system can be run and maintained at maximum efficiency

- Progressive management--which gives some recognition to the noneconomic but social values of solar energy, such as public relations, security of long-term supply, and reduced air pollution, leading perhaps to the application of less stringent payback criteria to investments in solar systems 
The increased cost of alternative fuels will probably influence near-term investments in solar technology more than any factor. The combination of energy deregulation in the United States with rapid price increases for imported energy will favor the introduction of solar IPH systems. Consequently, although solar energy is presently not competitive with efficiently used conventional energy sources, near-term solar IPH applications are possible if the costs of solar equipment rise at a lower rate than that of conventional alternatives.

Thus, the degree to which solar technology costs can be constrained will probably determine how quickly solar hardware is adopted by industry. Improved performance, leading to higher operating efficiencies, increased reliability, mass production techniques, and measures to reduce design and installation costs are needed. More research into air collector systems is also needed to develop efficient systems with low parasitic power requirements.

Another conclusion resulting from these studies is that the trend toward energy conservation could help foster solar energy applications in the near term. Both conservation and solar energy technologies face similar obstacles in the areas of financing, achieving cost effectiveness, and research and development needs (such as inexpensive heat exchangers designed for small temperature differentials). Many conservation measures, such as process temperature reductions, replacement of steam by hot water systems, and other measures that increase process efficiency, are favorable to solar appliçations. Although conservation measures should generally be considered before using solar systems for IPH applications, the resulting efficient industrial process may be amenable to economical solar applications sooner than the process would be without the conservation measures.

The PROSYS/ECONMAT computer codes proved to be very useful tools for the case study analyses, particularly in regard to their flexibility and ease of application. Continued development of these codes is warranted so that, after they are publicly distributed, industry could perform its own initial screening of solar IPH applications. 
THIS PAGE

\section{WAS INTENTIONALLY \\ LEFT BLANK}


TABLE OF CONTENTS

$\underline{\text { Page }}$

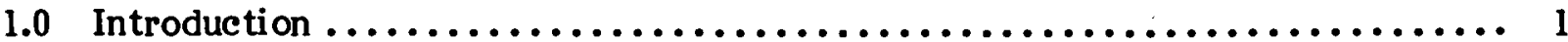

1.1 Industrial Energy Use $\ldots \ldots \ldots \ldots \ldots \ldots \ldots \ldots \ldots \ldots \ldots \ldots \ldots \ldots \ldots \ldots \ldots \ldots$

1.2 Industrial Case Study Program ...........................

1.2.1 The Need for Case Studies......................... 1

1.2.2 Case Study Methodology .......................... 2

2.0 IPH Case Study: Crude Oil Dewatering $\ldots \ldots \ldots \ldots \ldots \ldots \ldots \ldots \ldots \ldots \ldots \ldots \ldots \ldots$

2.1 Description of Process $\ldots \ldots \ldots \ldots \ldots \ldots \ldots \ldots \ldots \ldots \ldots \ldots \ldots \ldots \ldots \ldots \ldots$

2.2 Energy Conservation Analysis .......................... 6

2.3 Solar Energy Applications Analyses $\ldots \ldots \ldots \ldots \ldots \ldots \ldots \ldots \ldots \ldots \ldots \ldots \ldots \ldots$

2.4 Conclusions ..................................... 11

3.0 IPH Case Study: Aluminum Container Manufacturing . . . . . . . . . . . . 13

3.1 Description of Process .............................. 13

3.2 Analysis for Energy Conservation ......................... 14

3.3 Solar Energy Applications Analysis $\ldots \ldots \ldots \ldots \ldots \ldots \ldots \ldots \ldots \ldots \ldots \ldots \ldots \ldots \ldots$

3.4 Conditions on Solar Design $\ldots \ldots \ldots \ldots \ldots \ldots \ldots \ldots \ldots \ldots \ldots \ldots \ldots \ldots \ldots \ldots \ldots$

3.5 Solar Applications ................................... 16

3.6 Summ ary of Solar Applications . ......................... 23

3.7 Appendix: Data Used in the Case Study ................... 23

4.0 IPH Case Study: Wet Corn Milling $\ldots \ldots \ldots \ldots \ldots \ldots \ldots \ldots \ldots \ldots \ldots \ldots \ldots \ldots \ldots$

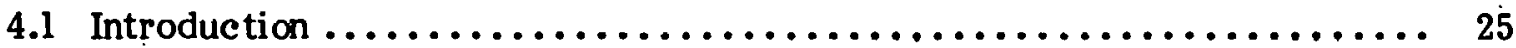

4.2 Corn Processing Operations ............................. 25

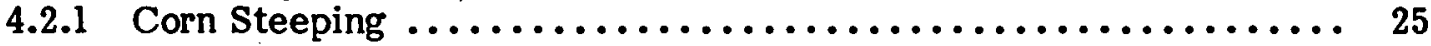

4.2.2 Starch Drying ............................... 27

4.2 .3 Gluten Feed Drying $\ldots \ldots \ldots \ldots \ldots \ldots \ldots \ldots \ldots \ldots \ldots \ldots \ldots \ldots \ldots \ldots \ldots \ldots$

4.3 Energy Conservation ................................ 29

4.4 Solar Energy Applications $\ldots \ldots \ldots \ldots \ldots \ldots \ldots \ldots \ldots \ldots \ldots \ldots \ldots \ldots \ldots \ldots \ldots$

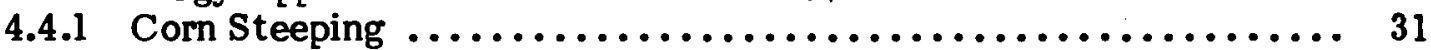

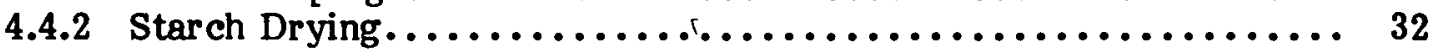

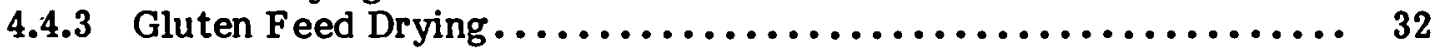

4.4 .4 Results of Solar Analysis .......................... 32

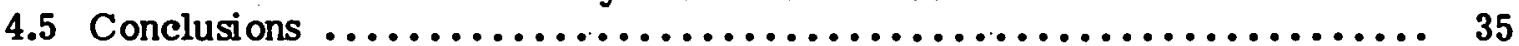

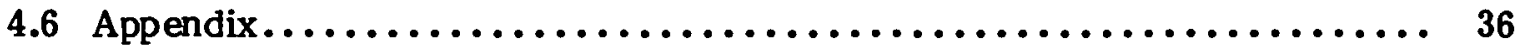

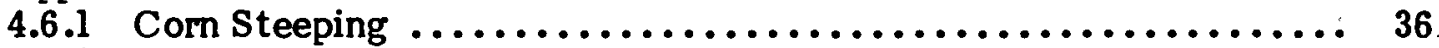

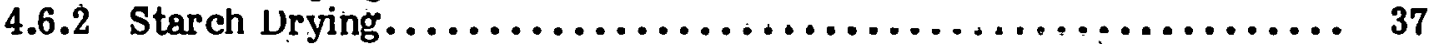

4.6.3 Gluten Feed Drying $\ldots \ldots \ldots \ldots \ldots \ldots \ldots \ldots \ldots \ldots \ldots \ldots \ldots \ldots \ldots$

5.0 IPH Case Study: Polymeric Resin Manufacture................. 41

5.1 Introduction $\ldots \ldots \ldots \ldots \ldots \ldots \ldots \ldots \ldots \ldots \ldots \ldots \ldots \ldots \ldots \ldots \ldots \ldots \ldots \ldots$

5.2 Description of Processes $\ldots \ldots \ldots \ldots \ldots \ldots \ldots \ldots \ldots \ldots \ldots \ldots \ldots \ldots \ldots \ldots, \ldots 1$

5.3 Acrylic Resin Manuf acture $\ldots \ldots \ldots \ldots \ldots \ldots \ldots \ldots \ldots \ldots \ldots \ldots \ldots \ldots \ldots$ 
TABLE OF CONTENTS (concluded)

$\underline{\text { Page }}$

5.4 Alkyd Resin Manuf acture............................. 42

5.5 Energy Conservation Potential ........................... 43

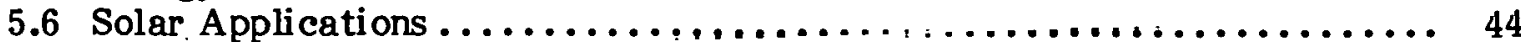

5.7 Summarȳ..................................... 48

6.0 IPH Case Study: Fluid Milk Processing $\ldots \ldots \ldots \ldots \ldots \ldots \ldots \ldots \ldots \ldots \ldots \ldots \ldots . . \ldots 9$

6.1 Introduction $\ldots \ldots \ldots \ldots \ldots \ldots \ldots \ldots \ldots \ldots \ldots \ldots \ldots \ldots \ldots \ldots \ldots \ldots \ldots$

6.2 Process Heat Utilization $\ldots \ldots \ldots \ldots \ldots \ldots \ldots \ldots \ldots \ldots \ldots \ldots \ldots \ldots \ldots \ldots \ldots \ldots$

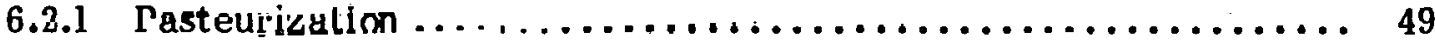

6.2 .2 Deodorization .............................. 49

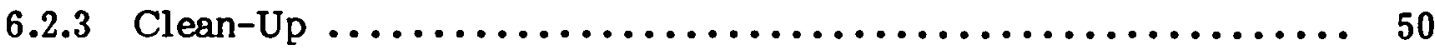

$6.2 .4 \quad M$ is cellaneous Processes .......................... 50

6.3 Energy Conservation $\ldots \ldots \ldots \ldots \ldots \ldots \ldots \ldots \ldots \ldots \ldots \ldots \ldots \ldots \ldots \ldots \ldots \ldots$

6.4 Solar Energy Systems $\ldots \ldots \ldots \ldots \ldots \ldots \ldots \ldots \ldots \ldots \ldots \ldots \ldots \ldots \ldots \ldots \ldots$

6.5 Summary.................................... 55

7.0 IPH Case Study: Bread and Bun Bakery $\ldots \ldots \ldots \ldots \ldots \ldots \ldots \ldots \ldots \ldots \ldots \ldots$

7.1 Process Description $\ldots \ldots \ldots \ldots \ldots \ldots \ldots \ldots \ldots \ldots \ldots \ldots \ldots \ldots \ldots \ldots \ldots \ldots$

7.2 Energy Balances $\ldots \ldots \ldots \ldots \ldots \ldots \ldots \ldots \ldots \ldots \ldots \ldots \ldots \ldots \ldots \ldots \ldots \ldots$

7.3 Conservation Potential Analysis ....................... 63

7.4 Solar Applications ....................................... 64

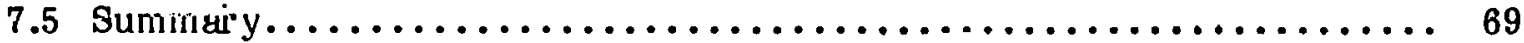

8.0 IPH Case Study: Meat Processing $\ldots \ldots \ldots \ldots \ldots \ldots \ldots \ldots \ldots \ldots \ldots \ldots \ldots \ldots$. $7 \ldots \ldots$

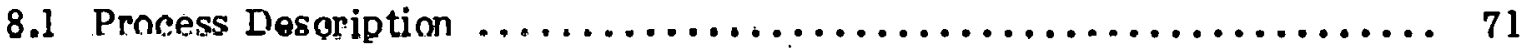

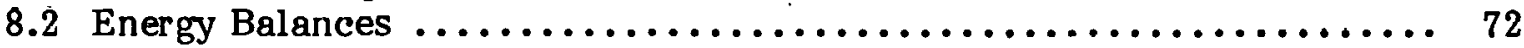

8.3 Energy Conservation Potential ....................... 74

8.4 Solar Applications ................................. 75

9.0 Conclusions $\ldots \ldots \ldots \ldots \ldots \ldots \ldots \ldots \ldots \ldots \ldots \ldots \ldots \ldots \ldots \ldots \ldots \ldots \ldots$

10.0 Ref crences $\ldots \ldots \ldots \ldots \ldots \ldots \ldots \ldots \ldots \ldots \ldots \ldots \ldots \ldots \ldots \ldots \ldots \ldots \ldots \ldots \ldots \ldots$

Appendices

Appendix A - A Description of the PROSYS/ECONMAT Computer Program $\ldots \ldots \ldots 85$

Appendix B - Solar System Schematics .......................... 91

Appendix $\mathrm{C}-$ Insolation Maps of the United Stutes $\ldots \ldots \ldots \ldots \ldots \ldots \ldots \ldots \ldots \ldots$

Appendix D - Collector Efficiency Versus Operating Temperature........... 103

Appendix E - The Advantages of Liquid Over Steam Heating Systems for Industrial Process Heat and the Potential for Solar Energy Applications .................................... 107 


\section{LIST OF FIGURES}

$\underline{\text { Page }}$

2-1 Crude Oil/Water Separator Tank $\ldots \ldots \ldots \ldots \ldots \ldots \ldots \ldots \ldots \ldots \ldots \ldots \ldots \ldots \ldots$

2-2 Crude Oil/Water Separation Facility: Oil-Through-Collector

System ...................................... 7

2-3 Crude Oil/Water Separation Facility: External Heat Exchange

System ...................................... 9

2-4 Crude Oil/Water Separation Facility: In-Tank Heat Exchange

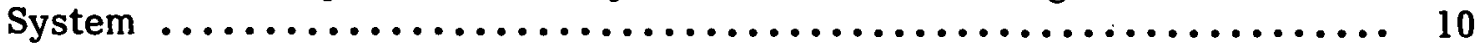

2-5 Crude Oil/Water Separation Facility: Present Worth of External

Heat Exchange System Versus Conventional Fuel Cost.............. 12

3-1 Schematic Diagram of Metal Container Process .................. 13

3-2 Metal Container Process Energy Flow Diagram ................... 14

3-3 Schematic Diagram of System Using Can Coolers to Preheat

Incoming Air ..................................... 19

3-4 Schematic Diagram of Solar Preheating of Combustion Air............ 19

3-5 Schematic Diagram of Recycling Hot Gases and Solar Preheat.......... 20

3-6 Flow Diagram of Recycling Hot Gases and Solar Preheat $\ldots \ldots \ldots \ldots \ldots \ldots$

4-1 Schematic Outline of Corn Wet-Milling Process $\ldots \ldots \ldots \ldots \ldots \ldots \ldots \ldots \ldots$

4-2 Section View of Continuous Through-Circulation Conveyor Dryer ........ 27

4-3 Two-Stage Pneumatic Conveyor Dryer $\ldots \ldots \ldots \ldots \ldots \ldots \ldots \ldots \ldots \ldots \ldots$

4-4 Direct Heat Cocurrent Rotary Dryer.......................... 29

5-1 Low-Temperature Reactor-Typical Temperature Profile ............ 42

5-2 High-Temperature Reactor-Typical Temperature Profile............. 43

6-1 Milk Pasteurization Process $\ldots \ldots \ldots \ldots \ldots \ldots \ldots \ldots \ldots \ldots \ldots \ldots \ldots \ldots \ldots \ldots$

$7-1 \quad$ Schematic of Bakery Process $\ldots \ldots \ldots \ldots \ldots \ldots \ldots \ldots \ldots \ldots \ldots \ldots \ldots \ldots$

7-2 Bakery Energy Flow Diagram $\ldots \ldots \ldots \ldots \ldots \ldots \ldots \ldots \ldots \ldots \ldots \ldots \ldots \ldots \ldots \ldots$

7-3 Estimated Energy Content Versus Temperature.................. 64 
LST OP FIGURES (concluded)

Page

7-4 Schematic Diagram of Heat Recovery and Solar Preheat of Bakery Water .................................... 67

7-5 Schematic Diagram of Hot-Air Recycle and Solar Preheat of Make-up Air .................................... 68

8-1 Meat Processing Plant Energy Flows: Percentages of Total Process Energy Input $\left(3.2 \times 10^{4} \mathrm{GJ} / \mathrm{yr}\right)$ relative to $21^{\circ} \mathrm{C}$ Contained in Each Stream

0-2 Truẹk Wásh Energy Flows; Percentages of Total Enel'yy Input $\left(2.9 \times 10^{3} \mathrm{GJ} / \mathrm{yr}\right)$ Relative to $21^{\circ} \mathrm{C}$ Contained in Each Stream ........ 73

B-1 Simplified Schematic of Hot Water Direct Solar System . . . . . . . . . . . .. 92

B-2 Simplified Schematic of Hot Water Indirect Solar System . . . . . . . . . . . . 93

B-3 Simplified Schematic of Hot Air Direct Solar System . . . . . . . . . . . . . . 94

B-4 Solar Hot Air Indirect System ........................... 95

B-5 Simplified Schematic of Water Flash Steam Generating System ......... 96

B-6 Simplified Schematic of Indirect Steam Generating System $\ldots \ldots \ldots \ldots \ldots \ldots$

C-1 Average Daily Global Solar Radiation on a Horizontal Surfage $\left(\mathrm{kJ} / \mathrm{m}^{2}\right) \ldots \ldots \ldots \ldots \ldots \ldots \ldots \ldots \ldots \ldots \ldots \ldots \ldots \ldots \ldots \ldots \ldots \ldots \ldots$

C-2 Average Daily Direct Normal Solar Radiation $\left(\mathrm{kJ} / \mathrm{m}^{2}\right) \ldots \ldots \ldots \ldots \ldots$

D-1 Annual Energy Output of Several Collector Types over a Range of Temperatures for El Paso ............................. 104

D-2 Aruual Energy Output of Several Collector Types over a Range of Temperatures for Charleston, SC 


\section{LIST OF TABLES}

$\underline{\text { Page }}$

2-1 Economic Parameters Used in ECONMAT Life-Cycle Analysis ........... 7

2-2 Solar System Parameters ............................... 8

3-1 . Solar System Parameters .............................. 17

3-2 Energy Content of Exit Gas Streams $\ldots \ldots \ldots \ldots \ldots \ldots \ldots \ldots \ldots \ldots \ldots \ldots \ldots \ldots$

3-3 . Solar System Parameters: Solar Preheat to $87^{\circ} \mathrm{C}\left(189^{\circ} \mathrm{F}\right) \ldots \ldots \ldots \ldots \ldots \ldots \ldots$

4-1 Economic Parameters Used in Lif e-Cycle Cost Analysis ............... 31

4-2 Solar System: Engineering Parameters ....................... 33

4-3 Solar System: Economic Parameters......................... 34

5-1 Economic Parameters Used in ECONMAT Life-Cycle Analysis ........... 45

5-2 Solar System Performance..............................46

5-3 Solar System Costs $\ldots \ldots \ldots \ldots \ldots \ldots \ldots \ldots \ldots \ldots \ldots \ldots \ldots \ldots \ldots \ldots \ldots \ldots \ldots \ldots \ldots \ldots$

6-1 Solar System Performance............................. 52

6-2 Solar System: Economic Parameters....................... 53

6-3 Economic Parameters Used in Lif e-Cycle Cost Analysis ............... 54

7-1 Process Input and Output Energy for Bakery $\ldots \ldots \ldots \ldots \ldots \ldots \ldots \ldots \ldots \ldots$

7-2 Results of Solar Applications to Existing Process Requirements.......... 65

7-3 Economic Parameters Used in ECONMÁT Life-Cycle Analysis........... 66

7-4 Results of Solar Applications to Preheating Bakery Water Streams ........ 66

7-5 Results of Heat Recovery and Solar Water Preheating . . . . . . . . . . . . 67

7-6 Results of Partial Gas Recycle and Solar Preheat of Incoming Air ......... 68

8-1 Process Input and Output Energy for Meat Processing Plant ............. 74

8-2 Results of Solar Applications $\ldots \ldots \ldots \ldots \ldots \ldots \ldots \ldots \ldots \ldots \ldots \ldots \ldots \ldots \ldots$

9-1 Factors Favoring the Application of Solar IPH Systems ............. 78

A-1 Features of the PRUSYS/ECONMAT Code.................... 86 


\section{LST OF TABLES (concluded)}

\section{Page}

A-2 Collector Parameters used in PROSYS Simulations ................ 87

A-3 Definition of Payback Perind $\ldots \ldots \ldots \ldots \ldots \ldots \ldots \ldots \ldots \ldots \ldots \ldots \ldots$ 


\section{SECTION 1.0}

\section{INTRODUCTION}

\subsection{INDUSTRIAL ENERGY USE}

Industry is the largest consumer of energy in the United States today. Of the U.S. gross energy demand, about $37 \%$ is used by industry. Approximately half of this demand is for industrial process heat (IPH)-the thermal energy used in the preparation and treatment of manufactured goods (Brown et al. 1980). Since approximately 27\% of the total IPH requirement is at temperatures below $288^{\circ} \mathrm{C}\left(550^{\circ} \mathrm{F}\right)$, commercially available solar collectors could potentially be applied to this large market.

\subsection{INDDUSTRIAL CASE STUDY PROGRAM}

\subsubsection{The. Need for Case Studies}

The nature of solar technologies, particularly the dependence of solar collector efficiency on operating temperature and the cost of solar systems, makes it imperative to achieve maximum economic benefit by closely matching industrial process characteristics to the most suitable solar technology. Such an end-use matching approach has a theoretical basis: it maximizes Second Law (Second Law of Thermodynamics) efficiency, i.e, minimizing the production of entropy.

It is apparent that to determine the industrial potential for the application of solar energy, more information than the gross fuel use figures published in the literature are required. Such figures suffice for the application of conventional sources of fuel, but are inadequa te to gauge the applicability of solar technologies. With this in mind, a wideranging program was initiated at the Solar Energy Research Institute (SERI) to determine patterns of incustrial process heat usage. Factors such as temperature requirements, plant scheduling, fuel costs; and insolation levels were regarded as highly important. This information, gathered from the literature and numerous, brief plant visits, allowed only a rough overall assessment to be made of possible solar penetration of the industrial fuels market. More detalled information is required for an assessment to be made with any degree of confidence. The case study program was formulated to provide such information. This approach can consider alternatives to existing fuel use such as energy conservation, different fuels, or the reconfiguration of the process. Site-specific factors that could preclude the solar option, such as land availability, can be identified. When detailed information is available for specific plants, extensions and broad generalizations regarding solar potentials can be made for plants industry-wide. In summary, the objectives of the IPH case study progra m are as follows:

- to determine the near-term feasibility of solar IPH in selected industries, both technically and economically, with currently available solar collectors and systems;

- to identify energy conservation measures and energy-saving IPH process modifications, where possible;

- to identify characteristics of IPH systems that affect the potential use of solar energy; 
- to test SERI's solar IPH analysis software (PROSYS/ECONMAT) and to identify improvements;

- to disseminate information to the industrial community about solar IPH applications; and

- to provide inputs and guidance to the SERI research program.

\subsubsection{Case study Methodology}

Solar IPH case studies were performed for plants in several different industries. A description of seven case studies is presented in this report. The procedure for each case study was as follows:

- Contact was mare with a person in the upper' inulugement of the company to arrange for the study and to gain initial infurmulion about the industrial plant. In some cases, SERI initiated the contact; in others, the company approached SERI with an interest in solar energy, and this led to a case sludy.

- A site visit and plant tour were conducted with members of the SERI study team.

- During meetings and subsequent telephone conversations between SERI and the plant staff, individual processes were chosen for study, and data for heat and mass balances were gathered. In most cases, all the needed information was not available. Thus, either the needed in-plant measurements were taken by the plant staff or by SERI, or the missing data were estimated according to the experience of plant personnel or from the results of energy studies of similar plants.

- Potential energy conservation and/or process reconfiguration measures (if any) were identified. In those cases where sufficient information was available, the energy savings that could be expected from particular conservation measures were calculated.

- Solar systems designed by SERI were sized for each application and their longterm performance determined by using the PROSYS software. For those applications where specific conservation measures were identified, the solar analysis was also performed based on the assumption that the conservation measures were in place and that the plant energy demand was lessened.

- Economic analyses of each application were performed using the ECONMAT computer code, yielding results such as present value and discounted payback period.

- The results of the case study were written into a report and submitted to the plant staff for review. Comments received by SERI were incorporated into the report.

The primary tools used in the case study analyses were the PROSYS/ECONMAT computer codes. A complete description of these codes can be found in Brown et al. (1980). Appendix A includes a brief explanation of the codes, including the analysis techniques, assumptions, etc. For the purposes of each case study, the PROSYS code calculates the long-term average performance of the generic types of solar collectors that are capable of supplying the desired process load. To size the collector field, it is assumed that the maximum thermal output of the collectors can be absorbed by the process. Since no thermal storage is incorporated in the delivery system (back-up energy 
sources can supply $100 \%$ of the process load), sizing is simply a matter of dividing the process load by the maximum delivery rate (at whatever time this occurs during the year) per square foot of collector surface.

Information stored within the data bases of the ECONMAT program is used to determine the initial cost of the installed solar system. Auxiliary equipment serving to transport the collected energy to the process is costed based on the simplified system schematics illustrated in Appendix B. Heat is generally delivered as either hot air, hot water, or steam. These fluids can be passed directly through the collector field, or an auxiliary heat transfer fluid can be used with a heat exchanger to indirectly impart heat to the process. The advantages and disadvantages of each scheme are also briefly discussed in Appendix B. General information of relevance to this report is presented in Appendix C (United States insolation maps-both of direct normal and total solar radiation on a horizontal surface) and in Appendix D, which illustrates graphically the dependence of various types of solar collectors on the temperatures at which they operate. Appendix $E$ is a brief comparison of high-temperature water and steam heat delivery systems. There are many technical and economic factors favoring liquid-based systems. Such systems are also more easily integrated with solar technologies.

The case studies described in this report represent a part of SERI's initial effort to define near-term industrial process heat applications for currently available solar technologies. They were not intended as detailed audits of energy use or conservation potential, nor were postulated improvements in future solar collector performance or economics included. However, the case studies do serve as good indicators of needed improvements in solar and auxiliary equipment. This work identifies those technical, economic, and site-specific factors most likely to influence the early adoption of solar technologies to provide supplemental industrial process heat. 
$r$

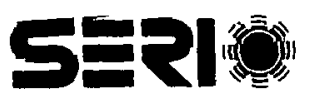




\section{SECTION 2.0}

\section{IPH CASE STUDY: CRUDE OIL DEWATERING}

An industrial process heat case study was performed for a crude-oil/water separation facility owned by an independent oil producer. The particular facility chosen was one a mong 15 small units operated by the company in Wyoming. The study was performed at their request.

\subsection{DESCRIPTION OF PROCESS}

A schematic of the separation facility is shown in Fig. 2-1. The crude-oil/water emulsion enters the separator tank at $80^{\circ} \mathrm{F}$ from a nearby oil well at a rate of $725 \mathrm{lb} / \mathrm{h}$. The facility normally operates 24 hours per day, 7 days per week, on a year-round basis. The ratio of crude oil to water in the incoming emulsion is about 59 to 1 by volume. The emulsion is heated in the separator tank, to $135^{\circ} \mathrm{F}$ by a propane burner system. A heat rate of about $20,000 \mathrm{Btu} / \mathrm{h}$ is required to increase the emulsion temperature by $55^{\circ} \mathrm{F}$. This corresponds to an annual energy use of $1.75 \times 10^{8} \mathrm{Btu}$. Once heated to $135^{\circ} \mathrm{F}$ in the separator tank, the emulsion separates into its individual crude oil and water components. The less-dense crude oil floats to the top of the tank, where it is skimmed off, and water is drained from the bottom.

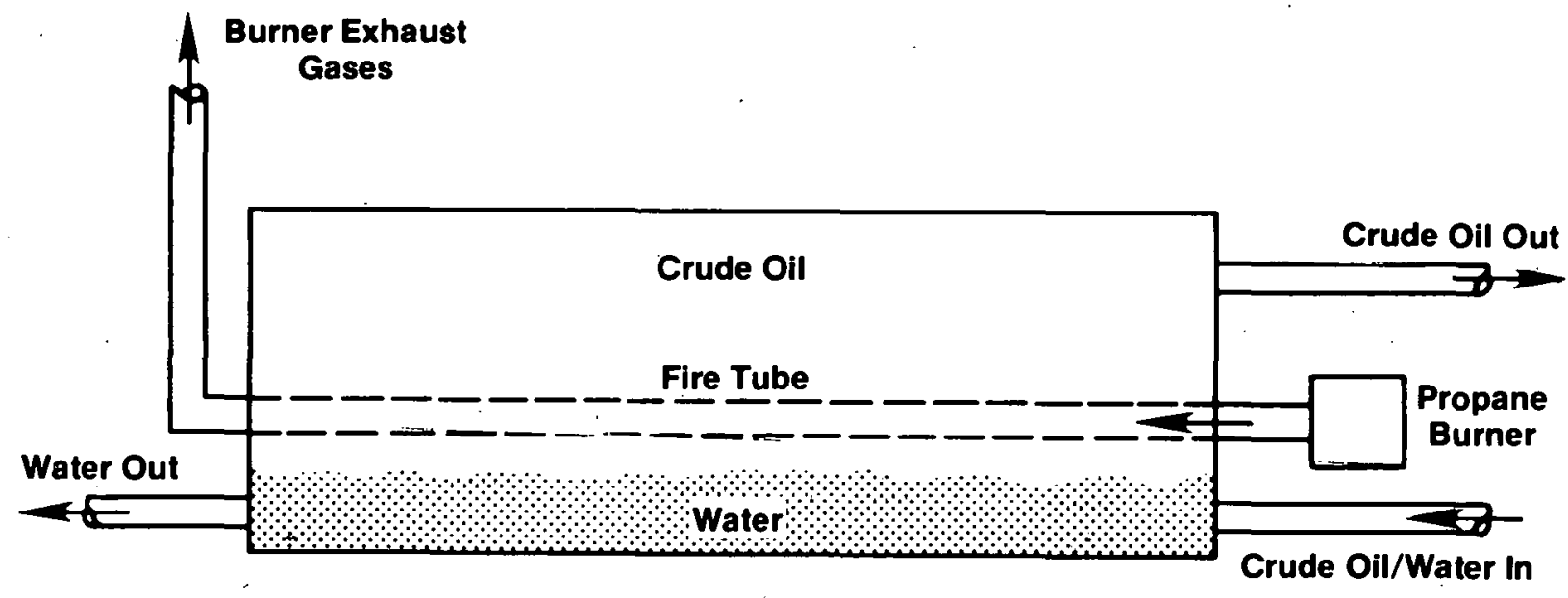

Process Data

$725 \mathrm{lb} / \mathrm{h}$ of Crude Oil/Water Emulsion

Required Heat Rate: 20,000 Btu/h

Required Annual Energy Use: 1.75 × $10^{\circ}$ Btu

Process Temperature: $135^{\circ} \mathrm{F}$

Propane Usage: $1,370 \mathrm{gal} / \mathrm{mon}$ th

Propane Energy Input: $1,49 \times 10^{9} \mathrm{Btu} / \mathrm{yr}$.

Figure 2-1. Crude Oil/ Water Separator Tank 
Many oil wells, particularly during their initial phase of production, produce natural gas, which is used as the fuel source for the separators. However, wells similar to the one considered here produce little or no gas, so propane is used as a source of fuel for the separation process. As of March 1979, the company was purchasing propane at 52\&/gal, which is equivalent to $\$ 5.62 / 10^{6} \mathrm{Btu}$ (assuming propane has a heating value of $92,500 \mathrm{Btu} / \mathrm{gal})$. Approximately $1370 \mathrm{gal} / \mathrm{month}$ of propane are used in the sepgrator at the well under study, resulting in an annual propane energy input of $1.49 \times 10^{9} \mathrm{Btu} / \mathrm{yr}$. Since $1.75 \times 10^{8} \mathrm{Btu} / \mathrm{yr}$ are required for heating the crude-oil/water emulsion, this implies a net propane energy utilization efficiency of about $11.7 \%$.

The low-efficiency use of propane in the system results from the design of the separator tank. The tank has a diameter of 4 feet and a length of 20 feet. It is oriented horizontally, with the propane burner located at one end. A fire tube, of approximately 6-in. diameter, runs axially through the tank from the propane burner, connects with a 90degree bend outside the tank on the end opposite the burner, and then extends vertically in to the air above the tank to disperse the burner exhaust gases to the atmosphere. When the propane burner is turned on, high-temperature gases flow down the fire tube, thus transferring heat to the emulsion. This mode of heat transfer is inherently inefficient. Consequently, only $11.7 \%$ of the heat content of the propane is transferred to the liquid in the tank. The remaining $88.3 \%$ of the propane energy content leaves the separator tank through the vertical fire tube extension and is lost.

\subsection{RNERGY CONSERVATION ANALYSIS}

An evaluation of energy conservation measures indicated little potential for additional energy savings with the existing system design. The separator tank currently has foam insulation (exact thickness unknown) encased in aluminum sheathing. Assuming $2.0 \mathrm{in.} \mathrm{of}$ foam insulation and an ambient temperature of $0^{\circ} \mathrm{F}$, the heat loss from the tank to the environment would be approximately $3400 \mathrm{Btu} / \mathrm{h}$. Thus, energy losses during most of the year would be less than or equal to this value. Additional insulation could be added to the tank to reduce the losses, but the amount of energy that could be saved would be insignificant compared to the a mount lost in the burner exhaust gases. Insufficient information was available to estimate how much of the burner exhaust gases, if any, could be recycled to the burner to reduce the use of propane.

\subsection{SOLAR ENRRGY APPLCATIONS ANALYSES}

The computer codes PROSYS/ECONMAT (Brown et al. 1980) described in Appendix A were used to analyze the potential applications of solar energy for the separator tank heating. Relevant economic parameters for this application are listed in Tables 2-1.

Different solar system configurations can be employed to heat the emulsion. The following three systems were examined:

- An oil-through-collector system (Fig. 2-2), where the crude-oil/water emulsion is pumped from the well directly to the collector array, heated to the process temperature, and sent to the separator tank;

- An external heat exchange system (Fig. 2-3), where the crude-oil/wa ter emulsion is heated to the process temperature by heat exchange with a closed-loop liquid collector system before entering the separator tank; and 
- An in-tank exchange system (Fig. 2-4), where the crude-oil/water emulsion is pumped to the separator tank from the oil well and is heated to the process temperature by a closed-loop liquid collector system by a heat exchanger inside the separator tank.

Each system has advantages and disadvantages, which will be examined in the following paragraphs.

Table 2-1. ECONOMIC PARAMETERS USED IN ECONMAT LIFE-CYCLE ANALYSIS

\begin{tabular}{lc}
\hline Rate of Return & \\
General Inflation Rate & $12 \%$ \\
Real Fuel Escalation Rate & $6 \%$ \\
Operation, Maintenance, Property Tax, & $5 \%$ \\
$\quad$ and Insurance as a Fraction of & \\
Investment & $2 \%$ \\
Corporate Tax Rate & $50 \%$ \\
System Lifetime & 20 years \\
Solar Tax Credit & $20 \%$ \\
Interest During Construction & $9 \%$ \\
Conventional Fuel Cost (propane) & $\$ 5.62 / 10^{6} \mathrm{Btu}$ \\
Labor Rate & $\$ 19 / \mathrm{h}$
\end{tabular}

Flat Plate Collectors

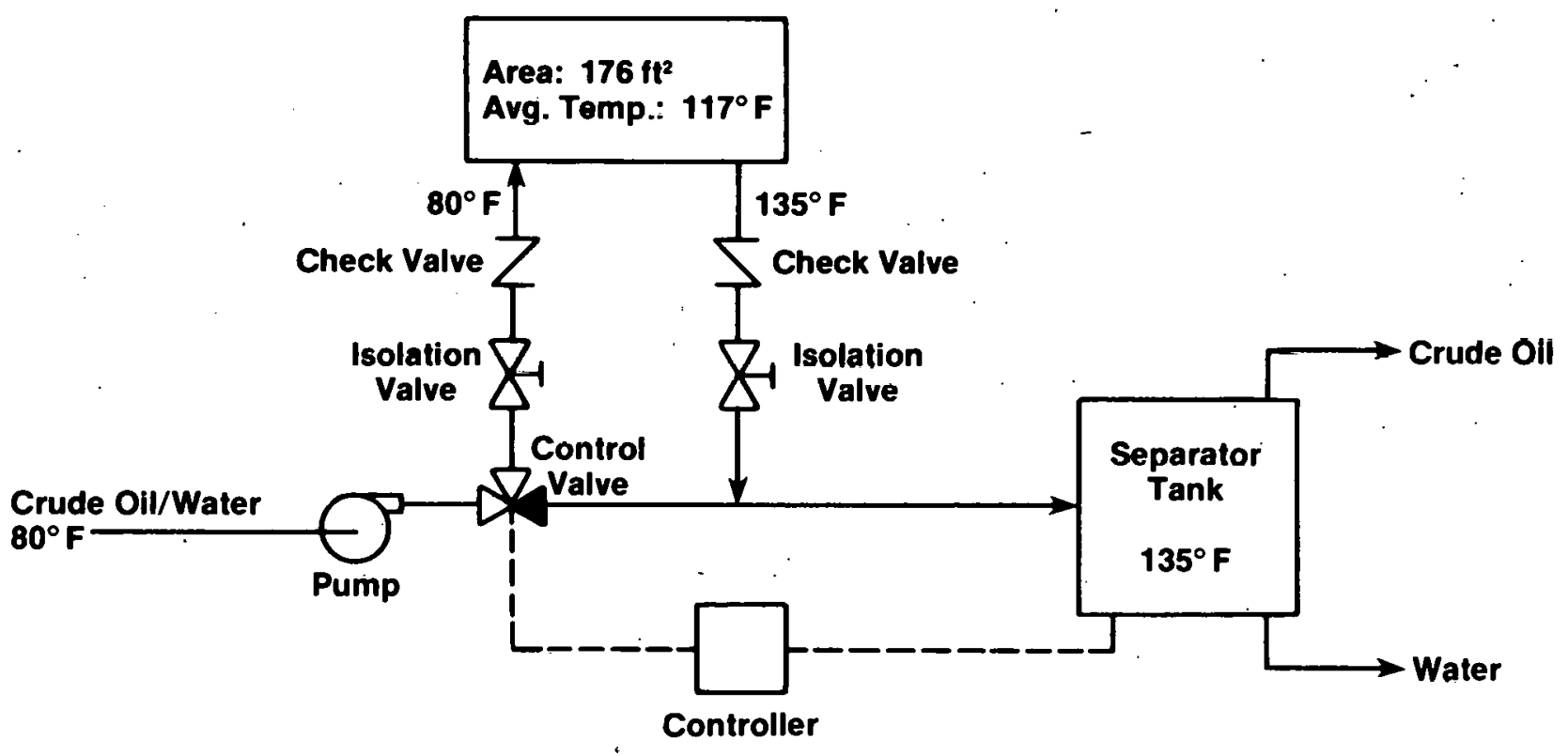

Figure 2-2. Crude Oil/Water Separation Facility Oil-Thru-Collector System 
The oil-through-collector system (Fig. 2-2) is the simplest of the three, because no heat exchanger is required. Using the PROSYS software in conjunction with ERSATZ weather data for Casper (Cinquemani et al. 1978), it was found that $176 \mathrm{ft}^{2}$ of a commercially available flat-plate collector (see Table 2-2) was required to supply one-third of the annual energy requirement. The average operating temperature of the flat-pla te collector array would be $117^{\circ} \mathrm{F}$. Since no thermal storage was included, this system would be operative only during the daylight hours. The full-scale propane backup system is in place, so storage is not essential and was not considered. Under these operating conditions, the portion of the process heating load provided by the solar system would vary each day, and the solar system would act as a supplement to the conventional propane burner system.

Table 2-2. SOLAR SYSTEM PARAMETRRS

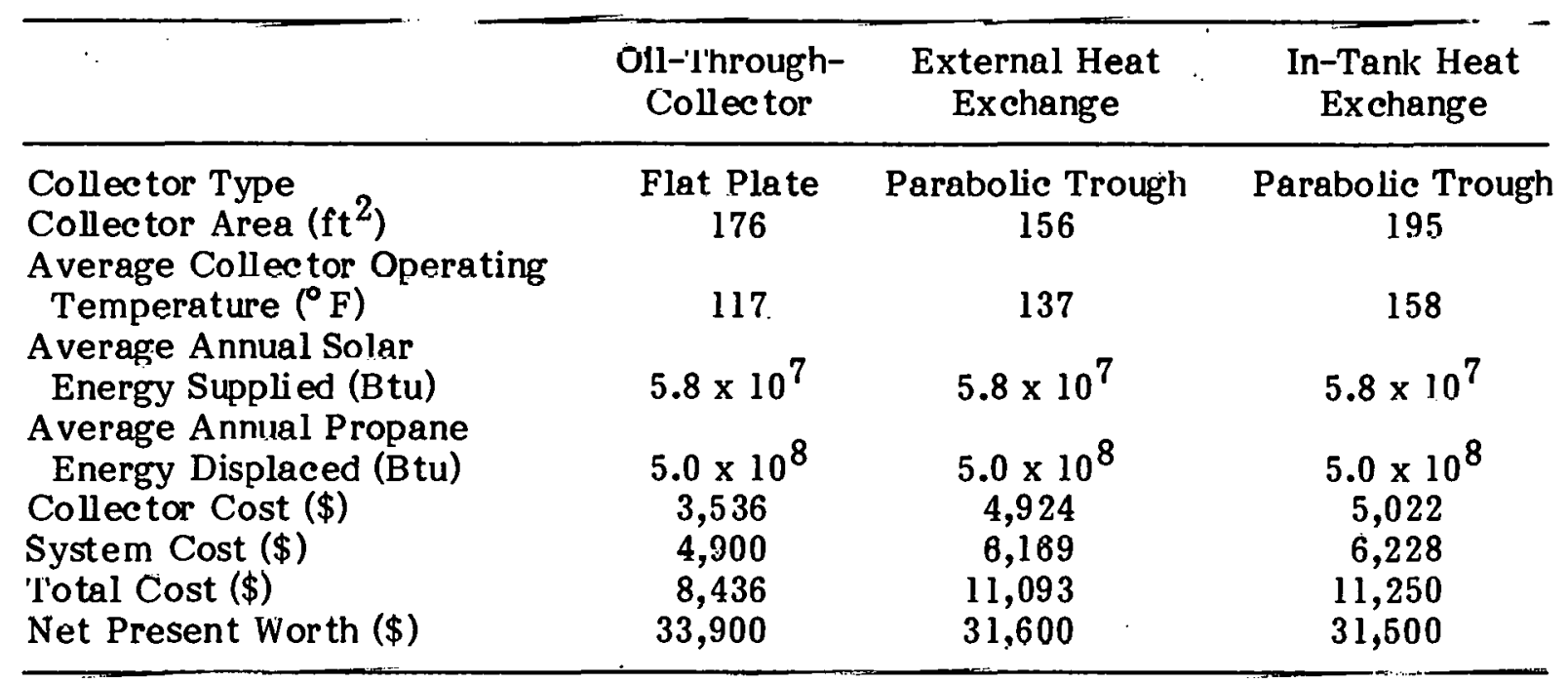

During a typical year, the solar system would displace approximately one-third of the process energy requirement, or $5.8 \times 10^{7} \mathrm{Btu} / \mathrm{yr}$. However, when the propane energy utilization efficiency is included, the resulting average propane energy displacement is $5.0 \times 10^{8} \mathrm{Btu} / \mathrm{yr}$. Thus, the solar system displaces more propane encrgy than it supplies to the process by a factor of $\mathbf{8 . 5}$ due to the low propane energy utilization efficiency. The propane cost savings in current dollars is about $\$ 2800 /$ yeur.

The flat-plate collectors chosen in the analysis cost a total of $\$ 20.11 / \mathrm{ft}^{2}$, resulting in a total installed collector cost of $\$ 3536$. The cost for the remainder of the system, includ ing a pump, pipirs, valves, contruls, collector skid mount, and installation was estimated to be $\$ 4900$ (Guthrie 1969; Perry and Chilton 1973; Peters and Timmerhaus 1968). Thus, the total installed oil-through-collector system cost was estimated to be $\$ 8436$.

Using life-cycle costing techniques in the ECONMAT software, the net present worth of the solar syslem was determined (i.e., the excess of the fuel-savings returns compared to the cost of the solar/conventional hybrid system). The assumptions used in the analysis regarding inflation rate, propane escalation rate, etc., are summarized in Table 2-1. A positive present worth indicates that the solar system is more cost effective over its 20year assumed lifetime than a conventional propane system over the same period. For the 
oil-through-collector system, the present worth was $\$ 33,900$, indicating that the solar system was competitive with the propane system. In fact, the payback period for the solar system was less than 4.5 years. These favorable economic results are due to:

- Direct liquid heating is generally the most economical solar configuration.

- The propane used by the company is relatively expensive.

- The propane energy utilization efficiency in this case is low.

The oil-through-collector system does pose at least one significant problem. Although it appears that the crude-oil/water emulsion could be pumped through a collector without a substantial penalty for pumping costs or collector corrosion, paraffin in the crude oil could be a problem if the temperature dropped below its melting point. This would occur at night as the collectors cooled. To solve this problem, the collector system would have to remain idle each morning until the system temperature was high enough to melt the paraffin, or it would have to be drained each evening. Both of these options detract from the feasibility of the oil-through-collector system.

The second potential configuration is the external exchange system shown in Fig. 2-3. The PROSYS simulation for this system in Casper indicated that $156 \mathrm{ft}^{2}$ of a commercially available parabolic trough collector (see Table 2-2) was the most cost effective. The parabolic trough collector was preferable to a flat-plate collector because of the increased average collector temperature in the external exchange system $\left(137^{\circ} \mathrm{F}\right)$ as compared to the oil-through-collector system $\left(117^{\circ} \mathrm{F}\right)$. The thermal efficiency of the parabolic trough is higher than a flat plate at the increased operating temperature.

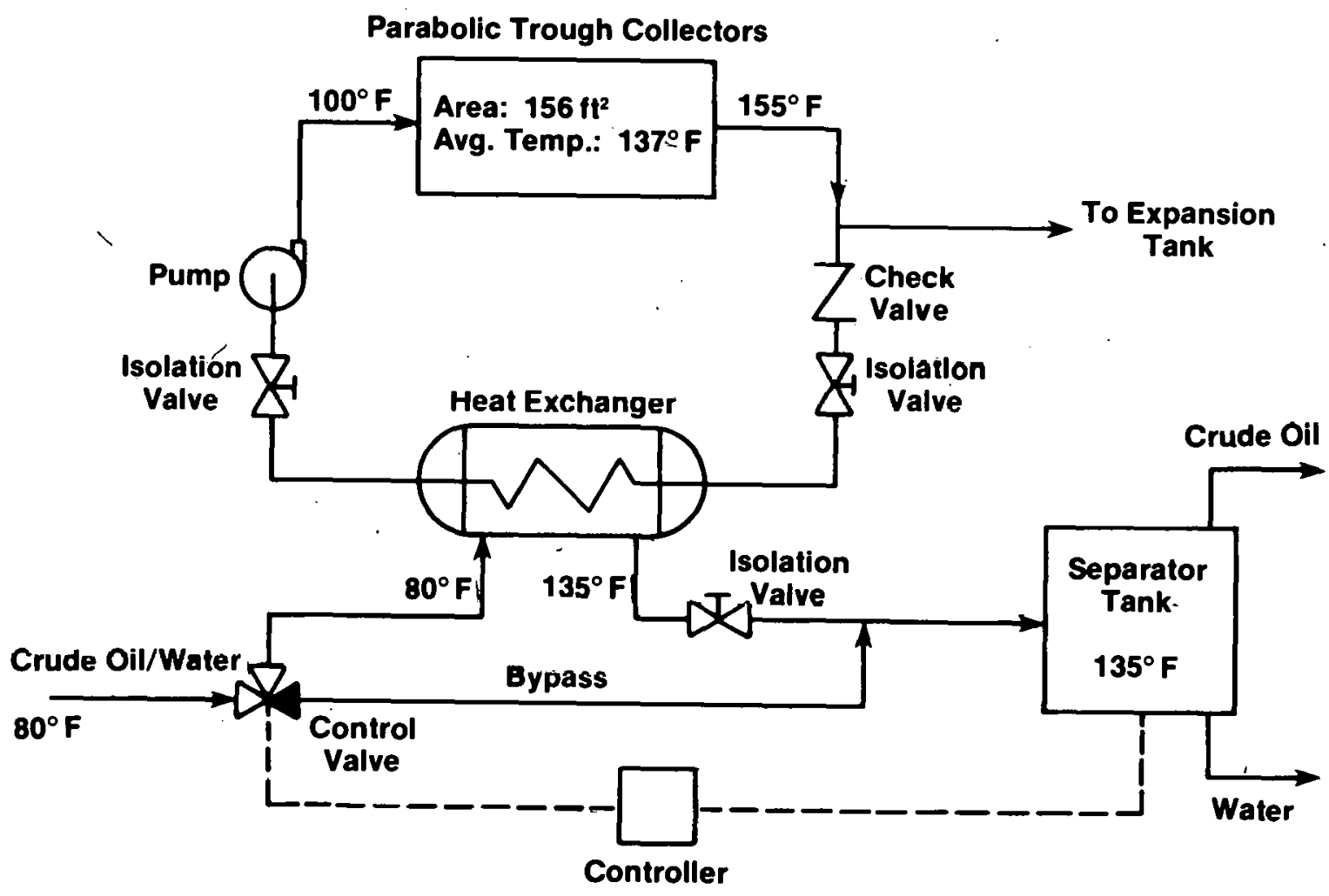

Figure 2-3. Crude Oil/Water Separation Facility External Heat Exchange System 
The external heat exchange system was sized to displace approximately one-third of the process energy requirement during a typical year $\left(5.8 \times 10^{7} \mathrm{Btu} / \mathrm{yr}\right)$. As before, the solar system displaces $5.0 \times 10^{8} \mathrm{Btu} / \mathrm{yr}$ of propane energy due to the low propane utilization efficiency.

The parabolic trough collectors used in the simulation of the external exchange system $\left(156 \mathrm{ft}^{2}\right)$ cost a total of $\$ 4924$. The remainder of the system costs were estimated to be $\$ 6169$ (Guthrie 1969; Perry and Chilton 1973; Peters and Timmerhaus 1968), resulting in a total installed cost of $\$ 11,093$. The life-cycle cost analysis showed that the external exchange system had a positive net present worth equal to $\$ 31,600$ when compared to the conventional propane system. Thus, the solar system is competitive with the existing propane system and has a payback period of 6.6 years. The high propane cost combined with its inefficient use account for this result.

The external heat exchange system does not appoar to have any major disadvantages. Tlie collector array and heat exchanger can be mounted on a single skid for ease of mobility. No modifications to the separator tank would be required. Thus, this configuration is a good candidate for a hea ter-treater utilizing solar energy as a supplement to the existing propane burner.

The last solar system considered for application to the separator tank was an in-tank exchange system (Fig. 2-4). Using Casper weather data, the PROSYS simulation showed a parabolic trough collector (see Table 2-3) to be the most cost effective and indicated that $195 \mathrm{ft}^{2}$ of collector was needed to displace one-third of the annual energy requirement. The average collector operating temperature would be $158^{\circ} \mathrm{F}$-higher than either of the other solar system configurations. As before, the higher average operating temperature resulted in the choice of a parabolic trough over a flat-plate collector. The solar energy supplied and propane energy displaced by the in-tank exchange system are equal to those of the external heat exchange system.

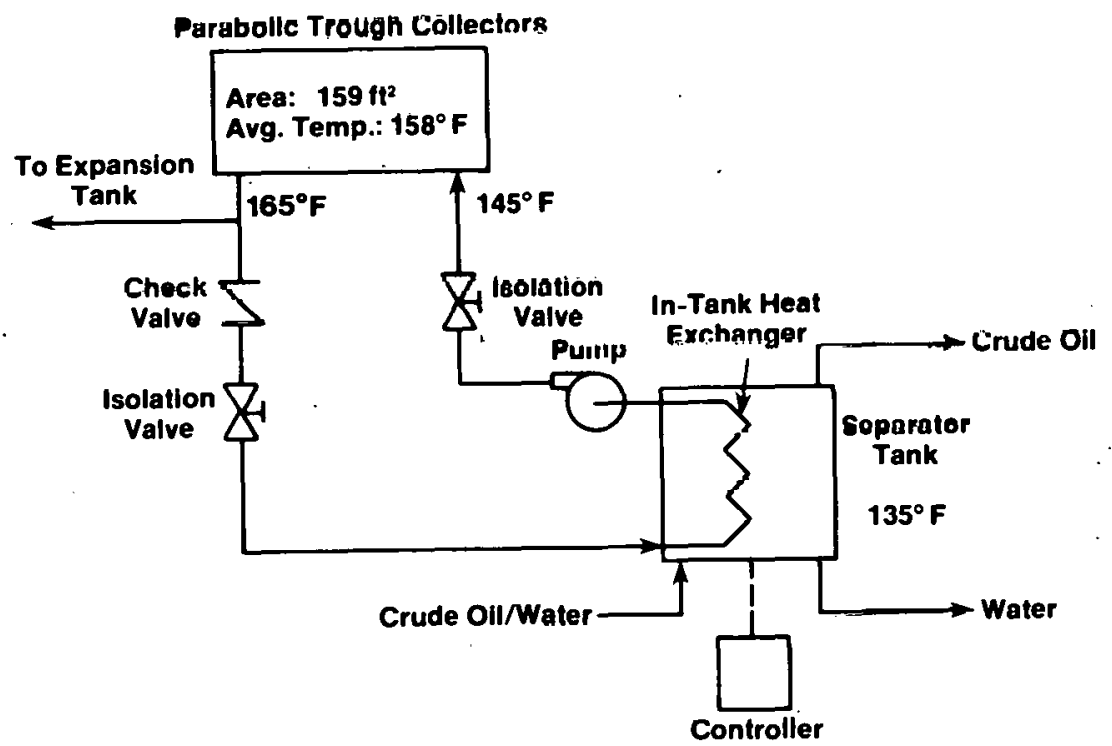

Figure 2-4. Crude Oil/Water Separation Facility In-Tank Heat Exchange System 
The total in-tank exchange system cost of $\$ 11,250$ was composed of $\$ 5022$ for the collectors and $\$ 6228$ for the remaining system cost (including installation on a skid and the heat exchanger installation inside the separator tank). The life-cycle cost analysis indicated that, compared to the conventional propane system, the in-tank exchange system was competitive, with a positive present worth of $\$ 31,500$. The payback period for this system would be 6.7 years.

The in-tank exchange system is a feasible solar option, but the requirement for separator tank modification is a disadvantage. Installation of a heat exchanger in the tank would require disassembly of the system, opening of the separator tank, and possible interference with the existing propane heater system.

\subsection{CONCLUSIONS}

Based on the analysis performed for this case study, it appears that any one of the three potential solar systems previously described would be feasible as a supplement to the separator tank propane burner system (potential problems associated with pumping crude oil through collector receivers in the oil-through-collector system were not examined in detail). In addition, each possibility is cost effective when compared to the propane system and have payback periods of 6.7 years or less. They are all capable of displacing an average of one-third of the propane energy used in the existing configuration.

The preferred solar system for this application would use external heat exchange. This avoids problems-associated with the other configurations, such as the necessity for system draindown each evening or modifying the existing separator tank assembly. A variety of nonfreezing heat transfer fluids could be used in the closed-loop collectors, eliminating problems of collector contamination or blockage from paraffin or other substances present in the crude oil. The system could be controlled to automatically turn on when the collectors heat to a sufficiently high temperature each morning, and to turn off and bypass the heat exchanger each evening. In fact, pressure drop through the exchanger is probably small enough to allow the bypass piping to be dispensed with entirely. Little monitoring by maintenance personnel should be required for such a system.

Figure 2-5 illustrates the cost effectiveness of the external heat exchange system for displacing conventional fuels in the separator tank. The plot shows the net present worth of the solar system (156 $\mathrm{ft}^{2}$ of a parabolic trough collector) as a function of conventional fuel cost. The custs of natural gas, fuel oil, and propane are indicated on the plot for comparison. The solar system is cost effective (i.e., its present worth is greater than or equal to zero) for all fuels costing more than $\$ 1.50 / 10^{6} \mathrm{Btu}$. The payback period varies with conventional fuel cost. The plot is based on the assumption that any conventional fuel used in the existing separator tank would have a utilization efficiency equal to that of the present propane system, or 11.7\%. Electrical immersion heaters could be used in the tank in a more cost-effective manner than the conventional fuels shown in Fig. 2-5, because the heaters would have essentially a $100 \%$ utilization efficiency. A detailed study of the cost effectiveness of the solar systems compared to electrical immersion heaters has not been made, but it is estimated that the life-cycle costs of the two system types would be approximately equal.

It is possible that additional propane energy could be displaced by using the separator tank as thermal storage. This could be accomplished by solar heating the tank to $200^{\circ} \mathrm{F}$ rather than the required $135^{\circ} \mathrm{F}$. During the times when the solar system was not operative, the propane system would function only if the temperature fell below $135^{\circ} \mathrm{F}$. 


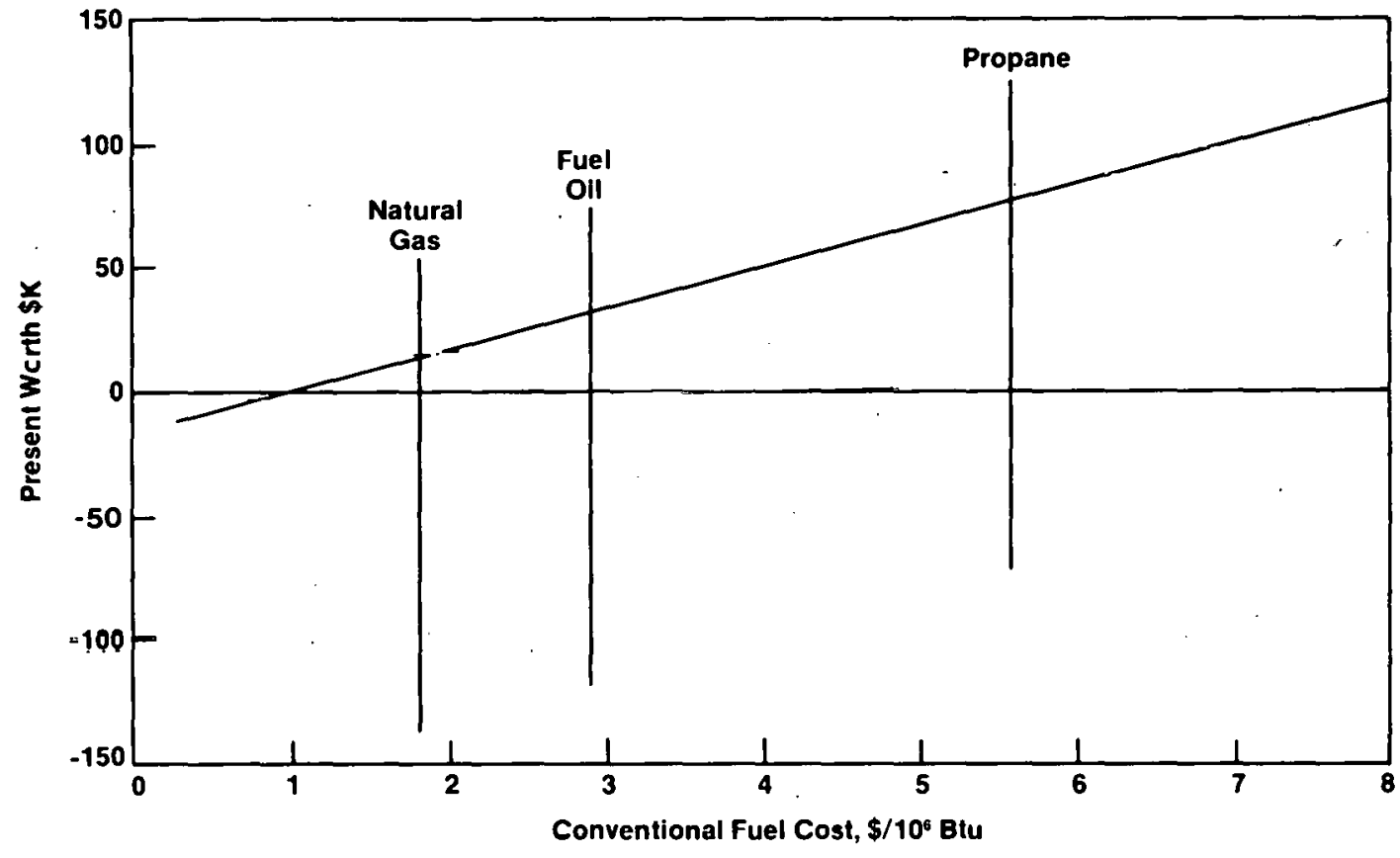

Figure 2-5. Crude Oil/Water Separation Facility: Present Worth of External Heat Exchange System Versus Conventional Fuel Cost

Indicated propane cost is for Casper, WY in March 1979; costs for natural gas and fuel oil are for Denver, $C O$ in March 1979; the same energy utilization efficiency of $11.7 \%$ was assumed in all cases.

Thus, when the solar collectors turned off each evening, the $200^{\circ} \mathrm{F}$ emulsion in the separator tank would drop in temperature as $80^{\circ} \mathrm{F}$ emulsion was added, and as heat was lost, until the tank temperature was $135^{\circ} \mathrm{F}$. At that time, the propane system would turn on to maintain the $135^{\circ} \mathrm{F}$ emulsion temperature for the remainder of the night. Assuming that this procedure would not cause operational problems, the fraction of propane energy displaced by the solar system could be increased from one-third to between one-half to two-thirds. The increased solar load, greater heat loss rate, and increased average collector operating temperature (hence, lower collector efficiency) would increase the required collector area. Although this mode of operation has not been examined in detail, it is probable that the solar system would be cost effective.

If potential problems should be identified regarding blockage of the external heat exchanger by paraffin or other materials, then the in-tank heat exchange system would be the next choice. This system would still eliminate the need for collector draining each evening while avoiding potential heat exchanger blockage. The same benefits would result as with the external heat exchange system, namely, net cost savings compared to the conventional propane system and the conservation of fossil fuels. 


\section{SECTION 3.0}

\section{IPH CASE STUDY: ALUMTNUM CONTANER MANUFACTURING}

A case study was performed for a process unit manufacturing aluminum cans.

\subsection{DESCRIPTION OP PROCESS}

The process consists of shaping and trimming to produce the can bodies, followed by washing and drying. The cans are then printed and bottom coated, passed through an oven to cure the ink and coating, and are cooled. Next, they are coated internally, cured in an oven, cooled, necked, tested, and palletized.

Process heat is supplied to heat the wash water, to dry the cans after washing, and to heat the printer and internal coater ovens. A schematic diagram of those units requiring process heat is shown in Fig. 3-1. The plant operating schedule is continuous 7 days per week, 24 hours per day, year-round. With shutdowns, the average operating time is 24 hours per day, 6-1/2 days per week, 50 weeks per year.

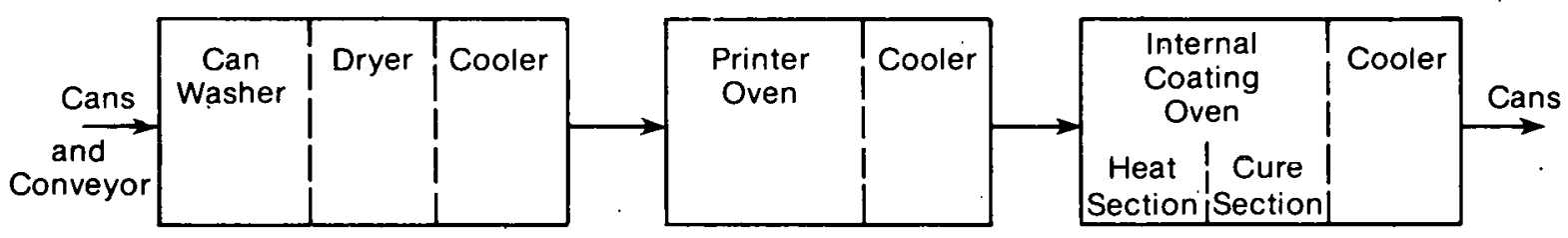

Figure 3-1. Schematic Diagram of Metal Container Process

Personnel at the plant were highly cooperative with the SERI study team. They conducted a tour of the entire facility and supplied engineering design drawings for the processheat units. These drawings showed design flow rates and temperatures. The case study was performed for one of the three parallel process lines. The total input energy was estimated by allocaling natural gas consumption (hased on one year's records) to each of the three lines according to production rate.

The initial step was to calculate energy balances on the process units based upon the data supplied. This showed that the information on the engineering drawings did not reflect actual operating conditions, for energy balance closure could not be achieved even approximately (the numbers showed 2-1/2 times more energy leaving in hot gases as was being added). After this was discussed with the company staff, they made measurements of actual flow rates and temperatures, and supplied these results to SERI. In addition, they supplied information on aluminum throughput, water make-up rate, boiler capacity, etc. With the revised data, it was calculated that the sensible heat of the exhaust gases, the cans, and the conveyor accounted for $55 \%$ of the estimated thermal input. This left an energy loss rate consistent with rough estimates for evaporation losses and heat losses to the surroundings. Since the losses could not be determined independently, the energy balance could not be closed by measurement-but the values available are reasonable. A more-detailed presentation of the hasic data is presented in an appendix (Section 3.7). 
The results of the energy balances, showing inputs and outputs, are summarized in Fig. 3-2. Examination of Fig. 3-2 shows that some $48 \%$ of the estimated total energy input of $4 \mathrm{GJ} / \mathrm{h}\left(3.8 \times 10^{6} \mathrm{Btu} / \mathrm{h}\right)$ to the process leaves in the exit hot gases. The remainder leaves as heat-of-vaporization of water, heat losses to the building air, and as sensible heat of the cans and can conveyor. The fuel presently used is natural gas, at $\$ 1.93$ per GJ $\left(\$ 2.04 / 10^{6} \mathrm{Btu}\right)$ of heating value (December 1978 price).

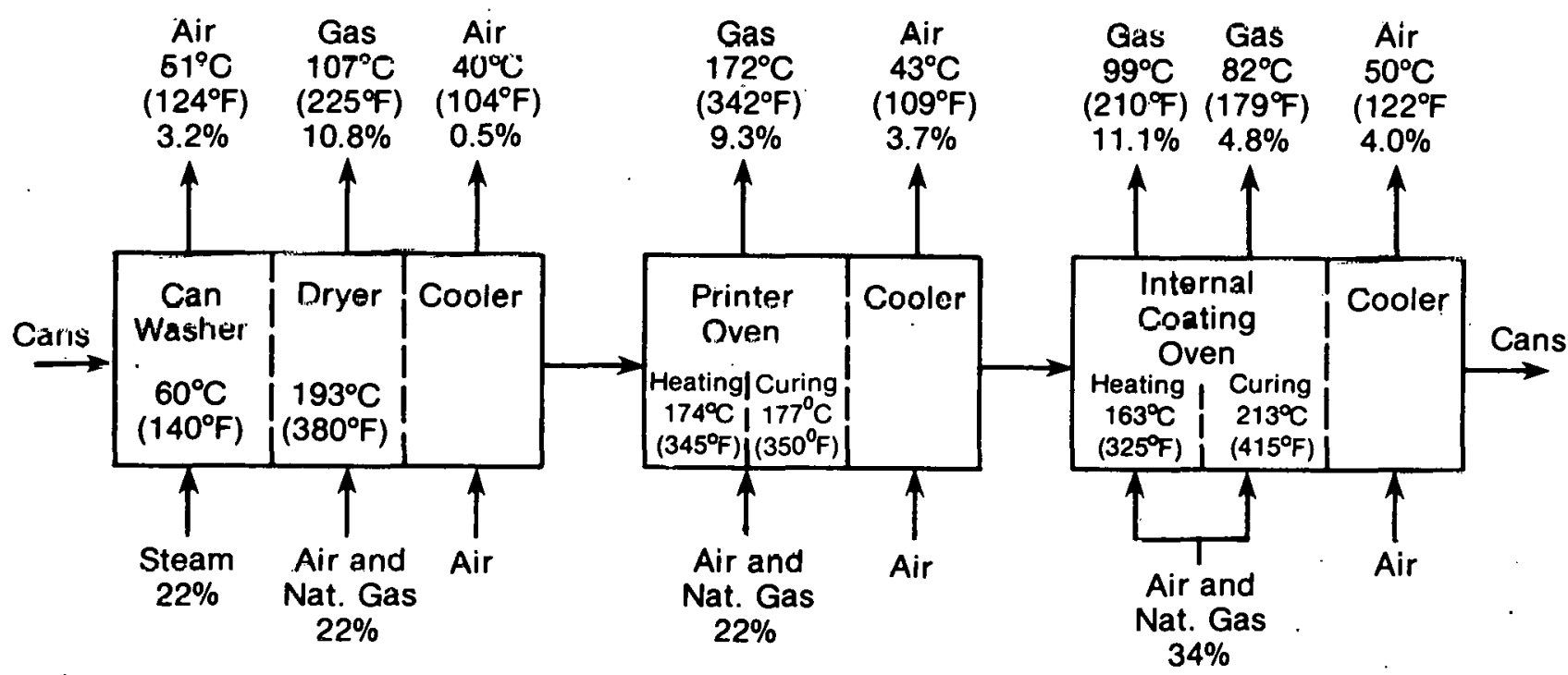

- Estimated Total Energy Input $4 \mathrm{GJ} / \mathrm{h}$

- Percentages are Sensible. Heat in Fas (Relative to $31^{n} \mathrm{C}, 88^{\circ} \mathrm{F}$ ) ds \% of Total Energy Input

- Sensible Heat of Off-Gases Accounts for $48 \%$ of Energy Input. Balance is Due to Water Evaporation and Heat Losses

Figure 3-2. Metal Container Process Energy Flow Diagram

\subsection{ANALYSIS FOR ENERGY CONSERVATION}

Water for washing the cans is heated via steam from a gas-fired boiler. Water from the washer, at about $43^{\circ} \mathrm{C}\left(110^{\circ} \mathrm{F}\right)$, is recycled and water is added to make up for evaporation losses and blowdown. The water stream is steam-heated to $60^{\circ} \mathrm{C}\left(140^{\circ} \mathrm{F}\right)$ and returned to the can washer. The rate of hcat supply to this heater is estimated to be $0.88 \mathrm{GJ} / \mathrm{h}$, nr $0.83 \times 10^{6} \mathrm{Btu} / \mathrm{h}$ ( $22 \%$ of the total encrgy input). Thls energy goes to heating the cans and conveyor, vaporizing water, heating the air exhausted through the washer, and heat losses to the surroundings. The energy requirement of this unit could be reduced somewhat by additional insulation and by reducing the exhaustion of air from the washer. Also, evaporation could be suppressed by solids floating on the water surface (e.g., foamed polystyrene particles). Therc were not sufficient data to estimate these losses or their potential reductions. Nonetheless, the use of a floating evaporation suppressant is recommended as is reduction of the induced air flow. No more detailed work was done on conservation in the washing step. 
The remaining $78 \%(3.1 \mathrm{GJ} / \mathrm{h})$ of the process heat is used for drying and curing the cans. The dryer, printer oven, and internal-coater oven are each direct, natural gas fired. Substantial excess air is used so as to produce temperatures in the $163^{\circ}$ to $212^{\circ} \mathrm{C}\left(325^{\circ}\right.$ to $414^{\circ} \mathrm{F}$ ) range, as required. About $45 \%$ of the input energy to these units leaves as hot exhaust gases. About $14 \%$ of the input energy is lost, as warm exhaust air, from the coolers, where air is used to cool the cans to near ambient. The other $41 \%$ of the input energy (1.3 GJ) leaves with the cans and conveyor, as losses to the building air, and as heat of vaporization of water in the dryer.

The sensible heat leaving each cooler with the cans is estimated to be only about $0.01 \mathrm{GJ} / \mathrm{h}$. Estimating that the conveyor thermal mass rate is ten times that of the cans gives about $0.1 \mathrm{GJ} / \mathrm{h}$ loss from each cooler, as sensible heat of cans and conveyor, or $0.3 \mathrm{GJ} / \mathrm{h}$ total. The remaining $1 \mathrm{GJ} / \mathrm{h}$ includes both evaporation and heat-transfer losses to building air. These losses could not be estimated independently. The evaporation loss cannot be reduced, since water must be evaporated in the dryer. Heat losses to the building could be reduced by an indeterminable amount via additional insulation. The gas-fired equipment is already quite well insulated. It appears that the total process heat requirement could be reduced by less than $0.5 \mathrm{GJ} / \mathrm{h}$ ( $12 \%$ of the total input) by adding insulation.

There is a substantial energy recovery potential in the dryer, ovens, and coolers in the form of the sensible heat in the exhaust gases. One means of recovery would be heat transfer between the exhaust gases and incoming air. This could be done but, since it is gas-to-air exchange, relatively large exchangers would be required. The most direct means of recovering this energy would be to reuse the gases. Indeed, the air used to cool the cans should be used as a preheated air supply to the gas burners; this could be done whether or not a solar system is used. The possibility remains of recycling some of the hot combustion product gases. These alternatives are considered in detail in the following section.

\subsection{SOLAR ENERGY APPLICATIONS ANALYSIS}

The application of solar energy to this process was examined in three ways:

- Using solar collectors to supply one-third of the total annual energy required for the dryer and ovens $\left(1 / 3 \times 22 \mathrm{TJ} / \mathrm{yr}, 7.0 \times 10^{9} \mathrm{Btu} / \mathrm{yr}\right)$ via hot air at the maximum required process temperature of $213^{\circ} \mathrm{C}\left(415^{\circ} \mathrm{F}\right)$;

- Using individual collector units to supply either hot air or water to each process unit at the maximum temperature required for that unit; and

- Using a reconfigured process air flow to take advantage of the air preheating in the coulers and to recycle a portion of the hot exhaust gases. Solar energy is used to further preheat the make-up air.

\subsection{CONDITONS ON SOLAR DESIGN}

The performance and costs of solar collectors feasible to provide the required process heat was calculated using the PROSYS/ECONMAT computer code described in Appendix A. For the first two uses described above, the solar system was sized to supply, on the average, one-third of the total annual energy requirement. This allows for an annual average of eight hours of collection per day. Smaller solar systems were also analyzed, 
but those results are not included here. No energy storage was considered in the analysis.

To heat water, hot-water-direct and hot-water-exchange systems were considered. (Simplified schematics of such systems are illustrated in Appendix B.) The capacity cost for a direct system was found to be less than that for an exchange system for the same service. This comes about because the direct system entails less equipment; also, because the solar collectors operate at a reduced temperature (and hence higher efficiency), less area is required.

A major assumption was made in the analysis for hot-air-direct systems operating at temperatures too hot for flat-plates [above about $66^{\circ} \mathrm{C}\left(150^{\circ} \mathrm{F}\right)$-namely, that the overall performance characteristics of the collectors would be the same whether air or water-ylycol was the working fluid. This assumption was made because the only performance data at the higher temperaturce in the cumputer model used to predirt colloctor thermal output are $f \mathrm{rr}$ an aquoour workin's fluld. Because of the many applications of hot air and the favorable cost of direct as compared to exchange systems, we suggest that research and development on efficient, high-temperature absorbers with air as the working fluid should be a priority item.

The temperature and total gas flow rate of each unit has been taken as fixed by the process requirements throughout the following analysis.

\subsection{SOLAR APPLICATIONS}

- Air heating for an existing process: Results for supplying one-third of the annual energy used for heating process air, at a proccss temperature of $213^{\circ} \mathrm{C}\left(415^{\circ} \mathrm{F}\right)$, are slown in 'l'able 3-1. The principal observation from these results is the large, negative present worth of the project. That is, solar energy is not cost effective for this service.

- Individual solar units for each process unit: Results for individual solar collector systems, each supplying energy to a process unit at the temperature required by that unit, also are shown in Table 3-1. Each unit shows a large, negative present worth. Thus, no solar application to an individual process unit is cost effective, including the heating of hot water to $60^{\circ} \mathrm{C}\left(140^{\circ} \mathrm{F}\right)$.

These results indicate that solur energy is not cost competitive with efficiently used natural gas, at $\$ 1.93 / \mathrm{GJ}$, and process temperaturco of $60^{\circ} \mathrm{C}\left(140^{\circ} \mathrm{F}\right)$ and highcr, if the solur system must supply the same amount of energy as supplied by the displaced natural gas. This result is consistent with our observations, in earlier case studies (Brown et al. 1980). It suggests that solar energy can be expected to be cost eompetitive with naturyl gas at present prices only if the gas is used very inefficiently, or if a way can be found to displace more energy from natural gas than must be supplied by solar.

- Solar heat to the reconfigured process: As noted above, a solar system has to displace more energy than it must supply in order to compete economically with efflciently used natural gas. Therefore, the hot air uses in the process were reexamined to determine whether this was possible. The rest of this analysis does not include heating water for the can washer, because for this application, the possibility of reconfiguration does not exist. 
Table 3-1. SOLAR SYSTEM PARAMETERS

\begin{tabular}{|c|c|c|c|c|c|c|}
\hline & & \multicolumn{5}{|c|}{ Service } \\
\hline & & $\begin{array}{c}\text { Total Process } \\
\text { Hot Air }\end{array}$ & $\begin{array}{l}\text { Water } \\
\text { Heating }\end{array}$ & $\begin{array}{c}\text { Can } \\
\text { Dryer }\end{array}$ & $\begin{array}{l}\text { Print } \\
\text { Oven }\end{array}$ & $\begin{array}{c}\text { Internal } \\
\text { Coating Oven }\end{array}$ \\
\hline Collector Type & & $\begin{array}{l}\text { Parabolic } \\
\text { Trough }\end{array}$ & $\begin{array}{l}\text { Parabolic } \\
\text { Trough }\end{array}$ & $\begin{array}{l}\text { Parabolic } \\
\text { Trough }\end{array}$ & $\begin{array}{l}\text { Parabolic } \\
\text { Trough }\end{array}$ & $\begin{array}{l}\text { Parabolic } \\
\text { Trough }\end{array}$ \\
\hline Collector Area & $\left(\begin{array}{l}\left.\mathrm{m}^{2}\right) \\
\left(\mathrm{ft}^{2}\right)\end{array}\right.$ & $\begin{array}{r}2240 \\
24,100\end{array}$ & $\begin{array}{r}560 \\
6100\end{array}$ & $\begin{array}{r}630 \\
6780\end{array}$ & $\begin{array}{r}600 \\
6450\end{array}$ & $\begin{array}{r}960 \\
10,300\end{array}$ \\
\hline Process & $(\mathrm{C})$ & 213 & 60 & 193 & 177 & 213 \\
\hline Temperature & (F) & 415 & 140 & 380 & 350 & 415 \\
\hline Average Collector & (C) & 146 & 71 & 133 & 122 & 146 \\
\hline Operating Temperature & (F) & 295 & .160 & 271 & 252 & 295 \\
\hline $\begin{array}{l}\text { Average Annual } \\
\text { Solar Energy }\end{array}$ & $\left(\mathrm{TJ}=10^{12} \mathrm{~J}\right)$ & 8.1 & 2.3 & 2.3 & 2.3 & 3.5 \\
\hline Supplied & $\left(10^{9} \mathrm{Btu}\right)$ & 7.7 & 2.2 & 2.2 & 2.2 & 3.3 \\
\hline System Type & & Hot Air & Hot Water & Hot Air & Hot Air & Hot Air \\
\hline & & Direct & Exchange & Direct & Direct & Direct \\
\hline Collector Cost & (thcusand \$) & 742 & 193 & 209 & 205 & 318 \\
\hline Total Cost & (thousand \$) & 800 & 244 & 226 & 222 & 343 \\
\hline Capacity Coșt & (\$!'GJ/yr) & 98 & 105 & 97 & 95 & 99 \\
\hline Delivered Energy Cost & $(\$ / G J)$ & 11 & . 12 & 11 & 11 & 11 \\
\hline Net Present Worth & (thousand \$) & -440 & -117 & -123 & -120 & -189 \\
\hline
\end{tabular}


About half of the energy input to the process leaves in the form of heated exhaust gases. These hot gas streams offer significant waste heat recovery potential. The temperature, volume flow rate, and energy flow rate of each exhaust stream are compiled in Table 3-2. Waste heat could be partially recovered by heat exchange with incoming air. However, since this requires relatively difficult gas-air. exchange, this option was not considered in detail. Another possibility would be to "cascade" the gases, that is, to use higher temperature exhaust gases for lower temperature purposes. However, the required temperatures and flow rates do not match up, as is revealed by examining Table 3-2, so little could be gained by doing so.

Table 3-2. ENERGY CONTENT OF EXIT GAS STREAMS

\begin{tabular}{|c|c|c|c|c|c|c|}
\hline \multirow{2}{*}{$\begin{array}{l}\text { Cas Stream Bource } \\
\text { Print Oven } \\
\text { Can-Washer Drier } \\
\text { IC Oven Heater } \\
\text { IC Oven Cure } \\
\text { Can-Washer Exhaust }\end{array}$} & \multicolumn{2}{|c|}{$\begin{array}{l}\text { Temperature } \\
{ }^{\circ} \mathrm{C} \quad(\mathrm{F})\end{array}$} & \multicolumn{2}{|c|}{$\begin{array}{l}\text { Flow Rate at STP } \\
\mathrm{m}^{3} / \mathrm{min}\left(\mathrm{ft}^{3} / \mathrm{min}\right)\end{array}$} & \multicolumn{2}{|c|}{$\begin{array}{c}\text { Energy }^{\mathrm{a}} \\
\mathrm{GJ} / \mathrm{h}\left(10^{6} \mathrm{Btu} / \mathrm{h}\right)\end{array}$} \\
\hline & $\begin{array}{r}172 \\
107 \\
99 \\
82 \\
51\end{array}$ & $\begin{array}{l}(342) \\
(225) \\
(210) \\
(179) \\
(124)\end{array}$ & $\begin{array}{l}35.1 \\
75.9 \\
86.9 \\
49.3 \\
84.4\end{array}$ & $\begin{array}{l}(1240) \\
(2680) \\
(3070) \\
(1740) \\
(2980)\end{array}$ & $\begin{array}{l}0.37 \\
0.44 \\
0.43 \\
0.19 \\
0.13\end{array}$ & $\begin{array}{l}(0.35) \\
(0.42) \\
(0.41) \\
(0.18) \\
(0.12)\end{array}$ \\
\hline Total Exhaust Gas & & & 331.6 & $(11,710)$ & 1.56 & $(1.48)$ \\
\hline $\begin{array}{l}\text { IC Oven Cooler } \\
\text { Print Oven Cooler } \\
\text { Can-Washer Cooler }\end{array}$ & $\begin{array}{l}50 \\
43 \\
40\end{array}$ & $\begin{array}{l}(122) \\
(109) \\
(104)\end{array}$ & $\begin{array}{r}110.4 \\
172.7 \\
38.2\end{array}$ & $\begin{array}{l}(3900) \\
(6100) \\
(1350)\end{array}$ & $\begin{array}{l}0.16 \\
0.15 \\
0.02\end{array}$ & $\begin{array}{l}(0.15) \\
(0.14) \\
(0.02)\end{array}$ \\
\hline Total Cooler Air Flow & & & 331.3 & $(11,350)$ & 0.33 & $(0.31)$ \\
\hline
\end{tabular}

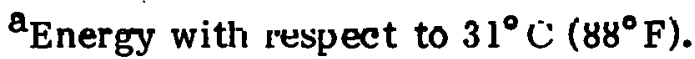

As shown by Table 3-2, the total flow rate of air through the three can coolers is essentially equal to the total exhaust gas flow rate of the ovens, dryer, and washer. Thus, the coolers could be used to preheat all the air to the gas burners to about $46^{\circ} \mathrm{C}\left(116^{\circ} \mathrm{F}\right)$, as showil schematically in Fig. 3-3. This action would reduce the total process heat requirement by about $8.2 \%$. It could he arrenmplished at the cost of the alditionlul ducting, blowers, and controls needed, even if a solar system is not used. Although no design without solar has been done, it would probably prove to be cost cffective. In the rest of this analysis, the fuel savings achieved by preheating have been credited to the solar system, even though it could be accomplished without a solar system.

Next, the use of solar to further heat the preheated air was considered, as illustrated in Fig. 3-4. Solar was examined for heating the air to several temperatures, ranging from $102^{\circ}$ to $213^{\circ} \mathrm{C}\left(215^{\circ}\right.$ to $\left.415^{\circ} \mathrm{F}\right)$. None of these systems was found to be cost effective. There is some temperature between $46^{\circ}$ and $102^{\circ} \mathrm{C}\left(115^{\circ}\right.$ to $\left.214^{\circ} \mathrm{F}\right)$ at which such an arrangement would break even with natural gas, but this was not explored further.

Next considered was recovery of some of the energy in the hot exhaust gases, by recycling them to the process, as well as the use of a solar preheat, as shown schematically in Fig. 3-5. 


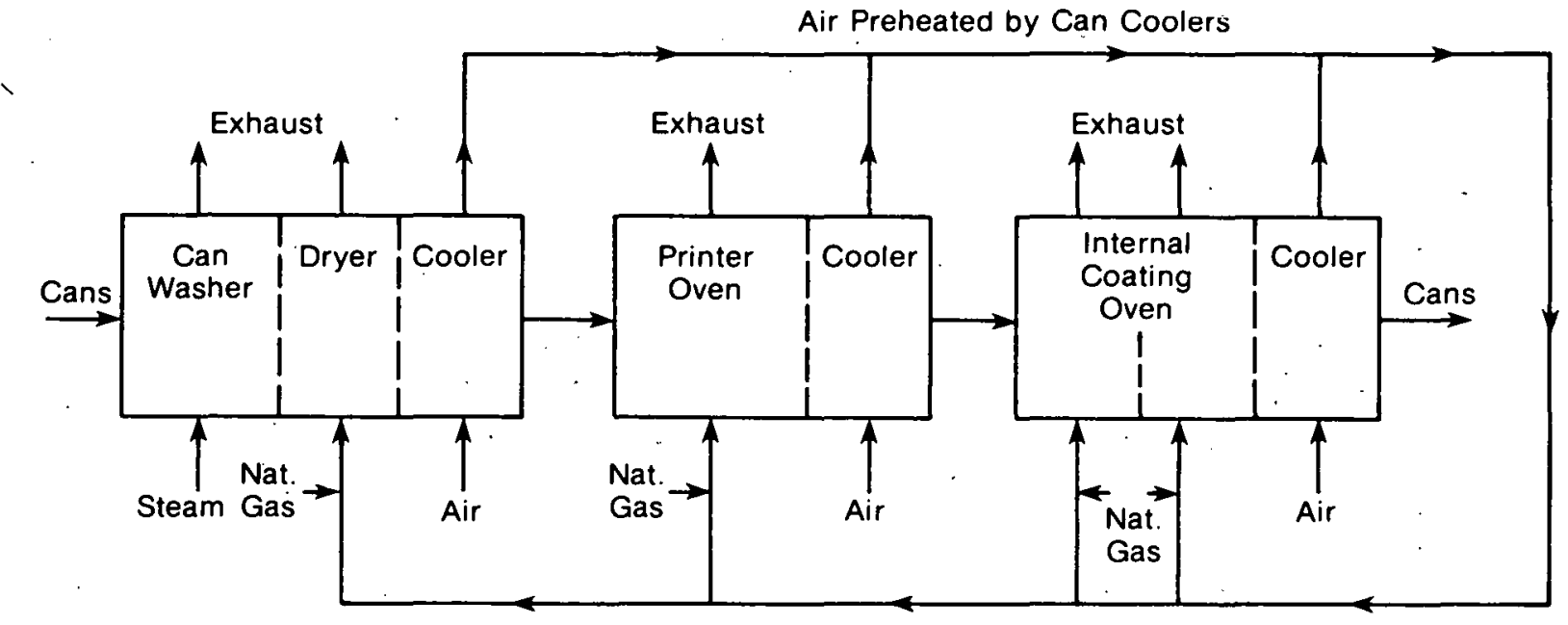

Figure 3-3. Schematic Diagram of System Using Can Coolers to Preheat Incoming Air

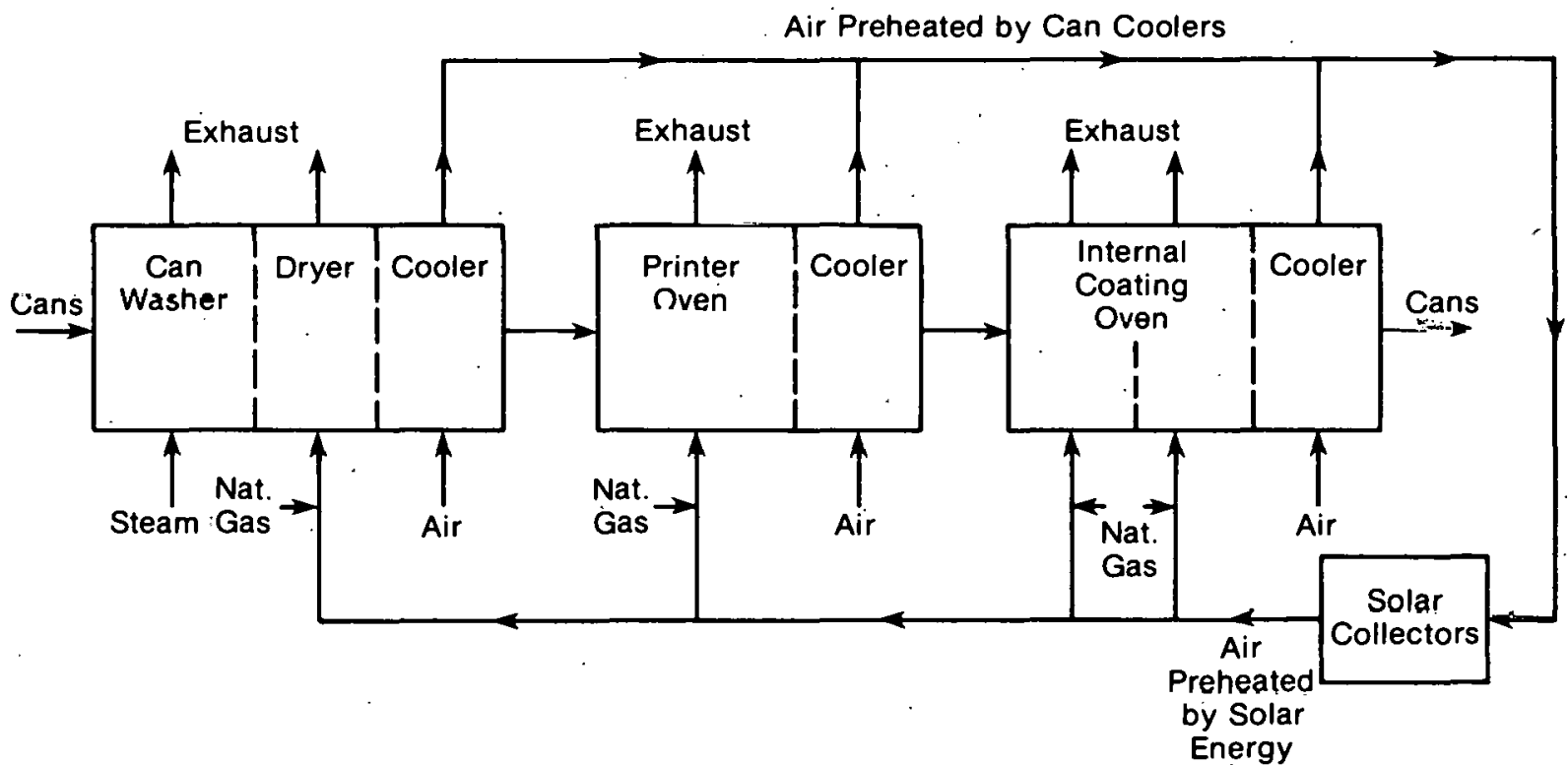

Figure 3-4. Schematic Diagram of Solar Preheating of Combustion Air 


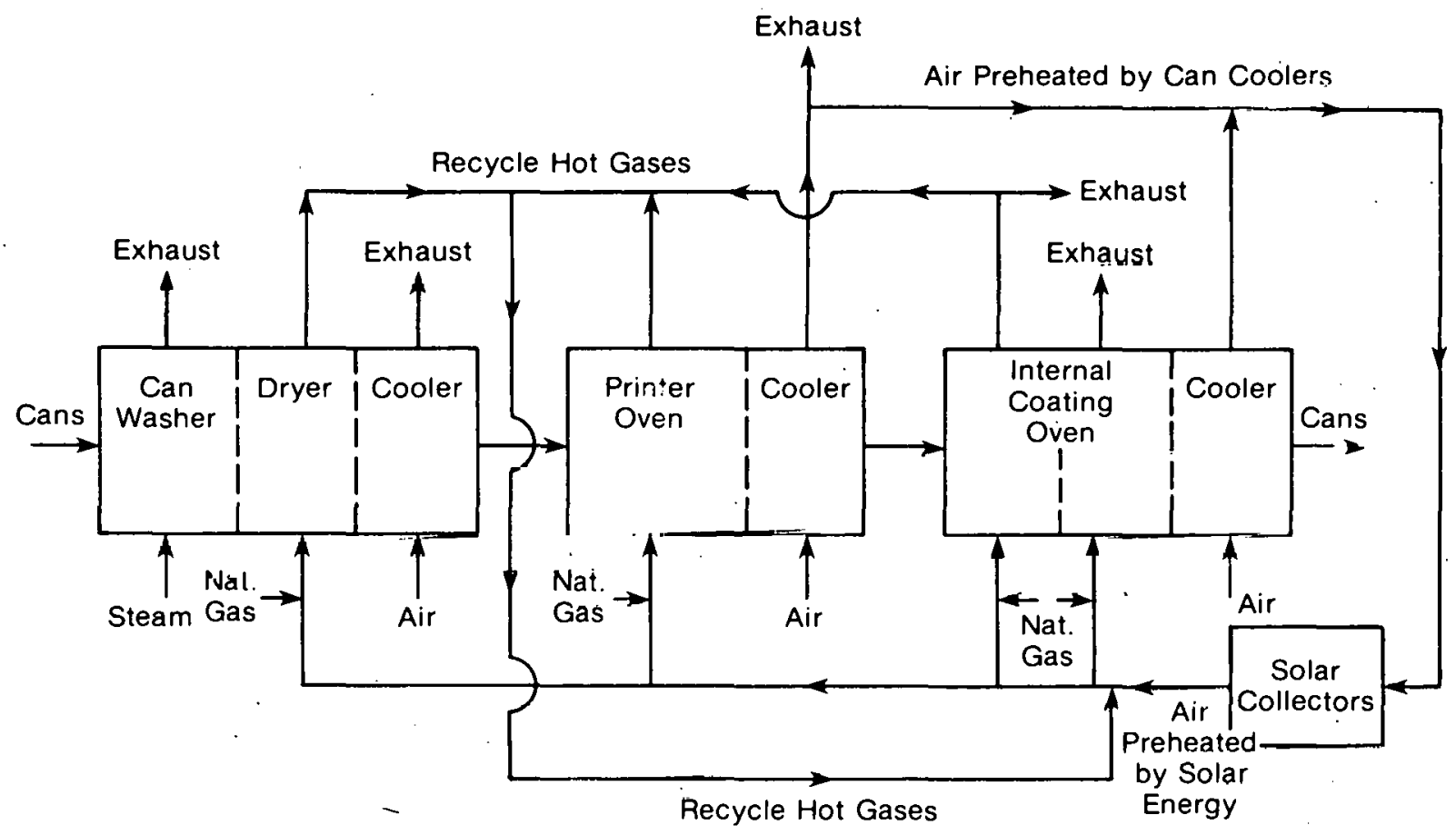

Figure 3-5. Schematic Diagram of Recycling Hot Gases and Solar Preheat

There are three factors that might limit exhaust gas recycle:

- Urganic solvents are vaporized in the printer and internal coater ovens. The solvent vapor concentrations must be maintained at less than $25 \%$ of the lower explosion limit.

- Water is vaporized in the can-washer dryer. The water vapor concentration must be maintained belnw saturation at thc lowest temperature in the gas ducting, to prevent condensation and corrosion.

- The air used for combustion becomes depleted of oxygen. Sufficient fresh air must be introduced to supply at least the minimum oxygen required for combustion. The amount of gas that must be burned is that required to bring the gases back to the temperatures required in the process.

One of these factors will determine the maximum total amount of gases that can be recycled, and/or the a mounts of dryer or oven off-gases that can be recycled.

Calculations to determine the maximum amount of recycle were based on these considerations. A basic guideline was to use all the hottest off-gas first, then the next hottest, etc. The results were as follows:

- If the solvent vapor concentration in the total off-gas is limited to the same value as is presently reached in the internal-coater oven, the maximum recycle is 
$55 \%$ of the off-gas streams. At this recycle rate, the solvent vapor concentration in the coater oven off -gas would be twice its current value if no combustion of the recycled vapors occurs. It is suspected that these vapors will burn in the gas-combustion zones, effectively removing them from the recycle streams; however, this has not been demonstrated. If, in fact, they are combusted, an even higher recycle fraction could be used.

- The water vapor does not become limiting before the solvent vapors do, and thus it presents no problem-since the moist gas from the dryer is diluted by mixing with other gas streams, reducing the relative humidity, and the lowest mixed-gas temperature is about $103^{\circ} \mathrm{C}\left(217^{\circ} \mathrm{F}\right)$.

- In considering oxygen depletion, the ratio of fresh air to natural gas was kept the same as the current ratio. This may not be a necessary limitation, for at present considerable excess air is used, and it may be possible to operate with a lower fresh air-to-natural gas ratio. However, there is not sufficient information about the combustion to resolve this matter now. Based on the current ratio, a maximum of $25 \%$ of the off-gases could be recycled if solar heating is not used, because of the natural gas and make-up air needed. If the fresh air is preheated by solar, however, less natural gas must be burned, less oxygen will be required for combustion, and more off-gases can be recycled. Indeed, there is no oxygen limit to the fraction that can be recycled if sufficient energy. is added via solar heating.

From the foregoing analysis, the accumulation of solvent vapors in the system is the key factor that limits the amount of recycle. The following results are based upon $50 \%$ recycle of the off-gases, rather than the maximum $55 \%$ calculated, to be somewhat conservative.

The minimum temperature to which the incoming air must be heated by solar was calculated such that $50 \%$ of the off-gases could be recycled; it was found to be $87^{\circ} \mathrm{C}\left(189^{\circ} \mathrm{F}\right)$.

The final air flow configuration is shown in Fig. 3-6, and consists of the following:

- Incoming air passes through the can coolers. The hottest of this air, that from the internal-conating oven can cooler and about one-third of that from the print oven can cooler, is circulated to solar collectors, where it is heated to $87^{\circ} \mathrm{C}\left(189^{\circ} \mathrm{F}\right)$.

- The off-gas from the print oven, the can-washer dryer, and about two-thirds of that from the internal-coater-oven heater section are mixed with the solar preheated air.

- This mixed-gas stream is then used as preheated combustion air to the gas-fired units: the can-washer dryer, the print oven, and the internal coating oven.

The advantage of this configuration is that while the solar system supplles $0.48 \mathrm{GJ} / \mathrm{h}(0.45 \mathrm{MBtu} / \mathrm{h})$, the natural gas displaced is equivalent to $1.8 \mathrm{GJ} / \mathrm{h}\left(1.7 \times 10^{6} \mathrm{Btu} / \mathrm{h}\right)$.

The characteristics of the solar system are summarized in Table 3-3. The striking result is that the total system shows a positive present value. That is, the life-cycle economic analysis indicates that this integration of solar energy into the system is cost effective. 


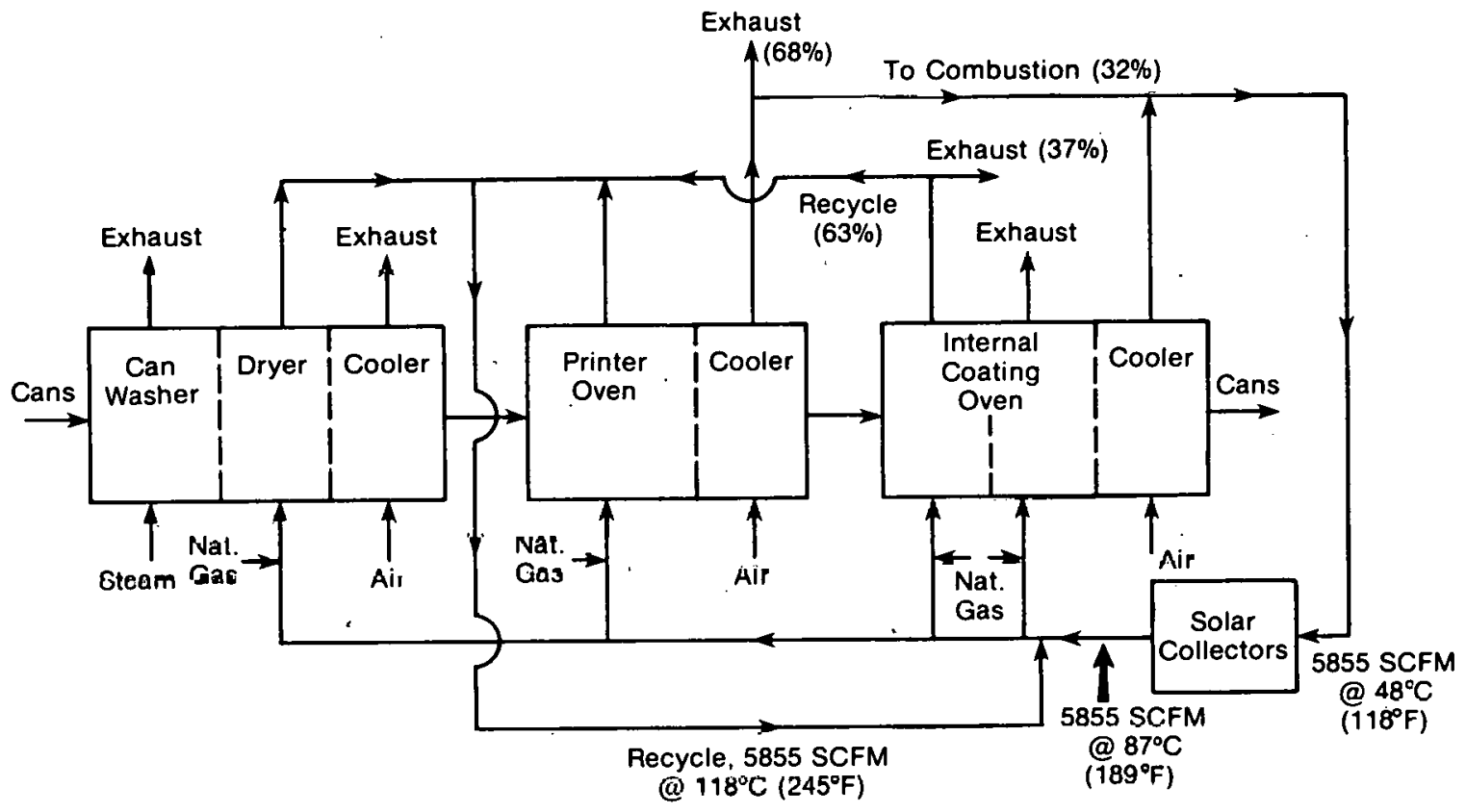

Figure 3-6. Flow Diagram of Recycling Hot Gases and Solar Preheat

Table 3-3. SOLAR SYSTEM PARAMETERS:

SOLAR PREHEAT TO $87^{\circ} \mathrm{C}$

$\left(189^{\circ} \mathrm{F}\right)$

Collector Type

-.Collector Area

Process Temperature

Average Collector

Operating Temperature

A verage Annual Bolar

Energy Supplied

System Type

Collector Cost

Total Cost

Capacity Cost

Delivered Energy

Cost

Net Present Worth
Parabolic Trough

$274 \mathrm{~m}^{2}\left(2950 \mathrm{ft}^{2}\right)$

$87^{\circ} \mathrm{C}\left(189^{\circ} \mathrm{F}\right)$

$73^{\circ} \mathrm{C}\left(164^{\circ} \mathrm{F}\right)$

1.2 TJ (1.1 GBtu)

Hot Air Direct

$\$ 94 \mathrm{~K}$

$\$ 102 \mathrm{~K}$

$\$ 88 / \mathrm{GJ} / \mathrm{yr}$

$\$ 9.8 / \mathrm{GJ} / \mathrm{yr}$

$\$ 28 \mathrm{~K}$ 
The system shown has not been completely optimized with respect to the energy supplied by solar collectors. If the preheat temperature were increased, more hot off-gases could be recycled (assuming that organic vapor combustion occurs in the gas flame). In this case, a cost-effective system could be sized with a larger fraction of the energy supplied by solar.

\subsection{SUMMARY OF SOLAR APPLCATIONS}

The use of solar to replace natural gas, and its use strictly as a preheat for incoming air, did not prove to be economical. However, when solar was used in combination with air preheating and partial recycle of hot off-gases, an economical design was found. This design consisted of recycling the hottest half of the off-gas streams, using the can coolers to preheat incoming air, and then using solar collectors to further preheat this air. The can coolers supply $5 \%$ of the total process energy requirement (for an average of 8 of the 24 operating hours per day), solar supplies $12 \%$, and the recycled gases supply 27\%. The remaining $56 \%$ is supplied by buming natural gas. The energy recovery from the can coolers and some of that from the recycle of hot gas could be achieved without the solar system. However, more gas can be recycled with a solar system than without it.

\subsection{APPENDIX: DATA USED IN THE CASE STUDY}

The data supplied by the plant and used in the case study are:

- Total energy input: Natural gas consumption on the case-study manufacturing line, allocated according to line throughput, was 3490 million $\mathrm{ft}^{3}$ in one year, 7982 operating hours. Heating value of the gas was $840 \mathrm{Btu} / \mathrm{ft}^{3}$.

- Process unit operating temperatures, measured by plant personnel, and energy inputs, estimated in cooperation with plant personnel:

\begin{tabular}{|c|c|c|c|c|}
\hline Unit & \multicolumn{2}{|c|}{${ }_{{ }^{\circ} \mathrm{C}}^{\text {Temperature }}{ }^{\circ} \mathrm{F}$} & \multicolumn{2}{|c|}{$\begin{array}{l}\text { Energy Input } \\
\text { GJ/h MBtu/h }\end{array}$} \\
\hline Can Washer & 60 & 140 & 0.88 & 0.84 \\
\hline Can Dryer & 193 & 380 & 0.88 & 0.84 \\
\hline Printer Oven & & & 0.88 & 0.84 \\
\hline Heating Zone & 174 & 345 & & \\
\hline Curing Zone & 177 & 350 & & \\
\hline Internal Coating Oven & & & 1.33 & 1.26 \\
\hline Heating Zone & 163 & 325 & & \\
\hline Curing Zone & 213 & 415 & & \\
\hline
\end{tabular}

- Stream flow rates and temperatures. Gas flow rates and temperatures measured hy plant personnel: 


\begin{tabular}{lllr}
\hline \multicolumn{1}{c}{ Unit } & \multicolumn{1}{c}{ Stream } & Flow Rate & $\begin{array}{c}\text { Temperature } \\
\left({ }^{\circ} \mathrm{F}\right)\end{array}$ \\
\hline Can Washer & Water & $350 \mathrm{gal} / \mathrm{min}$ & 140 \\
& Make-up Water & $15 \mathrm{gal} / \mathrm{min}$ & 65 \\
Cun Dryer & Exhaust Air & 2980 SCFM & 124 \\
Can-Dryer Cooler & Exhaust Air & 2680 SCFM & 225 \\
Printer Oven & Exhaust Air & 1350 SCFM & 104 \\
Printer Oven Cooler & Exhaust Air & 1240 SCFM & 345 \\
Internal Coating Oven & Exhaust Air & 6100 SCFM & 109 \\
Heating Zone & & & \\
Curing Zone & Exhaust Air & 3070 SCFM & 210 \\
Cooler & Exhaust Air & 1740 SCFM & 179 \\
\hline Exhallst Air & 3000 SCFM & 122 \\
\hline
\end{tabular}

${ }^{\mathrm{a}} \mathrm{SCFM}=$ standard cubic feet per minute at $1 \mathrm{~atm}, 60^{\circ} \mathrm{F}$.

Make-up air enters from the building (at $88^{\circ} \mathrm{F}$ when measurements were made), except for the internal coater oven cooler, where air is drawn from outside.

- Other information: boiler rating, $125 \mathrm{hp}$; boiler operating pressure, 15 psig; solvent vapors-maximum allowable concentration $=25 \%$ of lower explosion limit; and solvent evaporation rate for the printer oven is $0.7 \mathrm{lb} / \mathrm{h}$ and for the internal. coater oven it is $15.4 \mathrm{lb} / \mathrm{h}$. 


\section{SECTION 4.0}

\section{IPH CASE STUDY: CORN WET MILLNG}

\subsection{INTRODUCTION}

The corn wet milling process produces corn sweeteners, starch, oil, and animal feed byproducts. At present, 18 plants (Casper 1977) are primarily engaged in corn wet milling. They are mainly located in the Midwest corn-growing region. The industry consumes about $6 \%$ of the U.S. corn crop, which has exceeded 7 billion bushels for the last two years. ( A bushel of corn weighs $56 \mathrm{lbs}$.) Plants range in size from 15,000 to 150,000 bushels per day capacity, with an average of about 50,000 bushels per day. Production is continuous, 24 hours per day, 7 days a week.

The industry is in a state of expansion. Conventional corn syrups have always shared a percentage of the sucrose sugar market. However, technological advances in the last five years have resulted in the advent of high-fructose corn syrups, which are considerably sweeter than conventional corn syrups and sucrose, for the same calorie content. Fructose corn syrups have gradually increased their penetration of the sucrose sugar market, and have recently gained acceptance by soft drink manufacturers.

The corn wet milling process is extremely energy intensive. The average energy requirement for plants in 1971 was 242,600 Btu per bushel of corn processed, with a variation of between 176,000 to 360,000 Btu (Casper 1977). Energy usage at some of the newer corn wet milling plants, which produce primarily syrups, is below $150,000 \mathrm{Btu} / \mathrm{bushel}$. For comparison, this average, on a per pound of throughput basis, is twice the energy consumed in the oil refining industry. Energy costs represent a significant portion of the final product cost. Consequently, the industry has devoted considerable resources for conservation and efforts to improve energy efficiency. As a result of rising natural gas and fuel oil prices and increasing restrictions on their use, the industry is actively considering alternative energy sources such as coal and solar energy.

The following report describes an IPH case study performed for a Midwestern corn processing plant.

\subsection{CORN PROCESSING OPERATIONS}

The corn wet milling process involves a large number of unit operations. A schematic outline of the process is shown in Fig. 4-1. For the purposes of this study, the corn steeping, starch drying, and feed drying processes were chosen as representative of the type of fuel usage.

\subsubsection{Com Steeping}

In the first step of the corn wet milling process, cleaned corn is fed to a large vat. Deionized water, containing 0.1 to $0.3 \%$ sulfur dioxide, is added. Due to its previous use in downstream processes, such as starch washing, the water has already picked up heat 


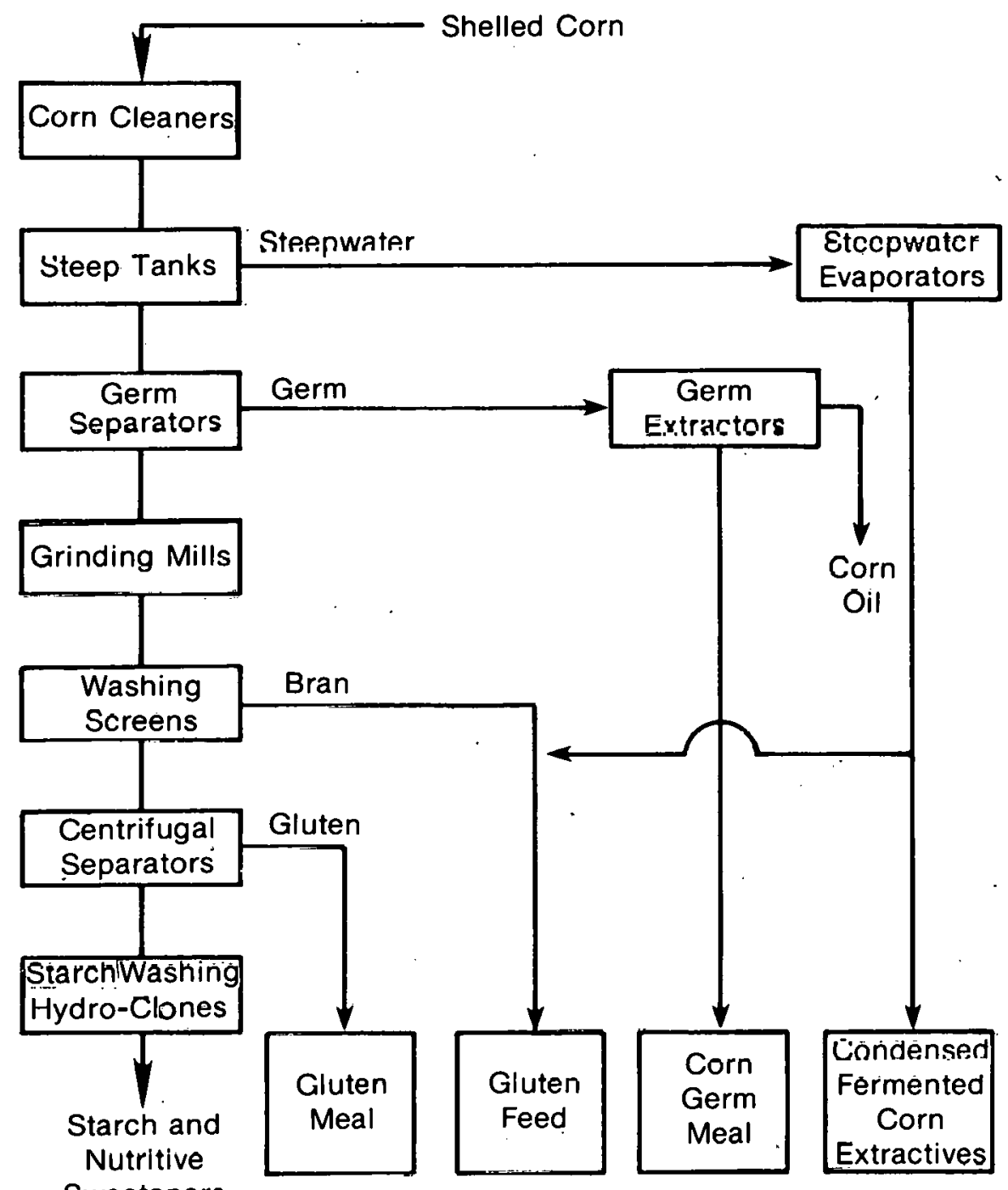

Figure 4-1. Schematic Outline of the Corn Wet=Milling Process (Brenner)

and some soluble material. The contents of the vat are heated to about $125^{\circ} \mathrm{F}$ by circulation through a heat exchanger, and then allowed to steep for 24 to 30 hours. The process is continuous in the sense that there are enough vats that all stages of the steeping operation ocur simultaneously. Process heat requirements are estimated at approximately $4000 \mathrm{Btu} /$ bushel $(166 \mathrm{~kJ} / \mathrm{kg})$ of corn processéd.

For the purpose of this study, a vat of nominal heat capacity $500,000 \mathrm{Btu} /{ }^{\circ} \mathrm{F}\left(949 \mathrm{MJ} /{ }^{\circ} \mathrm{C}\right)$ is used. Heat at the rate of 10 million $B t u / h(2.9 \mathrm{MW})$ is supplied to raise the vat temperature from $85^{\circ}$ to $125^{\circ} \mathrm{F}\left(29^{\circ}\right.$ to $52^{\circ} \mathrm{C}$ ) over a period of two hours. Heat losses are neglected. The calculations are documented in an appendix (Section 4.6.1). 


\subsubsection{Starch Drying}

Starch is a major product of the corn milling process. It can be sold directly as a product, but most is hydrolysed to a wide variety of corn syrups tailored for specific enduses. This includes liquid dextrose syrups and solid dextrose hydrate, as well as highfructose syrups. Care must be taken in drying the starch, since it will gelatinise at $144^{\circ}$ to $162^{\circ} \mathrm{F}$. Consequently, an indirect air drying process was employed in the plant under study, with steam generating the required heat. The equipment used was a throughcirculation conveyor dryer such as is shown in Fig. 4-2.

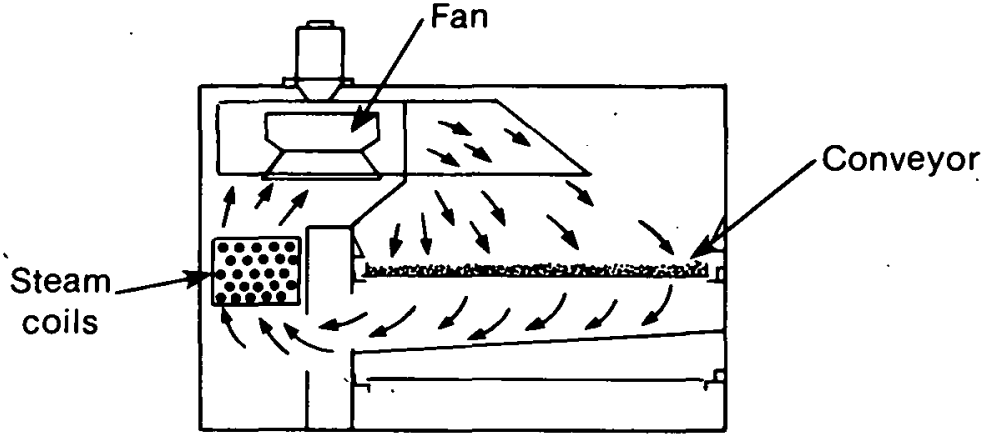

Figure 4-2. Section View of Continuous Through-Circulation Conveyor Dryer (Perry 1973).

Starch enters the high-temperature zone of the through-circulation conveyor dryer from rotary vacuum filters at about $100^{\circ} \mathrm{F}, 42 \%$ water content. Moving on perforated conveyors, the starch is contacted with hot air blown through the bed. This air is prehea ted by low-pressure steam and brought up to process temperature by contact with coils containing 125 psig steam. From here, the starch passes to the low-temperature zone hea ted by low-pressure steam. Finally, the starch is air cooled to about $115^{\circ} \mathrm{F}$. This preheated air is directed to the low-temperature dryer.

Theoretical heat requirements for this prosess were calculated at $880 \mathrm{Btu} / \mathrm{lb}(2 \mathrm{MJ} / \mathrm{kg})$ of product starch. An appendix (Section 4.6.2) details calculations for a typical dryer operation, whereby $125,000 \mathrm{lb} / \mathrm{h}(56,000 \mathrm{~kg} / \mathrm{h})$ of air are heated from $70^{\circ}$ to $270^{\circ} \mathrm{F}\left(21^{\circ}\right.$ to $\left.132^{\circ} \mathrm{C}\right)$ to supply a process heat load of 6 million Btu/h $(1.7 \mathrm{MW})$.

Starch drying technology has improved considerably in the last 10 years. As a result, for the latest installations, steam-heated, belt-driven dryers have been replaced by direct gas-fired, flash-type dryers. The operation of flash iryers is explained in the following section.

\subsubsection{Gluten Feed Drying}

This process consumes the major part of plant natural gas supplies. No. 6 fuel oil can be used as a substitute energy source if gas is unavailable. The plant used pneumaticconveyor or flash-type dryers similar to equipment illustrated in Fig. 4-3. 


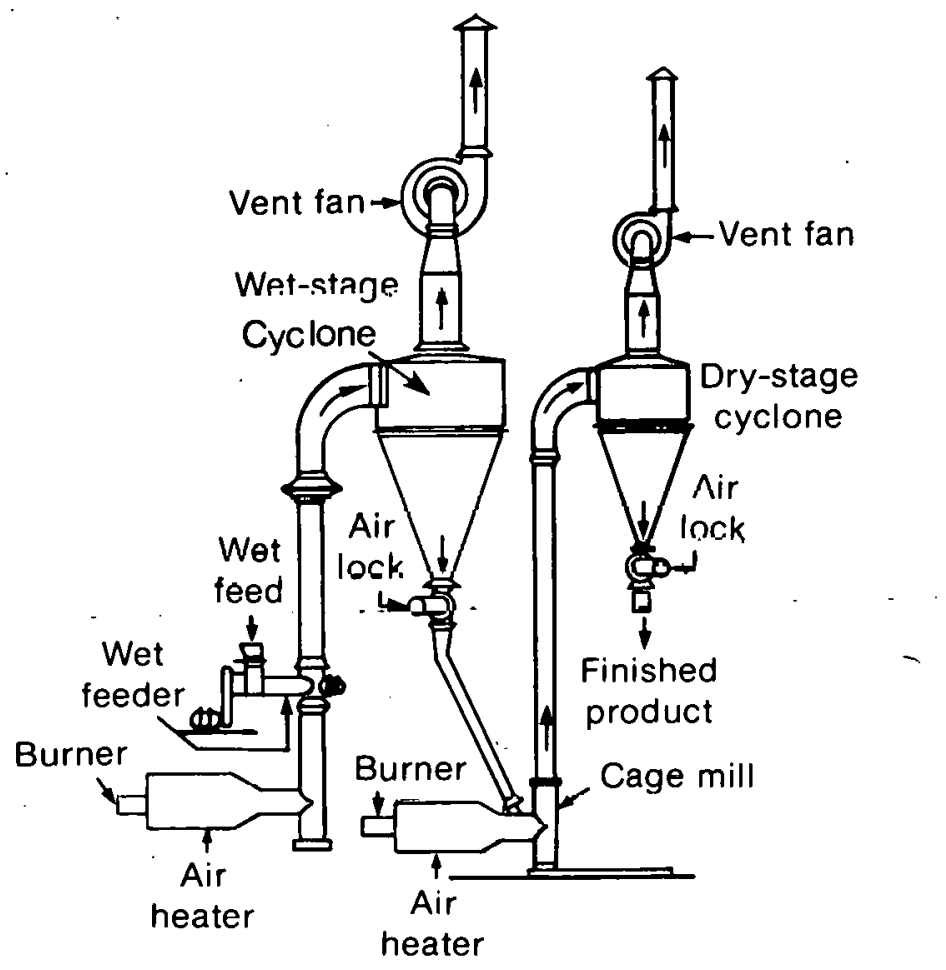

Figure 4-3. Two-Stage Pneumatic Conveyor Dryer

Fuel is burned with a large excess of air to prodine gas temperaturcz of about $1000^{\circ} \mathrm{F}$. The wet feed is injected into this gas stream hy pneumatio or sercw conveyors. The solld is entrained in the gas stream. Contact time is short, since heat transfer and drying takes place very rapidly. The solid material is disengaged from the gas stream in a cyclone.

During this process, evaporation of surface moisture occurs at essentially the wet-bulb air temperulure. This prevents degradation of the solid material. To continue the drying process, but at a lower temperature, a second drying stage is employed. The partially dried feed is reinjected into an airstream consisting of gas from the first stage diluted with an additional volume of a mbient air. $\Lambda$ eccond cyclone is used to again separate the gluten feed from the gas stream, which exits at about $220^{\circ} \mathrm{F}\left(1 \mathrm{n} 4^{\circ} \mathrm{C}\right)$. This temperature is high, muintaining the required temperature driving force necessary for the desired outlet moisture content. Dried feed exits the dryer at about $160^{\circ} \mathrm{F}\left(71^{\circ} \mathrm{C}\right)$.

Calculations, showing the theoretical heat requirements for the drying process to be about $1900 \mathrm{Btu} / \mathrm{lb}(4.4 \mathrm{MJ} / \mathrm{kg}$ ) of produrt, are illustratcd in an appendix (Section 4.6.3). They are based upon a dryer supplying 9.9 million $\mathrm{Btu} / \mathrm{h}(2.9 \mathrm{MW})$ to $50,800 \mathrm{lb} / \mathrm{h}(23,000$ $\mathrm{kg} / \mathrm{h})$ of air so as to raise its temperature from $70^{\circ}$ to $1000^{\circ} \mathrm{F}\left(21^{\circ}\right.$ to $\left.538^{\circ} \mathrm{C}\right)$.

Technological changes have also resulted in the replacement of flash dryers for gluten feed drying by direct-fired rotary dryers. A diagram of such equipment is shown in Fig. 4-4. Rotary dryers are similar in design and operation to rotary kilns used in lime 
and cement manuf acture. The process material passes through a slightly inclined, rotating cylinder. Rotary dryers are usually equipped with flights on the interior for lifting and showering the solids through the hot gas stream flowing through the cylinder. Gas flow is induced by either an exhauster or an exhauster-blower combination. Such arrangem ents allow the dryer to opera te slightly below atmospheric pressure, thus preventing the leakage of dust to surrounding work areas.

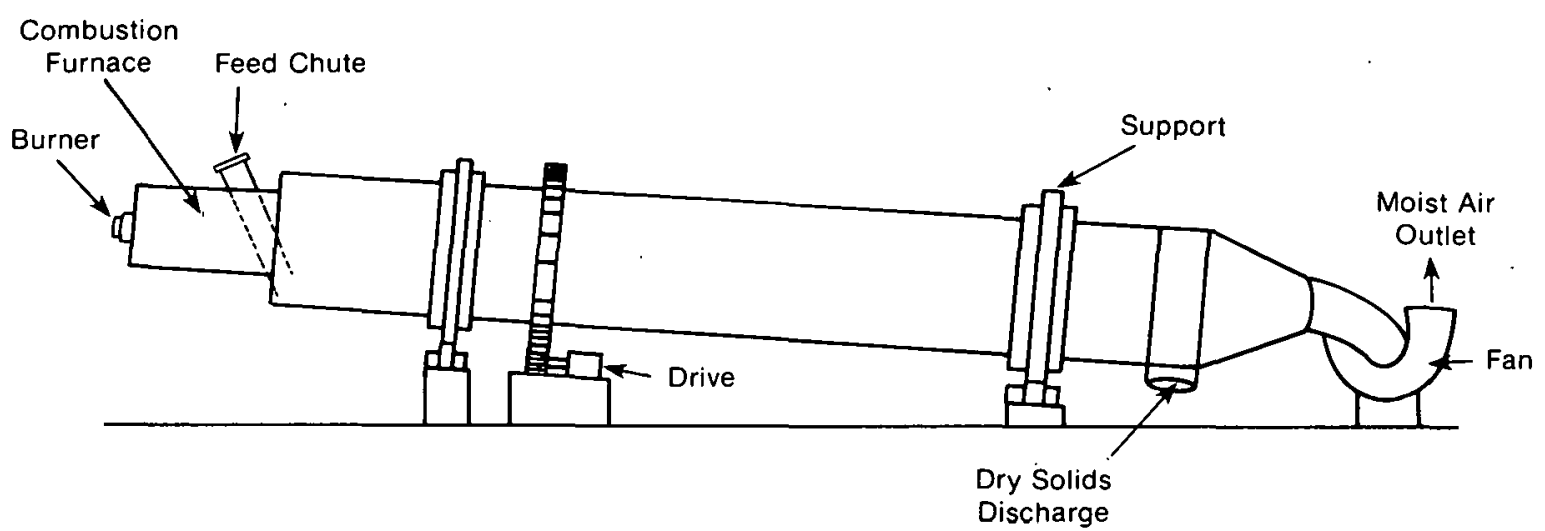

Figure 4-4. Direct Heat Cocurrent Rotary Dryer (McCabe 1976)

\subsection{ENERGY CONSERVATION}

Corn milling plants are large, sophisticated operations. Equipment is complex and highly automated. Large technical staffs are employed. A major concem is energy conservation. The efficiency of evaporative processes has been improved by increasing the number of effects, and by employing vapor recompression cycles. Heat losses have been reduced by the installation of more insulation and by better maintenance procedures, such as repairing steam traps. A large percentage of the electrical power consumed is generated on site. The degree nf cogeneration is limited by downstream process heat requirements. Boiler efficiencies are being increased by the installation of econumizers and air-preheaters. The efficiency of electrical generation would be increased by using higher steam pressures. By doing so, less steam would be exhausted, and the degree of electrical cogeneration could be increased. When available, and if equipment and environmental regulations allow, greater use is being made of coal to replace increasingly expensive and unavailable natural gas and fuel oil. Recycling of process water, largely the result of environmental regulations, has produced considerable energy savings.

For the plant under investigation, the feed-drying process is the largest single consumer of natural gas. The high temperatures involved allow efficient drying to be achieved at high throughput rates in compact units. These facts are reflected in technological changes taking place within the industry, which have tended to replace indirectly heated equipment, such as belt dryers, with direct gas-fired equipment. High throughput rates are often achieved at some sacrifice of product quality. However, this presents no problem for products, such as gluten feed, destined for animal consumption. 
If the relatively clean fluid fuels on which the drying processes depend were unavailable, low-temperature drying processes could be employed instead. (Feed is a low-value product; yet, a greater quantity of energy is consumed in its production than in producing more-valuable corn products.) A low-temperature process could use low-quality waste heat resulting in an increase in the potential for electrical cogeneration. In effect, a substitution of coal for oil and natural gas could be made. However, a low-temperature drying process would consume considerably more electrical power, since larger gas flow rates would be involved. Also, the same evaporative load would require a greater heat input. Contact times would be much longer and consequently larger, more expensive equipment would be necessary. At very low drying temperatures the quantity of moisture in the ambient air would be significant, and an air predrying step could be involved. These factors are illustrated in an appendix (Section 4.6.4), where the previous drying calculation is repeated, but at a lower hea ter outlet temperature.

For the given examples, it is shown that a low-temperature process consumes 1.3 times as much energy, and requires 5.6 times the air flow rate as compared to the hightemperature process. Yet in spite of this, and even considering the distribution inefficiencies in a coal-to-steam system, the change to a low-temperature drying process could be economical for this corn milling plant. This arises because the cost of energy from natural gas is approximately $50 \%$ more than the cost of energy from coal. In the future, with newly discovered and imported natural gas selling at 36 cents/therm (as of January 1980), the gap between the cost of energy from natural gas and coal is likely to widen dramatically.

As is the case with most industrial installations, steam is widely used as a heat transfer medium. However, there are many advantages to be gained from the use of hightemperature hot water instead, particularly for new installations; where the costs of retrofitting do not exist. A brief outline of these advantages can be found in Appendix $\mathrm{E}$.

\subsection{SOLAR ENERGY APPLICATHONS}

Total energì usage for an average-sized wet corn milling plant is about $500 \mathrm{million} B t \mathrm{~h} / \mathrm{h}$ $(147 \mathrm{MW})$ or 4.4 trillion Btu/yr $\left(4.6 \times 10^{15} \mathrm{~J} / \mathrm{yr}\right)$. To supply a significant portion of this energy usage, a solar collector field would be extremely large. Thus, land availability is a major constraint. Also, an upwind location is a necessity, because milling operations result in much dust fallout. Fallout from syrup operations at the plant under study produces a sticky, water-soluble residue, which could coat collectors and significantly reduce their performance.*

In considering solar energy as a partial alternative to conventional fuel supplies for corn milling, it is assumed that such a substitution would result in reduced fossil usage. This would seem to be the case, since much low-temperature process heat is supplied by cascading from high-temperature sources.

*Problems of dust accumulation on collectors have been observed at several DOEsponsored solar industrial engineering tests. This was particularly the case at a soybean processing plant located in Decatur, Alabama. A laquer-like residue from soybean dust accumulated on the flat-plate collectors, greatly reducing their performance. An automatic cleaning system was eventually installed, thus allowing collector efficiency to be restored to a satisf actory level. 
Solar collector performance data for the following analysis was obtained by testing currently available equipment. Technological improvements would be expected to result in increased performance, particularly of collectors operating at the higher temperatures'. Predictions of thermal output are based upon the computer code PROSYS developed at SERI. This is a simplified code, and the performance of a particular collector can be determined rapidly. Solar energy input is based on long-term weather data. Thus, when interpreting the numbers that follow, uncertainties involved in predicting future weather patterns, and the imperfect nature of the solar model must be taken into account.

Collector cost data is based on manufacturers' quotes. Hopefully, economies of scale, mass production techniques, etc., will keep increases in collector costs somewhat below the general cost increase of other manuf actured goods. Economic parameters regarding the proposed solar systems are determined using the computer code ECONMAT. The complete program, PROSYS/ECONMAT, is described in Appendix A. The economic assumptions incorporated in the present value calculations for this plant are shown in Table 4-1.

Table 4-1. ECONOMIC PARAMETERS USED IN LIFECYCLE COST ANALYSIS

\begin{tabular}{lc}
\hline Rate of Return & $12 \%^{\mathrm{a}}$ \\
General Inflation Rate & $6 \%$ \\
Real Fuel Escalation Rate & $5 \%$ \\
Operation, Maintenance, Property Tax, & \\
$\quad$ and Insurance as a Fraction of & \\
$\quad$ Investment & $2 \%$ \\
Corporate Tax Rate & $50 \%$ \\
System Lif etime & 20 years \\
Depreciation Period (straight-line) & 20 years \\
Solar Tax Credit & $20 \%$ \\
Interest During Construction & $9 \%$ \\
Conventional Fuel Cost (Fuel Oil) & $\$ 3.92 \mathrm{~b} / 10^{6} \mathrm{Btu}$ \\
Labor Rate & $\$ 19 / \mathrm{h}$ \\
\hline a Cash, or equity flnancing assumed. & \\
b Fuel use efficiency assumed 80\%. &
\end{tabular}

\subsubsection{Corn Steeping}

Sular heat for the corn steeping prncess is most economically supplied by flat-plate collectors. Efficiencies at low temperatures are high, and they can utilize the diffuse component of solar radiation, which forms a large percentage of total insolation in the Midwest. Indirect heat exchange would allow the solar system to be easily integrated into the steep-water heating loop. Typical solar system designs are shown in Appendix B. A nonfreezing liquid, such as a water/glycol mixture, would be circulated through the solar collectors during periods of solar insolation sufficient to give a net energy output. Heat from the solar loop would be transferred to the steep-water via a heat exchanger.

The solar system is sized to deliver the process heat rate of 10 million $\mathrm{Btu} / \mathrm{h}$ only at the period of peak insolation. In this way, there is no problem of exceeding the process 
temperature or of having to reject heat. No energy storage is incorporated. Heat not provided by the sun is supplied by the existing heating system. If the steep tank is maintained in a stratified condition, such that liquid is removed from the bottom and returned hot to the top, constant operating conditions can be assumed. The heat is supplied to raise the steep-tank temperature from $85^{\circ}$ to $125^{\circ} \mathrm{F}$.

\subsubsection{Stareh Drying}

Heat to this higher-temperature process is most economically supplied using parabolic trough collectors, which can concentrate solar radiation. These would be aligned north/ south and would track the sun east-to-west. This configuration results in maximum thermal energy output.

Three possible systems could be used to supply solar energy to the starch drying process:

- Steam generation: A steam-generating system would interface directly with the present starch-drying equipment. Solar-generated steam, when available, would simply feed into the existing steam header. The most practical method of steam generation in freezing climates appears to be to pump a heat transfer fluid through the collector field, and to generate the steam in an unfired kettle boiler.

- Indirect air heating: Heat would be transferred to the drying air by pumping a solar-heated fluid through additional coils installed in the dryer.

- Direct air heating: Air blown through the solar collectors would be piped directly to the process. The use of air as a collector working fluid avoids problems of freezing inherent to liquid systems, at the expense of increased parasitic electrical power inputs. Unfortunately, at this lime, there are no collectors on the market capable of delivering air at temperatures much greater than those required for space heating. Consequently, a direct air system was not considered for this application.

\subsubsection{Gluten Feed Drying}

Solar thermal technologies capable of producing the temperatures currently used in the gluten feed drying process are presently only at the experimental stage. Factors forcing a shift to low-temperature drying processes would greatly improve the economics of supplying energy from the sun. Solar systems such as those feasible for the starch-drying process could be employed.

Solar systems employing currently available technolngy could be used to prcheat air for high-temperuture feed drying. This would preserve nonrenewable fossil fuels, stabilize energy costs, and would give some degree of security against future fuel curtailments.

\subsubsection{Results of Solar Analysis}

The results of the solar performance and costing routines are summarized in Tables 4-2 and 4-3. Competing fuel is taken as No. 6 fuel oil, costing 58 cents/gal. Utilized at an efficiency of $80 \%$, the effective cost of energy delivered to the process is $\$ 4.90$ per million Btu. Because of the technological constraints discussed above, the analysis was performed only for the corn-steeping and starch-drying processes. The economics of 
Table 4-2. SOLAR SYSTEM: ENGINEERING PARAMETERS

\begin{tabular}{|c|c|c|c|c|c|c|c|c|}
\hline Process & Location & $\begin{array}{l}\text { Collector } \\
\text { Type, Alignment, } \\
\text { Tilt }\end{array}$ & $\begin{array}{c}\text { Process } \\
\text { Temperature } \\
{ }^{\circ} \mathrm{F}\left({ }^{\circ} \mathrm{C}\right)\end{array}$ & $\begin{array}{c}\text { Average } \\
\text { Collector } \\
\text { Temperature } \\
{ }^{\circ} \mathrm{F}\left({ }^{\circ} \mathrm{C}\right)\end{array}$ & $\begin{array}{c}\text { Collector } \\
\text { Area } \\
\mathrm{ft}^{2} \\
\left(\mathrm{~m}^{2}\right)\end{array}$ & $\begin{array}{c}\text { Max Solar } \\
\text { Output } \\
10^{6} \mathrm{Btu} / \mathrm{h} \\
\text { (MW) }\end{array}$ & $\begin{array}{c}\text { Energy } \\
\text { Delivered } \\
\text { Btu/yr } \\
\text { (TJ/yr) }\end{array}$ & $\begin{array}{c}\text { Process } \\
\text { Heat Load } \\
\text { Supplied by } \\
\text { Solar (\%) }\end{array}$ \\
\hline $\begin{array}{l}\text { Corn } \\
\text { steeping, } \\
\text { Hot Water } \\
\text { Exchange }\end{array}$ & Midwest & $\begin{array}{l}\text { Flat Plate, } \\
\text { Nor th/Soutr, } \\
\text { Latitude } \\
\text { Angle }\end{array}$ & $\begin{array}{l}125 \\
(52)\end{array}$ & $\begin{array}{l}122 \\
(50)\end{array}$ & $\begin{array}{l}108,932 \\
(10,124)\end{array}$ & $\begin{array}{c}10 \\
(2.9)\end{array}$ & $\begin{array}{c}26.4 \times 10^{9} \\
(27.8)\end{array}$ & 30.2 \\
\hline $\begin{array}{l}\text { Corn } \\
\text { Steeping, } \\
\text { Hot Water } \\
\text { Exchange }\end{array}$ & $\begin{array}{l}\text { El Paso, } \\
\text { Texas }\end{array}$ & $\begin{array}{c}\text { Flat Plate: } \\
\text { N/S, Latitude } \\
\text { Angle }\end{array}$ & $\begin{array}{l}125 \\
(52)\end{array}$ & $\begin{array}{l}122 \\
(50)\end{array}$ & $\begin{array}{r}74,683 \\
(6941)\end{array}$ & $\begin{array}{c}10 \\
(2.9)\end{array}$ & $\begin{array}{c}32.7 \times 10^{9} \\
(34.5)\end{array}$ & 37.3 \\
\hline $\begin{array}{l}\text { Starch } \\
\text { Drying, } \\
\text { Steam } \\
\text { Generation }\end{array}$ & Midwest & $\begin{array}{l}\text { Parabolic } \\
\text { Trough, N/s, } \\
\text { No Tilt }\end{array}$ & $\begin{array}{c}270 \\
(132)\end{array}$ & $\begin{array}{l}447 \\
(231)\end{array}$ & $\begin{array}{r}100,000 \\
(9294)\end{array}$ & $\begin{array}{c}6 \\
(1.7)\end{array}$ & $\begin{array}{c}18.9 \times 10^{9} \\
(19.9)\end{array}$ & $3 j .9$ \\
\hline $\begin{array}{l}\text { Starch } \\
\text { Drying, } \\
\text { Hot Air } \\
\text { Exchange }\end{array}$ & Midwest & $\begin{array}{l}\text { Parabolic } \\
\text { Trough, N,'s } \\
\text { No Tilt }\end{array}$ & $\begin{array}{l}270 \\
(132)\end{array}$ & $\begin{array}{l}283 \\
(139)\end{array}$ & $\begin{array}{l}88,889 \\
(8261)\end{array}$ & $\begin{array}{c}6 \\
\cdot(1.7)\end{array}$ & $\begin{array}{c}19.6 \times 10^{9} \\
(20.7)\end{array}$ & 37.3 \\
\hline
\end{tabular}


preheating air for gluten feed drying would be similar to those presented for supplying hot air for starch drying.

Unfortunately, none of the proposed solar systems installed in the Midwest region appear to be economical at the present time. As explained below, this conclusion is a function of location, delivery temperature, and competing fuel costs.

Insolation maps of the United States can be found in Appendix C. Table 4-2 illustrates that a flat plate in El Paso, Texas, can deliver almost twice as much energy per square foot as a similar system located in the Midwest. Within the constraints of the computer program, producing low-temperature hot water using solar energy in regions of high insolation is shown to have a positive present value. Still, the discounted payback period was over 13 years for El Paso in 1979.

Appendix D illustrates the dependence of solar collertor types on temperature: Flat plates are currently the most economical type, but because of high thermal losses are restricted to low-temperature applications. A great deal of development work is in progress toward improving the performance and reducing the cost of parabolic trough concentrators. This could bring the cost of energy delivered by a parabolic trough into the range of present flat-plate costs, but the energy would be delivered at a substantially higher temperature.

The cost of competing energy was taken as 58 cents/gal of No. 6 oil. Although this is realistic for fuel oil, it is significantly higher than alternatives such as coal or even natural gas on an equivalent Btu basis. Using coal as an alternative fuel source, solar energy is much less competitive. However, the cost of premium fluid fuels is likely to advance rapidly in the future. Table 4-3 shows the effect of performing the economic calculations, assuming an escalation in fuel prices $5 \%$ higher than the rate of inflation, for the years 1983 and 1985 . (Recent events could continue to produce much greater fuel escalation rates.) Also assumed are technological advances maintaining the cost of the solar system (to deliver the energy shown) constant in dollar terms. Given these assumptions, heating hot water for process needs in the Midwest would have a payback period of less than 20 years by 1983 . However, even by 1985 the payback is too long to satisfy usual industry investment criteria of three to five years or less.

Table 4-3. SOLAR SYSTEM: ECONOMIC PARAMETERS

\begin{tabular}{|c|c|c|c|c|c|c|c|c|c|c|c|}
\hline \multirow[b]{2}{*}{ Process } & \multirow{2}{*}{\multicolumn{2}{|c|}{ Location }} & \multicolumn{3}{|c|}{$\begin{array}{c}\text { Total System Installed } \\
\text { Coot }\left(\$ 10^{6}\right)\end{array}$} & \multicolumn{3}{|c|}{$\begin{array}{l}\text { Present yalue } \\
\left(\$ 10^{6}\right)\end{array}$} & \multicolumn{3}{|c|}{$\begin{array}{c}\text { Discounted Payhark } \\
\text { Perlod (Years) }\end{array}$} \\
\hline & & & 1979 & 1983 & 1985 & 1979 & 1983 & 1985 & 1979 & 1983 & 1985 \\
\hline Corn Steeping & & Mi dwest & 2.8 & 2.9 & 3.0 & -0.128 & +0.422 & +1.011 & $20+$ & 17 & 13.3 \\
\hline Corn Stecping & El & Pasu, Texas & 2.0 & 2.1 & -- & +0.663 & +1.763 & -- & 13 & 9 & - \\
\hline $\begin{array}{l}\text { Starch Drying, } \\
\text { steam Generation }\end{array}$ & & Mi dwest & 3,3 & 3.3 & 3.4 & -1.395 & -0.748 & -0.303 & $20+$ & $20+$ & $20+$ \\
\hline $\begin{array}{l}\text { Starch Drying, } \\
\text { Air Exchange }\end{array}$ & & Mi dwest & 3.0 & 3.0 & 3.1 & -1.090 & -0.422 & +0.036 & $20+$ & $20+$ & 20 \\
\hline
\end{tabular}




\subsection{CONCLUSIONS}

The corn wet milling industry has a number of characteristics highly favorable to the introduction of alternative sources of energy. Energy usage is very large, and energy costs represent a significant fraction of the value added during processing. Processing temperatures are largely in the low to intermediate temperature range. Operations are continuous and are supervised by a skilled workforce. Thus, if solar energy is to make a significant impact on U.S. industrial energy requirements, the corn wet milling industry is of a type that solar must penetrate. Upon closer inspection, however, the prospects of near-term solar application are slight. The present location of the industry, in -terms of available solar insolation, is not favorable. At the plant under investigation, readily available coal allowed the production of electricity and by-product process heat at relatively low cost.

The difficulties illustrated in this example point out the necessity of identifying industries that need alternative energies, and that have desirable locations and process characteristics. These "markets by exception" will constitute the only near-term opportunities for solar energy to economically supply industrial process heat. More significant market penetration in the long-term will depend upon large reductions in the cost of solar equipment, improvements in reliability and performance, economic incentives, and increased cost and scarcity of conventional fuel. 


\subsection{APPENDIX}

\subsubsection{Com Steeping}

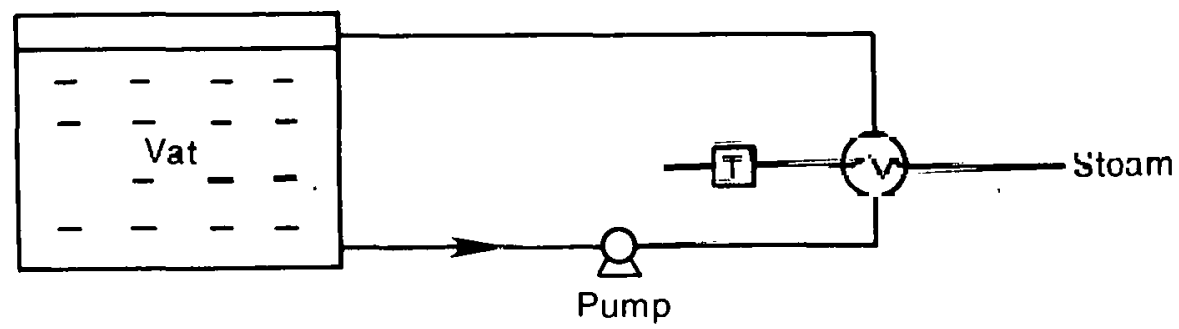

Initial temperature of vat

Final temperature of vat

Heat capacity

Heat required

Heat rate

Vat capacity

Specific heat consumption

$$
\begin{aligned}
& =85^{\circ} \mathrm{F} \\
& =125^{\circ} \mathrm{F} \\
& =500,000 \mathrm{Btu} /{ }^{\circ} \mathrm{F} \\
& =500,000(125-85) \\
& =2 \times 10^{7} \mathrm{Btu} \\
& =10^{7} \mathrm{Btu} / \mathrm{h} \text { for } 2 \text { hours } \\
& =5000 \mathrm{bushel} \\
& =4000 \mathrm{Btu} / \text { bushel of corn }
\end{aligned}
$$




\subsubsection{Starch Drying}

Simplified Diagram

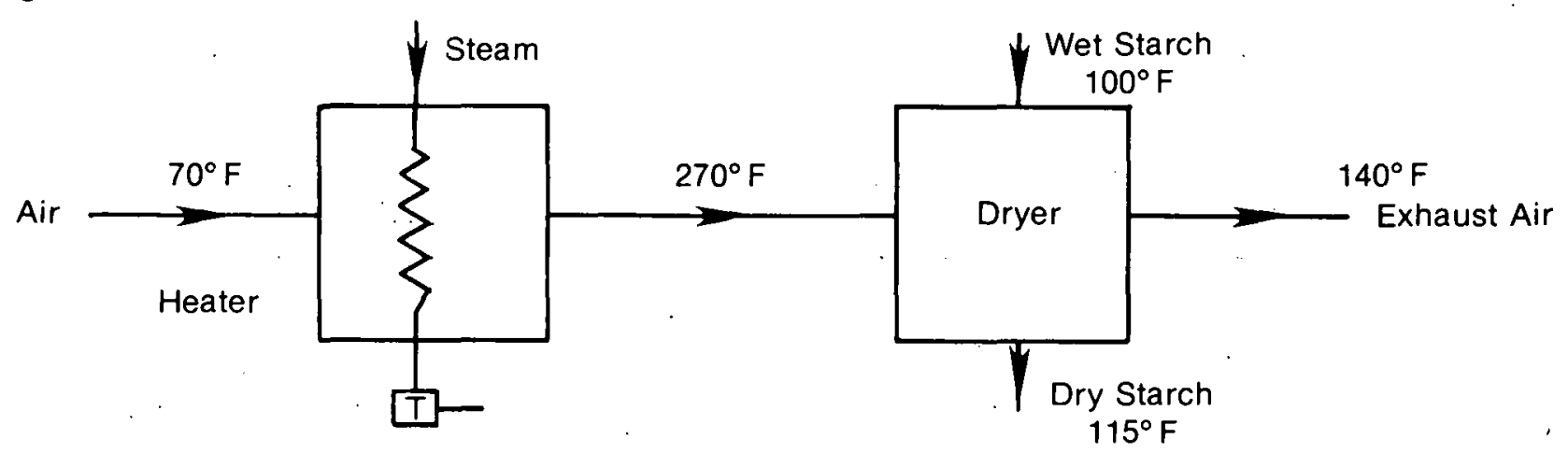

\begin{tabular}{|c|c|c|c|c|c|c|c|}
\hline & $\begin{array}{l}\text { Air into } \\
\text { heater }\end{array}$ & $\begin{array}{l}\text { Air out } \\
\text { of heater }\end{array}$ & \multicolumn{2}{|c|}{$\begin{array}{l}\text { Starch into } \\
\text { dryer }\end{array}$} & $\begin{array}{l}\text { Starch out } \\
\text { of dryer }\end{array}$ & \multicolumn{2}{|c|}{$\begin{array}{l}\text { Air out } \\
\text { of dryer }\end{array}$} \\
\hline Temperature, ${ }^{\circ} \mathrm{F}$ & 70 & 270 & \multicolumn{2}{|c|}{100} & 115 & & 140. \\
\hline Flow, lb/h & 125,000 & - & $\begin{array}{l}\text { Starch } \\
\text { Water }\end{array}$ & $\begin{array}{l}6,162.5 \\
4,462.5\end{array}$ & $\begin{array}{r}6,162.5 \\
762.5\end{array}$ & $\begin{array}{l}\text { Air } \\
\text { Water }\end{array}$ & $\begin{array}{r}125,000 \\
3,700\end{array}$ \\
\hline Relative Humidity, \% & 50 & - & \multicolumn{2}{|c|}{-} & - & & 28 \\
\hline Moisture content, $\%$.Wet Basis & - & - & \multicolumn{2}{|c|}{42} & 11 & & - \\
\hline
\end{tabular}

Specific heat of wet air

Specific heat of starch

$=0.243 \mathrm{Btu} / \mathrm{lb}{ }^{\circ} \mathrm{F}$

$=0.6 \mathrm{Btu} / \mathrm{lb}^{\circ} \mathrm{F}$

Heat rate

$=125,000 \times 0.243(270-70)$

$=6.075 \times 10^{6} \mathrm{Btu} / \mathrm{h}$

$\Delta \mathrm{H}$ starch

$\Delta H$ non-evaporated water

$=55,000 \mathrm{Btu} / \mathrm{h}$

$\Delta \mathrm{H}$ evaporation

$=11,000 \mathrm{Btu} / \mathrm{h}$

$=3700(1122-68)=3,900,000 \mathrm{Btu} / \mathrm{h}$

Total $\Delta H$ gain

$=3,966,000 \mathrm{Btu} / \mathrm{h}$

$\Delta \mathrm{H}$ loss by air

$=125,000 \times 0.243(270-140)$

$=3,949,000 \mathrm{Btu} / \mathrm{h}$

Specific energy consumption $=\frac{6.075 \times 10^{6}}{6925}$

$=880 \mathrm{Btu} / \mathrm{lb}$ of product starch 


\subsubsection{Gluten Feed Drying}

Block diagram is similar to Section 4.6.2, except the ailigas burner is used as the source of heat.

\begin{tabular}{|c|c|c|c|c|c|c|c|}
\hline & $\begin{array}{l}\text { Air into } \\
\text { heater }\end{array}$ & $\begin{array}{l}\text { Air out } \\
\text { of heater }\end{array}$ & \multicolumn{2}{|c|}{$\begin{array}{l}\text { Feed into } \\
\text { dryer }\end{array}$} & $\begin{array}{l}\text { Feed ou: } \\
\text { of dryer }\end{array}$ & \multicolumn{2}{|c|}{$\begin{array}{l}\text { Gas out } \\
\text { of dryer }\end{array}$} \\
\hline High-Temp. Process, ${ }^{\circ} \mathrm{F}$ & 70 & 1000 & \multicolumn{2}{|c|}{120} & 160 & & 220 \\
\hline Flow, lb/h & $\begin{array}{l}\text { High Temp. } \quad 50,800 \\
\text { Low Temp. } 233,000\end{array}$ & - & $\begin{array}{l}\text { Feed } \\
\text { Water }\end{array}$ & $\begin{array}{l}5,353 \\
9,942\end{array}$ & $\begin{array}{r}5,353 \\
792\end{array}$ & $\begin{array}{l}\text { Air } \\
\text { Water }\end{array}$ & $\begin{array}{r}50,800 \\
9,150\end{array}$ \\
\hline Moisture content, \% Wet Basis & - & - & \multicolumn{2}{|c|}{65} & 13 & . & \\
\hline
\end{tabular}

Specific Hezt of Feed

High Temperature Process
Specific heat of air/gas

Heat rate

$\Delta \mathrm{H}$ feed

$\Delta H$ non-evaporated water

$\Delta \mathrm{H}$ evaporation

Total $\Delta H$ gain

$\Delta \mathrm{H}$ lass by air

Specific energy consumption

\section{$0.6 \mathrm{Btu} / \mathrm{lb}^{\circ} \mathrm{F}$}

$=0.25 \mathrm{Btu} / 1 \mathrm{~b}{ }^{\circ} \mathrm{F}$

$=50,800 \times 0.25 \times(1000-70)$

$=11.81 \times 10^{6} \mathrm{Btu} / \mathrm{h}$

$=128,000 \mathrm{Btu} / \mathrm{h}$

$=32,0003 \mathrm{tu} / \mathrm{h}$

$=9,150(1153.4-87.92)$

$=9,749,000 \mathrm{Btu} / \mathrm{h}$

$=9,909,000 \mathrm{Btu} / \mathrm{h}$

$=50,800=0.25(1000-220)$

$=9,906,000 \mathrm{Btu} / \mathrm{h}$

$=\frac{11.81 \times 10^{6}}{6145}$

$=1920 \mathrm{Btu} / \mathrm{lb}$ of product 
Low-Temperature Process

Specific heat of air/gas

$\Delta \mathrm{H}$ feed

$\Delta H$ non-evaporated water

$\Delta H$ evaporation

Total $\Delta \mathrm{H}$ gain

$\Delta H$ loss by gas

Gas flow rate, $M$

Heat rate

Specific energy consumption

$$
\begin{aligned}
& =0.243 \mathrm{Btu} / \mathrm{lb}{ }^{\circ} \mathrm{F} \\
& =64,000 \mathrm{Btu} / \mathrm{h} \\
& =16,000 \mathrm{Btu} / \mathrm{h} \\
& =9,150(1130.2-87.92) \\
& =9,537,000 \mathrm{Btu} / \mathrm{h} \\
& =9,617,000 \mathrm{Btu} / \mathrm{h} \\
& =\Delta \mathrm{H} \mathrm{loss} \mathrm{by} \mathrm{gas} \\
& =\mathrm{M} \times 0.243(300-160) \\
& =9,617,000 \mathrm{Btu} / \mathrm{h} \\
& =283,000 \mathrm{lb} / \mathrm{h} \\
& =283,000 \times 0.243(300-70) \\
& =15.8 \times 10^{6} \mathrm{Btu} / \mathrm{h} \\
& =2570 \mathrm{Btu} / \mathrm{lb} \text { of product }
\end{aligned}
$$

Relative energy consumption

$\frac{\text { Low-temperature process }}{\text { High-temperature process }}$

Relative gas flow rate

Low-temperature process

High-temperature process
$=1.3$

$=5.6$ 


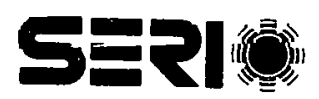




\section{SECTION 5.0}

\section{IPH CASE STUDY: POLYMERIC RESIN MANUFACTURE}

\subsection{INTRODUCTION}

Paint manufacturing can be broken down into a number of separate processes; these may or may not be carried out at a single facility. One of the earliest operations is the manufacture of polymeric base resins. This appears to be the most heat-intensive process in paint manufacturing. Other operations such as pigment manufacture, and the actual mixing and formulation of paints, consume energy mainly in the form of electricity. It is probable that the large number of plants identified with paint manufacturing are actually associated only with the final process of paint formulation. Resins are supplied from a smaller number of large operations. A resin manufacturing plant located in the Chicago, Illinois area was the subject of an IPH case study investigation.

\subsection{DESCRIPTION OP PROCESSES}

In the subject plant, both acrylic- and alkyd-type polymeric resins are manufactured. Acrylic resins form the basis for la tex, water-based paints. Such paints have achieved a position of dominance throughout the industry at the expense of alkyd, oil-based paints. Both types of resin are produced in reaction kettles by a batch operation. The kettles incorporate a heating jacket with internally located cooling coils. All processing equipment is constructed of stainless steel.

The plant operates continuously five days per week. Energy requirements are primarily for heating the reaction kettles, although some heat is also used for heating raw materials and product storage tanks, and for space heat. The temperature and means by which heat is supplied to a kettle depend upon the type of resin being manufactured.

\subsection{ACRYLIC RESIN MANUFACTURE}

Several kettles, ranging in size from 1000 to 5000 gallon capacity, are used in the production of acrylic resins. They are loaded for processing as required by production sclıduling. Liquids comprising $60 \%$ of the kettle charge are pumped from external storage. Solid material is loaded, of ten by hand, through hatches on top of the kettle. The reactants are stirred to ensure thorough mixing. They are brought up to reaction temperatures of no more than $250^{\circ} \mathrm{F}$, by injecting saturated steam at $340-360^{\circ} \mathrm{F}$ in to the heating jacket. The reaction is exothermic, and hold time is between 16 and 24 hours. A typical reaction temperature profile is shown in Fig. 5-1. Temperature control is maintained within $\pm 5^{\circ} \mathrm{F}$. Cooling is obtained by injecting $60-100^{\circ} \mathrm{F}$ water into the kettle jacket, and by circulating water through the internal coils.

Steam is supplied to the entire paint manufacturing complex-of which the resin manufacturing operation forms a small part-from a centralized facility. The boilers are fueled by Bunker $\mathrm{C}$ oil, natural gas, or reclaimed paint solvents, when available. Plant personnel estimate that $72 \%$ of the steam produced is used for processing, $8 \%$ for receiving and storage, and $20 \%$ for building heat. 


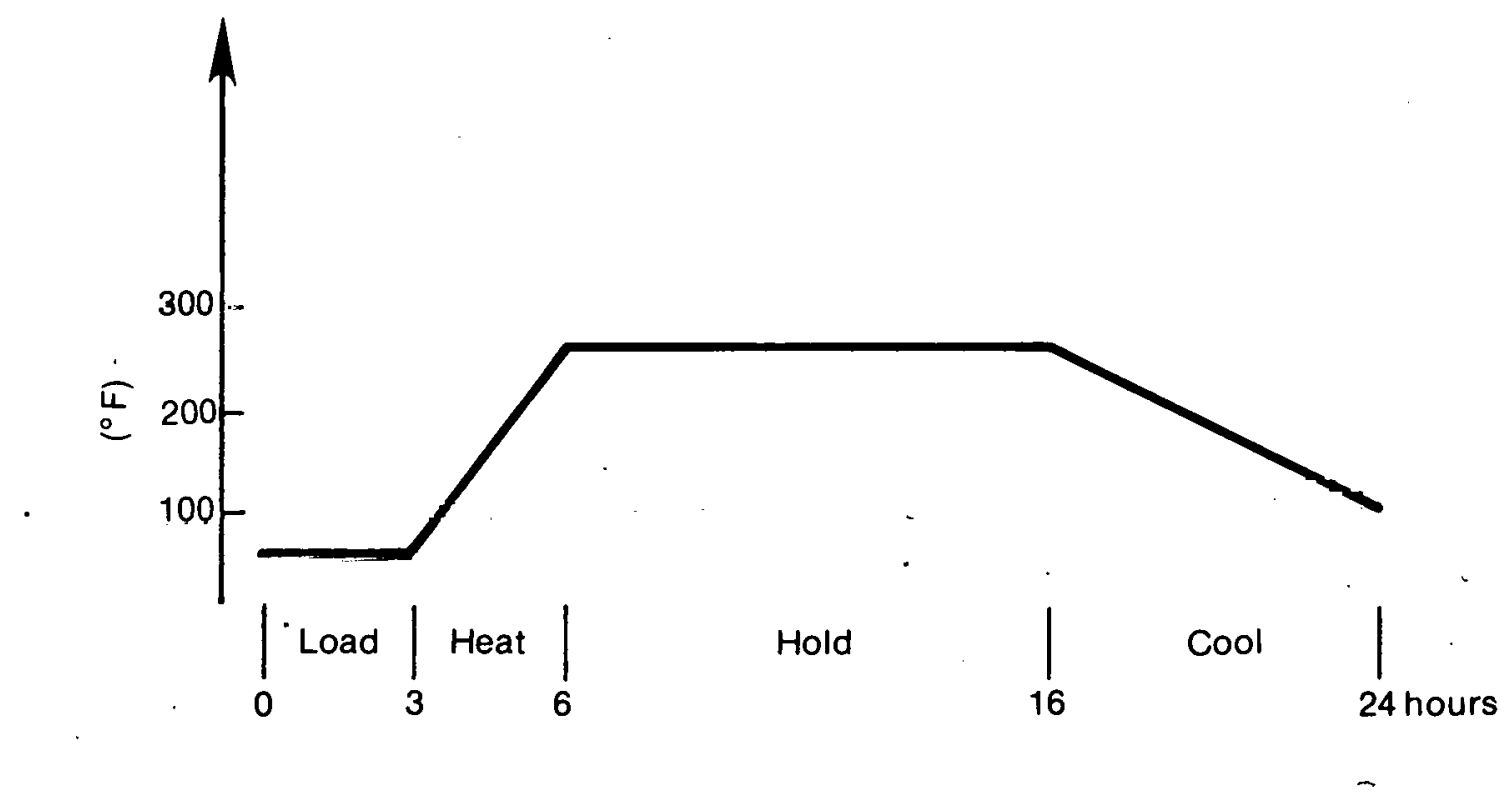

Figure 5-1. Low-Temperature Reactor-Typical Temperature Profile

To gain some measure of base steam load, plant personnel supplied weekly steam consumption values for a 10-month period. The ratio of the highest-to-lowest weekly rate was 2.7. A considerable seasonal variation, reflecting space heating requirements, was apparent. As a basis for design, the process steam load was taken as $72 \%$ of the lowest weekly steam rate. This was calculated as $4400 \mathrm{lb}$ steam/h, or approximately $4 \times 10^{6} \mathrm{Btu} / \mathrm{h}$.

Insulated raw material tanks, located outdnors, are steam-heated to $120-140^{\circ} \mathrm{F}$ to reduce viscosity and to facilitate pumping. Uninsulated product storage tanks located inside the process building are likewise heated to the same temperature. No direct information was available concerning the energy required for tank heating. Thus, an estimate was used, based upon the $8 \%$ figure quoted above, to give a value of $0.4 \times 10^{6} \mathrm{Btu} / \mathrm{h}$.

\subsection{ALKYD RESIN MANUFACTURE}

A condensation reaction occurring at temperatures up to $440^{\circ} \mathrm{F}$, aind involving phthalic anhydride as a major feed constituent, is used to pronduce alkyd rcsing. The reaution is reversiblc and mildly endothermic. 'lo push it to conclusion, additional heat is supplied to drive off the water produced in the reaction. A reflux system is employed to separate water from the evolved solvent, which is returned to the batch. Reaction times vary between 10 and 24 hours. A typical temperature profile is shown in Fig. 5-2.

The plant has several high-temperature kettles of 1000 to 3500 gallon capacity. Heat is supplied to the largest kettle using a liquid therminol heat transfer medium. The other kettles are heated by Dowtherm A vapor, which is condensed in the heating jackets. Cooling is obtained using a second heat transfer loop that can inject coll heat-transfer liquid at about $260^{\circ} \mathrm{F}$ into the kettle jacket. The efficiencies of the heaters are not known, but are estimated to be no more than $80 \%$ at peak output. 


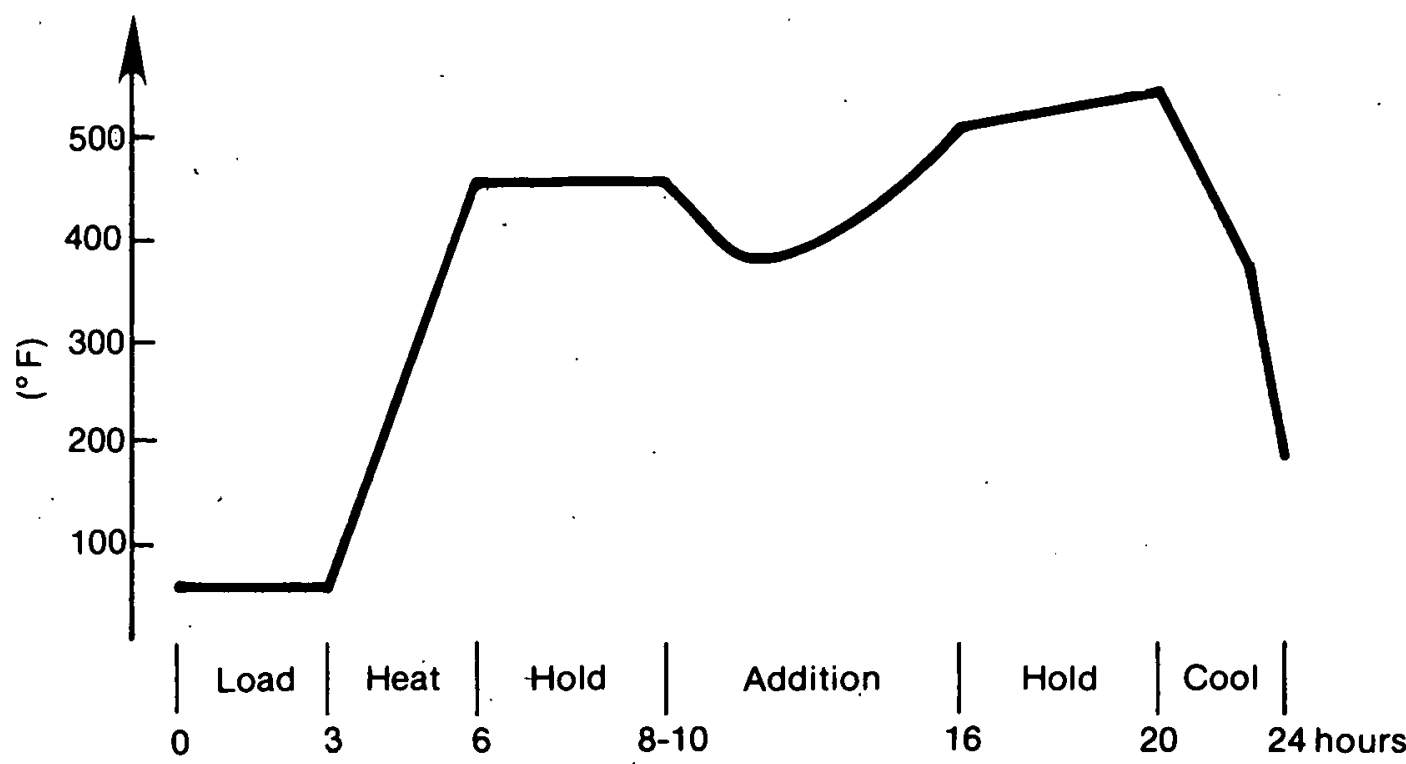

Figure 5-2. High-Temperature Reactor-Typical Temperature Profile

Plant personnel measured natural gas consumption for three-hour periods over a typical week of operations. Heat input to a particular kettle varies drastically with time. However, since there are several kettles and, apart from Monday morning, they are at various stages in the batch cycle, the heat demand profile is somewhat smoothed out. During the week, the ratio of the maximum to minimum three-hour demand (excluding the last 12 hours of the week, when the system was being shut down) was 2.5. This minimum heat load, a mounting to $2.7 \times 10^{6} \mathrm{Btu} / \mathrm{h}$, was used as a design heat rate.

\subsection{ENERGY CONSFRVATION POTENTIAL}

Nearly all the energy supplied to the process is to heat materials and equipment to reaction temperatures, to make up for heat losses from reactors and storage vessels, and to supply heat of vaporization of water to the condensation polymerization reaction. In principle, considerable energy savings could result by consolidating the number of process heaters. None of these heaters are particularly efficient and all are sized to cope with more than the peak load, which is of short duration. In practice, however, the opportunity for energy conservation is limited. This arises because of the necessity to maintain accurate temperature control, the batch nature of the process, which demands heating and cooling loads that can occur at anytime, and because of the high temperatures required to drive the reaction process compared to the low-temperature cooling requirements. Some energy could be saved by increased insulation of equipment, and by the possible installation of economizers on the process heaters. The possibility of replacing steam with high-temperature hot water to heat the acrylic resins could be considered, although temperature control of a jacketed vessel could be difficult. A general discussion of the advantages of such a system is described in Appendix E. A liquid system for 
heating and cooling would remove problems of water-hammer experienced when cooling water is introduced to the heating jacket and cooling coils.

The opportunity exists to use the organic heat transfer fluids, which cool the hightemperature reactors, to supply heat to the storage tanks. The data was insufficient to examine this possibility in detail. Some equipment changes would be required, since therminol-type fluids are incompatible with water.

Technical staff at the resin-manufacturing plant suggested that energy savings could also be realized by replacing the present single batch reactors with a series of continuously operated stirred tanks. In theory, such a system could result in more consistent product qualities, and less energy would be required, because constant heating and cooling loads would present greater opportunities for heat recovery. Plant maintenance should be reduced as equipment is subjester to less thermal shock. Probably the greatest disadvantage of a continuous system results from reduced flexibility of operation, considering the wide range of products manufactured.

\subsection{SOLAR APPLICATIONS}

Three potential solar applications were examined:

- supplying hot water to heat the storage tanks;

- supplying steam for the low-temperature reactors; and

- supplying Dowtherm vapor to heat the high-temperature reactors.

It is envisioned that the hot water supplying heat to the storage tanks would actually be a nonfreezing glycol mix ture. The solar system could actually be oversized, such that the temperature of the tank could be increased during the day to compensate for heat losses at night. Thus, no supplemental energy would be required. Steam would probably be generated by circulating a liquid heat-transfer fluid through the collector fielll and an unfired steril boller. When available, steam from the boiler would be fed intu the existing header. Such a system could also be employed in generating Dowtherm vapor. Alternatively, it is conceivable that the Dowtherm could be vaporized in the receiver tubes directly. In this case, only a liquid/vapor separator instead of a boiler would be required.

The computer programs used to carrv out the analysis, PROSYS/ECONMAT, flrst calculate the performance of various solar collectors at the given temperature and heat rate. The collector array is then sized, such that the maximum solar energy delivery rate equals the process heat rate. This eliminates problems of rejecting heat from the solar system. The cost of a system of this size is then determined. Finally, a discounted cash fiow calculation is performed using the econnmic parameters listed in Tablc 5 1 , giving the present value ol the proposed solar investment. The solar.system does not include any storage capacity. A description of the computer codes PROSYS/ECONMAT is presented in Appendix A. 
Table 5-1. ECONOMIC PARAMETERS USED IN

ECONMAT LIFE-CYCLE ANALYSIS

\begin{tabular}{lc} 
Rate of Return & $12 \%$ \\
General Inflation Rate & $6 \%$ \\
Real Fuel Escalation Rate & $5 \%$ \\
Operation, Maintenance, Property Tax, & \\
and Insurance as a Fraction of & $2 \%$ \\
Investment & $50 \%$ \\
Corporate Tax Rate & 20 years \\
System Lifetime & $20 \%$ \\
Solar Tax Credit & $9 \%$ \\
Interest During Construction & $\$ 2.80 / 106 \mathrm{Btu}^{\mathrm{a}}$ \\
Conventional Fuel Cost, Natural Gas & $\$ 19 / \mathrm{h}$ \\
Labor Rate & \\
\hline a This is the cost of fuel as provided by the utility. The cost \\
of fuel delivered to the process is $\$ 3.50$ per million Btu \\
based upon a fuel use efficiency of $80 \%$.
\end{tabular}

The results of the analysis are shown in Tables 5-2 and 5-3. None of the applications are economically attractive, even when costs are projected to 1985 . Future costs are based upon a $5 \%$ real annual escalation in the price of fuel, collector costs remaining fixed in dollar terms. The results can be explained in terms of geographic location, process temperature, and present fuel costs. The Midwest is not a particularly attractive region as regards solar insolation. This is illustrated in Appendix $\mathrm{C}$, which shows insolation maps of the United States. Solar collectors located in the Southwest can deliver twice as much energy as similar collectors located in the Midwest.

Appendix D illustrates the performance of solar collectors with regard to temperature. Flat plates are currently the most economical collector type. However, thermal losses increase rapidly at elevated temperatures, and depending on climatic conditions, 160$180^{\circ} \mathrm{F}$ is about their practical economical limit. The performance of concentrating collentors, such as parabolic troughs, is less temperature dependent, but they are more costly.

Natural gas at current prices is the most economical fuel source. However, if industry were obliged to turn to alternatives such as a fuel oil, and were charged $\$ 7$ per million Btu (the price charged within the company to the resin manufacturing process for this type of fuel), then the situation would be drastically different. Repeating the economic analysis to reflect this fuel cost indicated that the solar hot water heating process would produce a slightly positive present value, assuming a 20 -year life of the solar system.

Another process that could be amenable to solar application would be to preheat boiler feed water. Because only a small fraction of condensate is returned to the boiler, this could be particularly suitable to solar because of the low inlet temperature of the makeup water. However, this was not pursued, because the steam was generated at a centralized location to feed the whole complex. 
Table 5-2. SOLAR SYSTEM PERFORMANCE

\begin{tabular}{|c|c|c|c|c|c|c|}
\hline Application & $\begin{array}{c}\text { Delivery } \\
\text { Temperature } \\
\left({ }^{\circ} F\right)\end{array}$ & $\begin{array}{c}\text { Process } \\
\text { Hegt Rate, } \\
\left(10^{6} \mathrm{Btu} / \mathrm{h}\right)\end{array}$ & $\begin{array}{l}\text { Collector } \\
\text { Type }\end{array}$ & $\begin{array}{l}\text { Collector } \\
\left.\text { Area (ft }{ }^{2}\right)\end{array}$ & $\begin{array}{c}\text { Delivered } \\
\text { Solgr Energy } \\
\left(10^{9} \text { Btu/yr) }\right.\end{array}$ & $\begin{array}{c}\text { Delivered } \\
\text { Solar Energy } \\
\text { (\% Process } \\
\text { Load) }\end{array}$ \\
\hline $\begin{array}{l}\text { Hot Water Heat- } \\
\text { ing of Storage } \\
\text { Tanks }\end{array}$ & 160 & 0.4 & $\begin{array}{l}\text { Flat Plate } \\
\text { (Facing South, } \\
\text { Tilted at Lat- } \\
\text { itude Angle) }\end{array}$ & 5480 & 0.95 & 27 \\
\hline $\begin{array}{l}\text { Steam Heating of } \\
\text { Low-Temperature } \\
\text { Kettles }\end{array}$ & 350 & 4.0 & $\begin{array}{l}\text { Parabolic } \\
\text { Trough } \\
\text { (Aligned N/S) }\end{array}$ & 69,700 & 12.9 & 38 \\
\hline $\begin{array}{l}\text { Dowtherm A Va- } \\
\text { por Heating of } \\
\text { High-Temperature } \\
\text { Kettles }\end{array}$ & 550 & 2.7 & $\begin{array}{l}\text { Parabolic } \\
\text { Trough } \\
\text { (Aligned N/S) }\end{array}$ & 59,210 & 8.2 & 34 \\
\hline
\end{tabular}


Table 5-3. SOLAR SYSTEM COSTS

1

\begin{tabular}{|c|c|c|c|c|c|c|c|c|c|}
\hline \multirow[b]{2}{*}{ Application } & \multicolumn{3}{|c|}{$\begin{array}{l}\text { Fuel Cost } \\
\left(\$ \prime^{\prime} 10^{6} \mathrm{Btu}\right)\end{array}$} & \multicolumn{3}{|c|}{$\begin{array}{c}\text { Total Installed } \\
\text { System Cost }\left(\$ 10^{6}\right)\end{array}$} & \multicolumn{3}{|c|}{$\begin{array}{c}\text { Present } \\
\text { Value }(\$ 1000)\end{array}$} \\
\hline & $1979 \$$ & $1983 \$$ & $1985 \$$ & $1979 \$$ & $1983 \$$ & $1985 \$$ & $1979 \$$ & $1983 \$$ & $1985 \$$ \\
\hline $\begin{array}{l}\text { Hot Water Heating } \\
\text { of Storage Tanks }\end{array}$ & 2.80 & 4.25 & 5.24 & 0.140 & 0.148 & 0.153 & -68 & -50 & -37 \\
\hline $\begin{array}{l}\text { Steam Heating } \\
\text { of Low-Temperature } \\
\text { Kettles }\end{array}$ & 2.80 & 4.25 & 5.24 & 2.30 & 2.35 & 2.38 & -1270 & -968 & $\begin{array}{l}-760 \\
\end{array}$ \\
\hline $\begin{array}{l}\text { Dowtherm A } \\
\text { Vapor Heating } \\
\text { of High-Temperature } \\
\text { Kettles }\end{array}$ & 2.80 & 4.25 & 5.24 & 1.97 & 2.01 & 2.04 & -1228 & -1049 & -923 \\
\hline
\end{tabular}




\subsection{SUMMARY}

The polymeric resin manufacturing industry is unlikely to utilize solar energy as a source of process heat in the near future. Energy represents a small fraction of the final product cost. Thus, even a switch to more costly liquid fuel will produce a small impact. The industry is highly competitive, and consequently required payback periods for investments are short. The reliability of solar systems will have to be proven before the industry is likely to risk such an investment. The locution of the industry, primarily in the Mîdwest, is not favorable to the rapid introduction of solar energy. The wide variation in process heating loads is also an unfavorable factor. Considerable, probably costeffective, investments could be made in conservation methods as a means of saving energy. 


\section{SECTION 6.0}

\section{IPH CASE STUDY: FLUID MILK PROCESSING}

\subsection{INTRODUCTION}

An industrial process heat (IPH) case study was performed for a dairy located in the southwestern United States. In addition to a full range of fluid milk products, the dairy produces ice cream and cottage cheese. Throughput averages about 10 million pounds of milk per month, and the facility employs 190 people, including drivers.

The dairy work cycle is dictated by delivery constraints, and the legal obligation that the milk be sold not more than 14 days after it reaches the plant. Milk turnover time in the plant is 2 to 2-1/2 days. Taking transportation lags into account, maximum retail shelflife is about 10 days. As a result of these constraints, the pasteurization process starts early in the morning (12:30 a.m.) and is completed by about 10 a.m. Clean-up, an extended, energy-consuming process, starts around noon and is completed by 8:30 p.m. Pasteurization occurs five days per week; the manufacturing process continues on Saturday, when cottage cheese is produced. Milk is delivered six times weekly.

The dairy industry is not in a state of expansion. Per capita consumption of milk has decreased since 1960 (Casper 1977), although total consumption has increased slightly with the population. The industry produces about a $6 \%$ return on sales and about a $17 \%$ return on investment. New investments are based upon achieving a $20 \%$ rate of return on capital expenditures.

\subsection{PROCESS HEAT UTILIZATION}

\subsubsection{Pasteurization}

Milk is delivered to the dairy in bulk and stored at a temperature of $40^{\circ} \mathrm{F}$ before pasteurization. Pasteurization is performed by rapidly heating the milk to at least the legal minimum of $161.5^{\circ} \mathrm{F}$ for 15 seconds. Regenerative heat exchange is employed to reduce the process load. Performance efficiency of this exchange equipment is estimated at about $85 \%$, and the pasteurization process is calculated to consume about $20 \mathrm{Btu} / \mathrm{lb}$ (46 $\mathrm{kJ} / \mathrm{kg}$ ) of milk processed. Heat exchange with hot water is used to raise the milk to pasteurization temperature. At a milk flow of $50,000 \mathrm{lb} / \mathrm{h}(22,700 \mathrm{~kg} / \mathrm{h})$, this gives a heat load of one million Btu/h $\left(0.29 \mathrm{MW}_{\mathrm{th}}\right)$ for approximately nine hours each day and five days per week.

The process temperature depends on whether cottage cheese is the required product. Milk destined for cottage cheese production is pasteurized at as low a temperature as possible to minimize the "kill" of active ingredients necessary to initiate cheese fermentation. In practice, this is around $165^{\circ} \mathrm{F}$, giving some leeway over the legal minimum.

\subsubsection{Deodorization}

Milk destined for direct consumption is deodorized to produce a constant tasting product. This is done by injecting steam into the milk exiting the pasteurizer to raise its 
temperature to $185^{\circ} \mathrm{F}$. A further heat input of $20 \mathrm{Btu} / \mathrm{lb}$ is required. The milk is then vacuum-flashed to remove water vapor and odors. The result is a deodorized milk with the same solids content as the product leaving the pasteurizer. Alternatively, odors can be masked by slightly carmelizing the milk by holding it at $180-185^{\circ} \mathrm{F}$ for 30 seconds.

\subsubsection{Clean-Up}

Clean-up requires considerable inputs of energy, since the dirty wash water is discharged directly to the sewer. A minimum temperature of $110^{\circ} \mathrm{F}$ is required to dissolve milk fats. This is achieved by mixing steam with city water. Process heat load is estimated at 1.4 million Btu/h $(0.41 \mathrm{MW})$ to heat $35,000 \mathrm{lb} / \mathrm{h}(16,000 \mathrm{~kg} / \mathrm{h})$ from $70^{\circ}$ to $110^{\circ} \mathrm{F}$ during clean-up operstions (about noon to 8 p.m.).

\subsubsection{Misccllaneous Prucesses}

Energy is also consumed in by-product processing and in cottage cheese production. Heat is supplied to the open cottage cheese vats by direct steam injection.

Process heat for the dairy is generated in a 350-hp gas-fired boiler ( 11.7 million Btu/h), producing saturated steam at $95 \mathrm{psig}, 335^{\circ} \mathrm{F}$. There is no alternative fuel source. Heat is transferred to the dairy processes by direct steam injection or by heat transfer from circulating hot water.

The dairy consumes approximately 27,000 therms of natural gas per month. Assuming 5-1/4 operating days per week and a 16-hour day, this is equivalent to an average energy consumption of 7.5 million Btu/h. Natural gas prices have escalated rapidly, and the current cost is 23.8 cents/therm. At about $2250 \mathrm{Btu} / \mathrm{gal}$ of milk processed, the cost of natural gas represents approximately 0.5 cents per gallon of the final product cost. In 1976 , value added in processing was $23 \%$ of the value of shipments, and this percentage hud fallen steadily since 1972 (U.S. Dept. of Commerce 1978). Thus, in 1979, fuel costs accounted for about $2 \%$ of value added. This is small in comparison to the cost of packaging and distribution. However, the percentage is no longer insignificant, and in the future the cost of process fuel is likely to comprise a larger fraction of value added during milk processing. Investments in energy conservation are becoming increasingly attractive. Also, even though as a food processor the dairy industry is unlikely to face natural gas curtailments, long-term concerns have prompted consideration of alternative energy sources.

\subsection{ENERGY CONSERVATION}

To cope with peak energy demands, the steam boiler is considerably oversized-an inherently inefficient mode of operation. Overall average thermal efficiency is unlikely to exceed $65 \%$. This could be increased somewhat by the installation of an economizer to preheat boiler feed water and by measures to reduce condonsate losses. Currently, direct steam injection is used to heat clean-up water and cottage cheese vats. The installation of heat exchange coils to heat clean-up water would reduce water treatment costs and could be an economical conservation measure.

This dairy appears to be unusual in that the pasteurization process is carried out using hot water rather than steam as the heating medium. The circulating water is heated to 
$95^{\circ} \mathrm{F}$ by exchange with steam at $335^{\circ} \mathrm{F}$. This technique allows finer temperature control than does the direct use of steam. In fact, the only operation in the dairy that actually uses steam directly is the deodorizing process.

The generation of steam at elevated temperatures to heat fluids at considerably lower temperatures is a common occurrence throughout the industry. Package steam boilers are familiar and are available "off the shelf." However, there are arguments (summarized in Appendix E) in favor of high-temperature water systems to accomplish the same purpose, economically and at considerable energy savings. Liquid systems are also more easily integrated with solar thermal technologies.

A conservation measure suggested by plant personnel was to recover waste heat from the refrigeration compressors. This could be used to heat clean-up water or for space heating. The large, refrigerated storage areas have an electrically heated defrost cycle. Possibly a low-quality source of process heat could be used instead.

\subsection{SOLAR ENERGY SYSTEMS}

As illustrated in Appendix C, the Southwest is a region of high solar radiation. At the same time, present natural gas prices are low. Distillate typically priced at $80 \AA / g a l$, equivalent to about $\$ 6.20$ per million Btu, compares unfavorably with natural gas presently costing the dairy $\$ 2.38$ per million Btu. However, gradual federal deregulation and foreign gas imports have already resulted in a linkage between natural gas prices and alternative liquid fuels. Thus, the rapid escalation of gas and oil prices is likely to continue for the next few years.

The computer program PROSYS/ECONMAT (described in Appendix A) was used to calculate the size and cost of solar systems to supply heat to the pasteurization process and for clean-up. System parameters are illustrated in Table 6-1. Flat-plate collectors are most suitable for supplying energy for clean-up, because they function efficiently at low temperatures and are the cheapest type of collector. To provide higher temperatures for pasteurization, a concentrating collector, the parabolic trough, is used. In both cases, a nonfreezing, nontoxic heat-transfer fluid circulates through the collector field. Heat is transferred to the process fluid by heat exchange, with the back-up steam system making up uny deficit in temperature. A schematic of a possible solar pasteurization process is shown in Fig. 6-1. It is evident that it is very simple to retrofit a solar system to a liquid-based energy delivery system.

The computer code used to calculate the results shown in Fig. 6-1 uses average weather data and a simplified solar model. The output of actual collectors will vary somewhat from these estimates. For this application, it is estimated that over $10,000 \mathrm{ft}^{2}$ (almost $1 / 4$ acre) of flat-plate collectors, at maximum thermal output, would heat $35,000 \mathrm{lb} / \mathrm{h}$ of process water for clean-up from $70^{\circ}$ to $110^{\circ} \mathrm{F}$. The collector outlet temperature would be at least $120^{\circ} \mathrm{F}$ to provide the requiren heat-exchanger driving force. For the pasteurization process, $9000 \mathrm{ft}^{2}$ of parabolic trough collectors, again at maximum output, would heat $32,000 \mathrm{lb} / \mathrm{h}$ of circulating water from $169^{\circ}$ to $200^{\circ} \mathrm{F}$ to deliver energy to the process at $190^{\circ} \mathrm{F}$. (For maximum output, the parabolic troughs are aligned horizontally along a north-south axis, and the flat plates are mounted facing south and tilted at the latitude angle.) 
Table 6-1. SOLAR SYSTEM PERFORMANCE

\begin{tabular}{|c|c|c|c|c|c|c|}
\hline Process & $\begin{array}{l}\text { Ccllector Type, } \\
\text { Alignment, Tilt }\end{array}$ & $\begin{array}{c}\text { Process } \\
\text { Temperature } \\
{ }^{\circ} \mathrm{F}\left({ }^{\circ} \mathrm{C}\right)\end{array}$ & $\begin{array}{l}\text { Collector } \\
\text { Outlet } \\
{ }^{\circ} \mathrm{F}\left({ }^{\circ} \mathrm{C}\right)\end{array}$ & $\begin{array}{l}\text { Collector } \\
\text { Area } \\
\mathrm{ft}^{2}\left(\mathrm{~m}^{2}\right)\end{array}$ & $\begin{array}{c}\text { Maximum } \\
\text { Solar Output } \\
10^{6} \mathrm{Btu} / \mathrm{h} \\
(\mathrm{MW})\end{array}$ & $\begin{array}{c}\text { Energy } \\
\text { Delivered } \\
\text { to Process } \\
10^{9} \mathrm{Btu} / \mathrm{yr} \\
(\mathrm{TJ} / \mathrm{yr})\end{array}$ \\
\hline $\begin{array}{l}\text { Hot Water } \\
\text { Clean-up }\end{array}$ & $\begin{array}{l}\text { Flat Plate, } \\
\text { North/South, } \\
\text { Latitude Angle }\end{array}$ & $110(\leq 3)$ & $120(49)$ & $\begin{array}{c}10,600 \\
(990)\end{array}$ & $\begin{array}{c}1.4 \\
(0.41)\end{array}$ & $\begin{array}{c}4.0 \\
(4.2)\end{array}$ \\
\hline Pasteurization & $\begin{array}{c}\text { Parabolic trough, } \\
\text { N/S, Flat }\end{array}$ & $165(74)$ & $200(93)$ & $\begin{array}{l}9040 \\
(840)\end{array}$ & $\begin{array}{l}1.0 \\
(0.29)\end{array}$ & $\begin{array}{l}3.1 \\
(0.29)\end{array}$ \\
\hline
\end{tabular}

$\mathrm{a}_{6}$ day-per-week output of solar fjeld. 


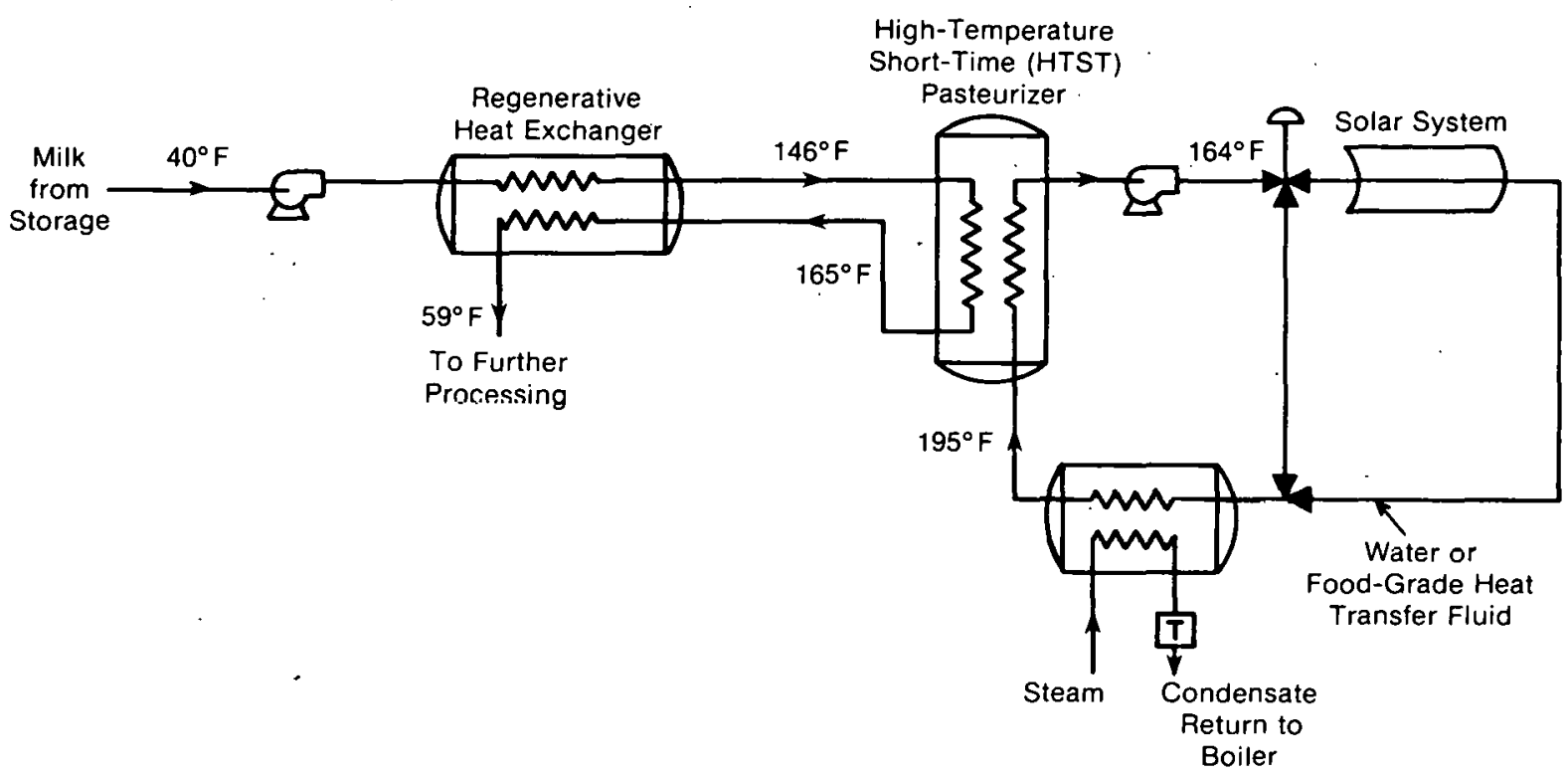

Figure 6-1. Milk Pasteurization Process

Solar installations are extremely capital intensive. To obtain maximum benefit from such investments, it is important that the entire thermal potential of the solar system be absorbed by the process. This can only be achieved for industries such as fluid milk processing that do not operate continuously, or that conduct major energy-consuming operations at night by using thermal storage and by correctly sizing the collector field. The technology of thermal storage is ill-developed at present, and the cost of storing large volumes of hot water can be prohibitive. (To store energy as hot water for the pasteurization process, a pressurized vessel would probably be required.)

For the purposes of this study, it is assumed that the plant can absorb the full-energy output of the collector flelds for six days per week. This is fairly reasonable due to the fact that the proposed solar systems will not supply the total heat demands of the plant; hot water from the flat plates can be used for domestic requirements as well as clean-up, and by-product processes could consume energy not utilized by the pasteurization.

Table 6-2. SOLAR SYSTEM: ECONOMIC PARAMETERS

\begin{tabular}{|c|c|c|c|c|c|c|c|c|c|}
\hline \multirow[b]{2}{*}{ Process } & \multicolumn{3}{|c|}{$\begin{array}{c}\text { Total System Installed } \\
\text { Cost }\left(\$ 10^{3}\right)\end{array}$} & \multicolumn{3}{|c|}{$\begin{array}{c}\text { Present Value } \\
\left(\$ 10^{3}\right)\end{array}$} & \multicolumn{3}{|c|}{$\begin{array}{c}\text { Discounted Payback } \\
\text { Periud (Years) }\end{array}$} \\
\hline & 1979 & 1983 & 1985 & 1979 & 1983 & 1985 & 1979 & 1983 & 1985 \\
\hline $\begin{array}{l}\text { Hot Water } \\
\text { Clean-up }\end{array}$ & 293 & 313 & 326 & -31 & 61 & 126 & $20+$ & 16 & 12 \\
\hline Pasteurization & 340 & 357 & 368 & -120 & -50 & -0.5 & $20+$ & $20+$ & $20+$ \\
\hline
\end{tabular}


Installation and the delivered costs of solar energy, incorporating the above assumption, are illustrated in Table 6-2. Additional economic assumptions are listed in Table 6-3. Systems installed at the present time would not pay back during their lifetime. The discontinuous nature of the fluid milk industry is a major factor contributing to this conclusion.

Table 6-3. ECONOMIC PARAMETERS USED IN LIFECYCLE COST ANALYSIS

\begin{tabular}{lc}
\hline Rate of Return & $12 \%^{\mathrm{a}}$ \\
General Inflation Rate & $6 \%$ \\
Real Fuel Escalation Rate & $5 \%$ \\
Operation, Maintcnance, Piroperty Tax, & - \\
$\quad$ and Insurance as a Frütion of & $2 \%$ \\
$\quad$ Investment & $50 \%$ \\
Corporate Tax Rate & 20 years \\
System Lif etime & 20 years \\
Depreciation Period (Straight-Line) & $20 \%$ \\
Solar Tax Credit & $9 \%$ \\
Interest During Construction & $\$ 2.38 / 10^{6}$ Btu \\
Conventional Fuel Cost 1979 (Natural Gas) & $\$ 19 / \mathrm{h}$ \\
Labor Rate & \\
\hline a Cash, or equity financing assumed. & \\
b Fuel use efficiency assumed 65\%.
\end{tabular}

Perhaps the greatest economic uncertainties concern the inflation rate, tax incentives, and the real rate of fuel escalation over the 20-year life of the solar system. Economic calculations for 1983 and 1985 are based on assumed advunces in sular technologies and economies of scale, which maintain collector costs constant in dollar terms. With fuel prices advancing 5\% faster than inflation, the solar system producing hot wash water would have a payback of 16 years in 1983 and 12 years in 1985 . These paybacks are too long to satisfy normal industry investment criteria.

As indicated earlier, present costs of natural gas in the Southwest are low compared to other fuels, but are rising rapidly. Prices increased more than 50\% during 1979 . However, even used at an inefficient $65 \%$, gas costing $\$ 2.38$ per million Btu delivers energy to the process at. \$3.6. por million Btu. To delermine the effect of another rapid jump in fuel price during 1980, the abnve calculations were repeuted, but with a 1980 fuel cost of $\$ 3.50$ per million Btu. For this case, paybacks of 9 and 14 years were indicated for the clean-up and pasteurization processes in 1985, respectively. Recent congressional proposals include provisions for investment tax credits of up to $30 \%$, and accelerated depreciation over periods as short as three years. The previous calculation using the high fuel cost was repeated using these inputs. Payback periods for 1985 declined to 6 and 9 years for the two processes.

These calculations indicate the effect that government initiatives could have on the use of solar technology. A payback of six years approaches the investment "hurdle rate" set by many industries. 


\subsection{SUMMARY}

The dairy industry is widely dispersed to satisfy local markets. Numerous plants are located in areas of high insolation. (Sixteen percent of U.S. milk consumption is in seven states with the highest levels of insolation: California, Texas, Colorado, Arizona, Utah, New Mexico, and Nevada.) Temperature requirements are low (less than $212^{\circ} \mathrm{F}$ ). In areas of high insolation, by the year 1985, and with suitable tax incentives, investments in solar technology could be in the range of the industry investment criteria. Hence, the dairy industry would appear eminently suitable for the adoption of solar thermal technologies to provide process heat. On the other hand, the industry, as a food processor, is unlikely to be affected by fuel curtailments. In other industries, this has been the major drive to consider alternative energy sources. Industries in the Southwest have, in the past, been able to obta in cheap natural gas, a situation which is likely to change as the price of natural gas rises to reflect the true value of its energy content. However, even increased energy costs will represent only a small fraction of the value added during processing, and such costs can be passed on to the consumer.

The cost of solar energy delivered to fluid milk processes is greatly increased by the discontinuous nature of dairy operations. As a result, solar equipment could not be fully utilized unless costly heat-storage systems were incorporated. Milk is a very valuable commodity and is perishable. Thus, any heat-delivery system has to be extremely reliable. The urban location of dairies, with attendant lack of land and the presence of pollution, which could soil collectors, is another disadvantage. Although roof space is generally available, it is usually not sturdy enough to bear the loads imposed by solar collector:s. Finally, the industry is not innovative. It is generally lacking in capital, and except for the largest dairies, there are insufficient manpower and skills to operate and maintain a complex IPH solar system, particularly at the present stage of development.

Overall, the dairy industry is not a prime candidate for the near-term adoption of solargenerated IPH. Solar technology will have to be thoroughly proven in other industries, both technically and economically, before it is likely to be accepted by fluid milk processors. 
SERI 


\section{SECTION 7.0}

\section{IPH CASE STUDY: BREAD AND BUN BAKERY}

A case study was performed for a large bread and bun bakery located in Denver, Colorado. Total bakery production averaged about $8100 \mathrm{~kg} / \mathrm{h}(17,900 \mathrm{lb} / \mathrm{h})$.

\subsection{PROCESS DESCRIPTION}

The bakery consists of two bread lines and one bun line. A schematic diagram of the process is shown in Fig. 7-1. Dough is loaded onto trays and placed in a proof box where the dough rises for about one hour. It then goes to an oven, where it is baked. From the ovens, the bread goes to coolers through which room air is drawn and exhaused to the atmosphere. The buns, however, are cooled directly in the room without the aid of a cooler. In addition, there is a washer where the baskets used for transporting the bread are cleaned in hot water. The baskets are dried in a direct-fired dryer.

Energy is supplied to the process via steam from a low-pressure (14 psig) boiler or by direct-firing of natural gas. Fuel oil is the back-up energy source to the boiler. Steam is used to heat water to $66^{\circ} \mathrm{C}\left(150^{\circ} \mathrm{F}\right)$ for space heat, to maintain the "sugar room" at $49^{\circ} \mathrm{C}$ $\left(120^{\circ} \mathrm{F}\right)$, and to heat water used for basket washing $\left[82^{\circ} \mathrm{C}\left(180^{\circ} \mathrm{F}\right)\right]$ and cleanup $\left[71^{\circ} \mathrm{C}\left(160^{\circ} \mathrm{F}\right)\right]$. Live steam is injected into the basket wash water to achieve the desired temperature. Water used for clean-up purposes is indirectly heated by steam coils. Steam in coils also heats the proof boxes and live steam is injected to maintain $90 \%$ relative humidity. The ovens at $232^{\circ} \mathrm{C}\left(450^{\circ} \mathrm{F}\right)$ and the basket-washer dryer at $204^{\circ} \mathrm{C}\left(400^{\circ} \mathrm{F}\right)$ are heated by direct-firing of natural gas. Propane is the back-up fuel for the ovens and dryer when the natural gas supply is curtailed.

The dota supplied by the bakery included the following [note that $M=10^{6}, G=10^{9}$, $\mathrm{T}=10^{[2}$ :

- Monthly natural gas usage for one year. There is a single natural gas meter for the bakery.

- Propane and fuel oil used when the natural gas supply was cut off.

- Boiler characteristics. The bakery operates two 350-hp boilers, although one of these generally is sufficient to handle the load. The boilers operate at 14 psig (about 29 psia, $117^{\circ} \mathrm{C}$ or $242^{\circ} \mathrm{F}$ ).

- Design capacities of heat exchangers. Steam heats water for space heat to $66^{\circ} \mathrm{C}$ $\left(150^{\circ} \mathrm{F}\right)$ in a $3-\mathrm{GJ} / \mathrm{h}(2.8-\mathrm{Btu} / \mathrm{h})$ capacity exchanger. Water is heated to $82^{\circ} \mathrm{C}$ $\left(180^{\circ} \mathrm{F}\right)$ for the basket washer in a $1.3-\mathrm{J} / \mathrm{h}(1.2-\mathrm{Btu} / \mathrm{h})$ capacity exchanger. Water for clean-up is heated to $71^{\circ} \mathrm{C}\left(160^{\circ} \mathrm{F}\right)$ in a $3-\mathrm{GJ} / \mathrm{h}(2.8-\mathrm{MBtu} / \mathrm{h})$ capacity exchanger.

- Equipment operating temperatures, as indicated above.

- Operating schedule. The bakery operates five days per week. One bread line normally operates 8 hours per day with a nominal bread capacity of $2700 \mathrm{~kg} / \mathrm{h}$ $(6000 \mathrm{lb} / \mathrm{h})$. The second bread line operates $12 \mathrm{~h} /$ day at $4100 \mathrm{~kg} / \mathrm{h}(9000 \mathrm{lb} / \mathrm{h})$. The bun line usually operates $8 \mathrm{~h} /$ day, but runs $24 \mathrm{~h} /$ day during the summer months. The capacity is $1300 \mathrm{~kg} / \mathrm{h}(2900 \mathrm{lb} / \mathrm{h})$. 


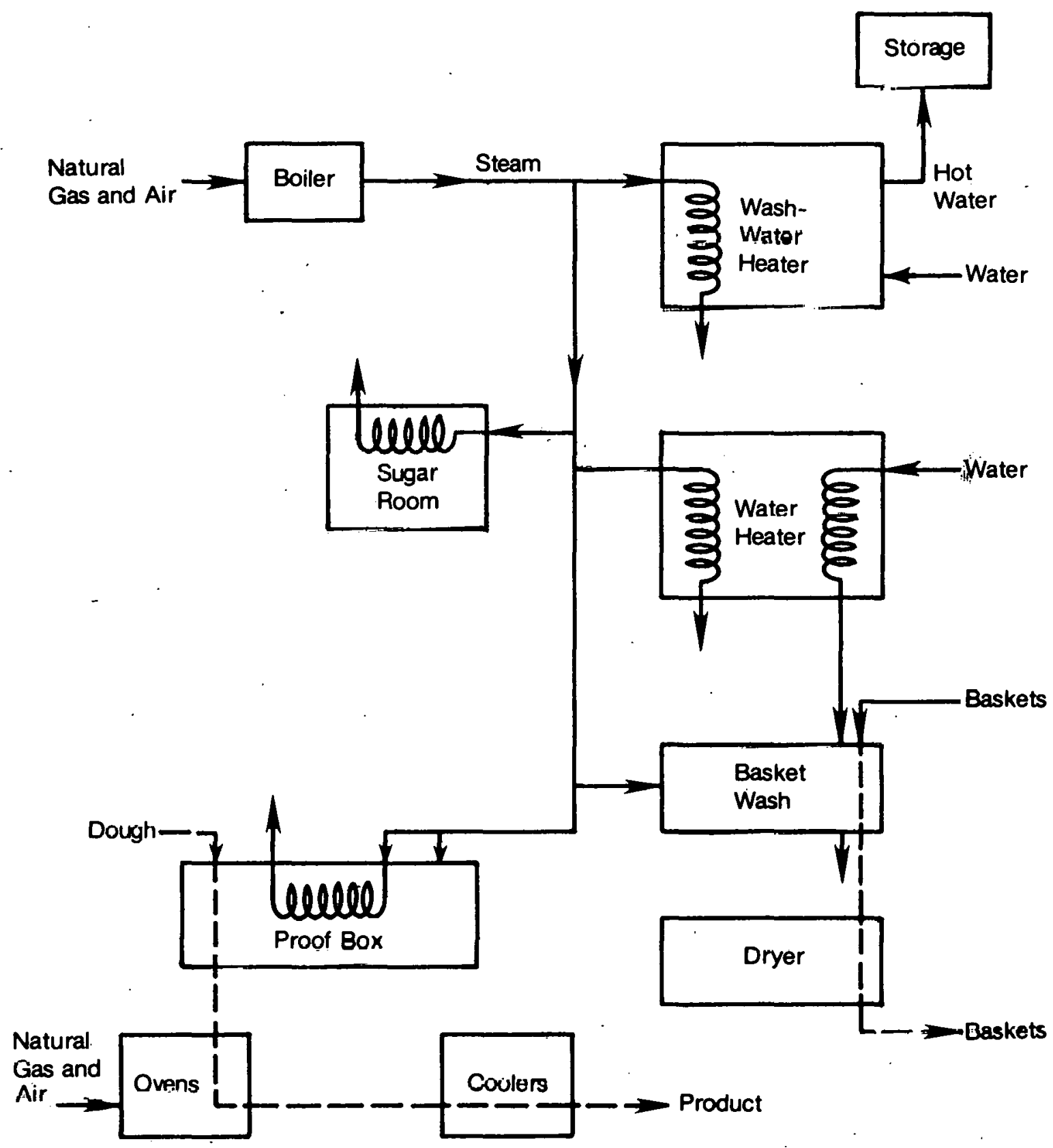

Figure 7-1. Schematlc of Bakery Process 


\subsection{ENERGY BAI,ANCES}

The seasonal variations of the total energy input were used to estimate the space and process energy requirements. The total energy input averaged $188 \mathrm{GJ} /$ working day (178.5 MBtu/working day) and showed a distinct seasonal variation. The average for May through October was taken to represent the process requirement (including sugar room heating). This value was $152 \mathrm{GJ} /$ working day (144 MBtu/working day). Energy used above this average rate was assumed to be for space heating. The maximum hourly heat input to the process was estimated to be $15.2 \mathrm{GJ} / \mathrm{h}(14.4 \mathrm{MBtu} / \mathrm{h})$. This was obtained by dividing the working-day heat input by 10 hours per working day (weighted average based on capacity and operating time of the individual lines). On a unit production basis, the process heat requirement (not including space heat) is $0.8 \mathrm{million}$ Btu and the total (including space heat) was 0.99 million Btu per thousand lbs of product. This value compares favorably with a value of $0.87 \mathrm{MBtu} / 1000 \mathrm{lb}$ (including space heat in a south central U.S. location), calculated from data reported in a case study of a bakery with a similar product line by Johns-Manville Corp (1976). A value of $0.85 \mathrm{MBtu} / 1000$ ib was indicated by a Drexel (1976) study (excluding space heat).

The distribution of the input energy to various uses within the plant had to be estimated because internal flows were not ordinarily measured by the plant personnel. The relative use rates of propane and fuel oil provided a partial basis for these estimates, because propane was used only in the ovens and basket-washer dryer, whereas fuel oil was used only for the boiler. The ratio of energy supplied as propane to that supplied as fuel oil was not the same for the two months for which data were available, but their average was used as the ratio of direct-gas fired input to boiler input. The estimated space heat requirement was subtracted from the total boiler input to yield that portion of the boiler input going to process requirements. The calculation gave $6.9 \mathrm{GJ} / \mathrm{h}$ process input via direct natural gas firing and $8.3 \mathrm{GJ} / \mathrm{h}$ input to the boiler for process purposes. A boiler efficiency of $80 \%$ was assumed (based on manufacturers rating), giving $6.6 \mathrm{GJ} / \mathrm{h}$ heat transf erred in the boiler for process purposes.

This allocation is reasonable, based on the boiler capacities and heat exchanger ratings. The total process plus space heat generated in the boilers during the two coldest months (with the assumed $80 \%$ efficiency) was $9.6 \mathrm{GJ} / \mathrm{h}(9.1 \mathrm{MBtu} / \mathrm{h})$. This is comparable with the rated capacity of a single boiler $(12.3 \mathrm{GJ} / \mathrm{h}, 11.7 \mathrm{MBtu} / \mathrm{h})$ and is consistent with the plant operations, because generally one boiler was sufficient to handle the total building load (although two boilers are of ten used). The estimated average space-heat rate during the heating season, when corrected to $24 \mathrm{~h} /$ day, 7 days/week, is $2.2 \mathrm{GJ} / \mathrm{h}$, which compares reasonably well with the heat-exchanger rating of $3 \mathrm{GJ} / \mathrm{h}$. The total rated capacity of the two steam-heated wash-water exchangers is $4.3 \mathrm{GJ} / \mathrm{h}$, compared to the estimated 6.6 GJ/h supplied as process steam. Since process steam is also used for proof-box heating and humidification, heat for the sugar room, and some direct heating of the washwater, this comparison is reasonable.

Moreover, a partial comparison of the allocation can be made with previous case studies (Johns-Manville 1976, and Drexel 1976). The process configuration and the breakdown of the energy allocation are somewhat different, so some aggregation has been done. In the J-M study, the ratio of the energy supplied to the ovens to the energy supplied to the boiler (excluding space and water heating) was 3.4. In the Drexel study, the ratio of all direct-fired energy input to the boiler input was 2.9 . In the present study, the ratio of the energy supplied to the ovens and dryer to that of the boiler (again excluding water and space heating) was 3.0. Once again, the agreement is reasonable. 
The foregoing analysis provides reasonable values for total and process heat requirements, allocation of process heat between steam and direct gas-firing, and a partial allocation of the steam use. The direct-fired natural gas usage cannot be divided between the ovens and dryer, however, nor can steam use in the-proof boxes be determined. It was concluded that some further data were needed to continue an analysis of energy conservation and recovery potentials.

The specifications of most of the bakery equipment were reviewed, and measurements were made of process exhaust-gas flows and temperatures from the bakery building (the loan of equipment for these measurements by the Chemical Enginering Department, University of Colorado, is gratefully acknowledged). It was hoped that this information would be sufficient to allocate energy inputs to the individual process units. The information obtained was useful as a guide, but did not give definitive results. For example, the measured values indicated $0.8 \mathrm{GJ} / \mathrm{h}$ of energy in the equipment exhaust gases, com pared to an estimated input of $6.5 \mathrm{GJ} / \mathrm{h}$. The energy contained in the exhaust gases was too low. The main reason for this occurrence is that essentially iristantaneous measurements werc made of the exhaust conditions and input rates were not measured concurrently. Simultaneous measurements averaged over an extended period, such as a week, would be needed to obtain reliable data.

Since detailed energy balances could not be obtained, the following procedure was used to estimate these balances:

- Process input rates (excluding space heat, except for the sugar room) were determined as described above.

- The boiler output rate of process heat was estimated using the input and the specifications for efficiency (80\%) and blowdown rate, and an assumed condensate return flow.

- Hot water, steam, and natural gas inputs to the basket washer and dryer were estimated from equipm ent specifications and operating schedule.

- The cleanup water heating rate was assumed to be $80 \%$ of the heat exchanger rating.

- The sugar room steam-use rate was estimated from the heater specifications.

- The steam rate to the proof box was taken from the specifications; the split between heating stèm and injested steam was assumed.

- The balance of the boiler output was unaccounted for losses; it amounted to about $12 \%$ of boiler nitput.

- The energy input to the ovens was divided between exhaust gases and product streams in the same proportion as reported in the Johns-Manville (1976) stidy.

The results of this analysis are summarized in Fig. 7-2, which shows the estimated energy content of various streams. Input and output energy streams are summarized in Table 7-1. It is estimated, from measured exhaust-gas flows and changes in humidity, that perhaps $24 \%$ of the total energy input leaves as latent heat of vaporization of water in the exhaust gas streams. 


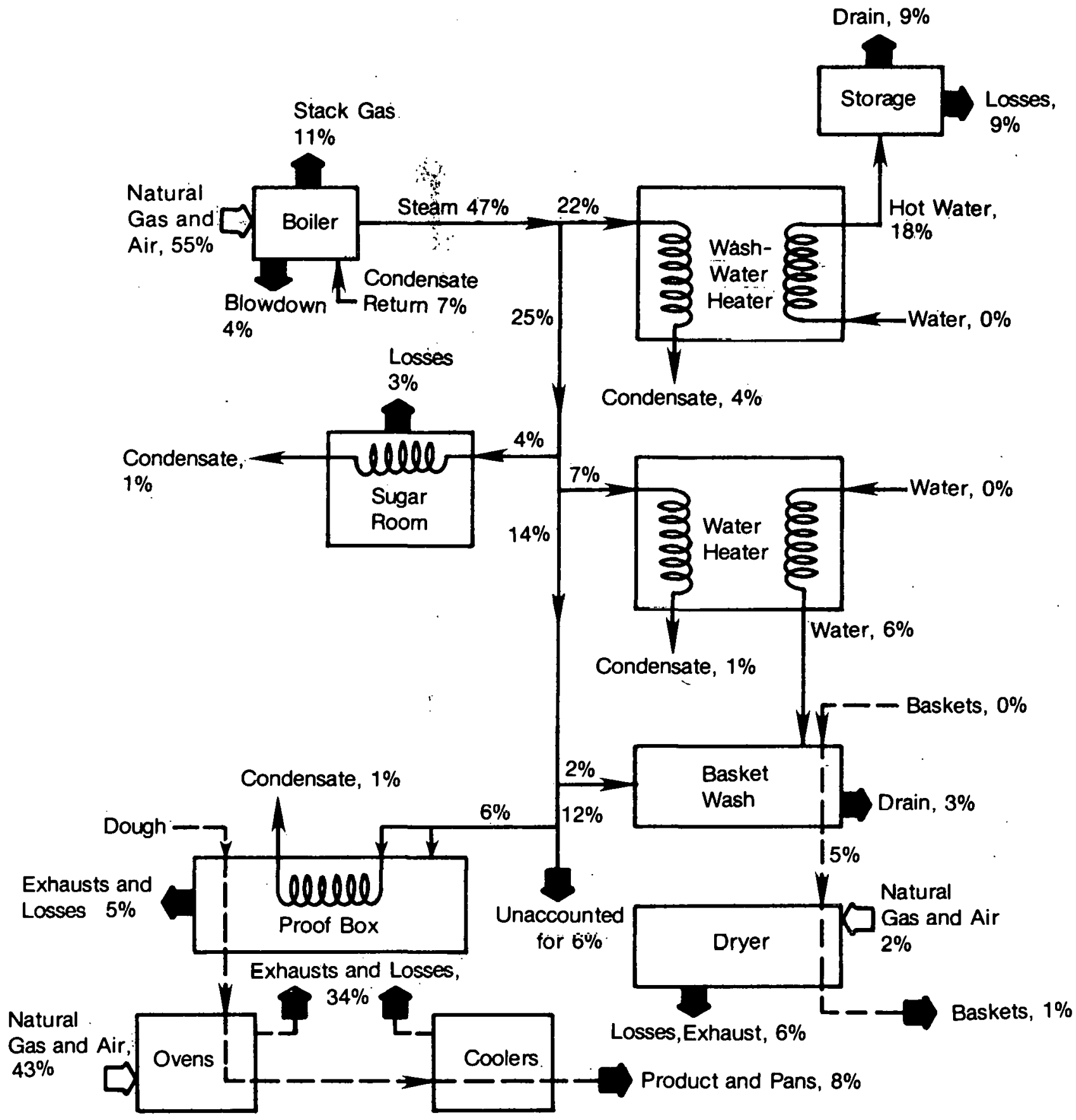

Figure 7-2. Bakery Energy Flow Diagram

The percentages are shown as percents of the total process input energy of $15.2 \mathrm{GJ} / \mathrm{h}$ All energies are with respect to $15^{\circ} \mathrm{C}\left(60^{\circ} \mathrm{F}\right)$ 
Table 7-1. PROCESS INPDT AND OUTPUT ENERGY FOR THE BAKERY

\begin{tabular}{|c|c|c|c|c|c|c|c|}
\hline \multicolumn{3}{|c|}{ Inputs } & \multicolumn{5}{|c|}{ OutF.uts } \\
\hline . & $\begin{array}{c}\text { Energy } \\
\text { GJ/h }\end{array}$ & $\begin{array}{l}\% \text { of } \\
\text { Total } \\
\text { Input }\end{array}$ & Stream & $\stackrel{\text { Tem }}{{ }^{\circ} \mathrm{C}}$ & ${ }^{a-u r e}$ & $\begin{array}{c}\text { Energy } \\
\text { GJih }\end{array}$ & $\begin{array}{l}\% \text { of } \\
\text { Total } \\
\text { Input }\end{array}$ \\
\hline \multicolumn{8}{|l|}{ Fuel to: } \\
\hline $\begin{array}{l}\text { Boilers } \\
\text { Ovens } \\
\text { Dryer } \\
\text { Total }\end{array}$ & $\begin{array}{r}8.3 \\
6.5 \\
0.4 \\
35.2\end{array}$ & $\begin{array}{r}55 \\
43 \\
2 \\
100\end{array}$ & $\begin{array}{l}\text { Boiler Blowdown } \\
\text { Wash-Water Drain } \\
\text { Basket-Water Drain } \\
\text { Boiler Stack Gas } \\
\text { Proof Box Exhaust } \\
\text { Oven Exhausts } \\
\text { Cosler Exhausts } \\
\text { Dryer Exhaust } \\
\text { Losses, Product } \\
\quad \text { Unaccounted for } \\
\quad \text { Totals }\end{array}$ & $\begin{array}{r}93 \\
38 \\
82 \\
107 \\
49 \\
68 \\
33 \\
100 \\
-\end{array}$ & $\begin{array}{r}2100 \\
130 \\
130 \\
225 \\
120 \\
155 \\
92 \\
212 \\
-\end{array}$ & $\begin{array}{l}0.61 \\
1.56 \\
0 . \leq 6 \\
1.67 \\
0.76 \\
0.76 \\
4.41 \\
0.91 \\
4.96 \\
15.2\end{array}$ & $\begin{array}{r}4 \\
9 \\
3 \\
11 \\
5 \\
5 \\
29 \\
6 \\
28 \\
100\end{array}$ \\
\hline
\end{tabular}




\subsection{CONSERVATION POTENTIAL ANALYSIS}

Based upon the energy balance results, approximately two-thirds of the input energy is contained in warm exit streams off ering potential for heat recovery. The following observations regarding energy conservation and recovery potentials are offered:

- The bakery equipment is reasonably well-insulated. There is no evidence of undue heat loss from the equipment. The cost of increased insulation on the hotwater storage tank would probably pay back in a short period.

- The majority of the input energy leaves as sensible heat of hot water and hot gas exhaust streams. Reducing water and especially exhaust-gas flows would conserve energy. Oven exhaust-gas flows should be reduced to the minimum compatible with safe and effective operation. Exhaust blowers for the coolers and the basket dryer are of ten not used-probably they never should.

- Heat exchange could be utilized between makeup water and outgoing clean-up water, basket wash water, and boiler blowdown streams flowing to the drain. These streams contain an estimated $16 \%$ of the input energy and possibly half of that could be recovered by heat exchange. A double-walled heat exchanger would probably be required to avoid possible contamination problems.

- The exhaust air from the coolers could be used for space heat or as preheated combustion air to the ovens or boilers. This exhaust is estimated to contain as much as $29 \%$ of the input energy at approximately $33^{\circ} \mathrm{C}\left(92^{\circ} \mathrm{F}\right)$. However, the allocation of the exhaust energy between the ovens and the coolers is quite uncertain, because it was based on design maximum exhaust rates. The exhaust measurements suggest that the oven exhausts include much more energy than the cooler exhausts. The $29 \%$ figure is an upper limit on the energy in the cooler exhaust, whereas the $34 \%$ total for the oven and cooler exhaust is more certain.

- A portion of the oven exhaust gases could be recycled to the oven combustion zone. These gases are hot, but they are partially depleted of oxygen as well as being increased in humidity, so they cannot be totally recycled.

- Heat could be exchanged between boiler stack gases and incoming combustion air using a recuperator. This would require the conversion of the existing boiler to either forced- or induced-draft configurations.

These energy conservation and recovery possibilities have not been evaluated in detail. The output streams mentioned contain nearly $75 \%$ of the input energy, and perhaps onethird to one-half of that, or 25 to $40 \%$ of the input energy, is potentially recoverable.

Figure 7-3 illustrates the energy available in output gas and water streams as a function of their temperature. The energy that could be obtained by cooling gases from their existing temperature to, say, $92^{\circ} \mathrm{F}$ can be found by subtracting the percent contained at $92^{\circ} \mathrm{F}$ from the percent at the maximum temperature $\left(107^{\circ} \mathrm{C}, 225^{\circ} \mathrm{F}\right)$. Thus, if all gases above $92^{\circ} \mathrm{F}$ were cooled to $92^{\circ} \mathrm{F}, 19 \%(56 \%-37 \%)$ of the input energy would be recovered.

\subsection{SOLAR APPLICATIONS}

Possible solar applications to the bakery process were examined by running the PROSYS/ ECONMAT simulation program, described in Appendix A, for various heat rates and 
temperature requirements of the process. Solar system installation dates of 1979 and 1985 were considered.

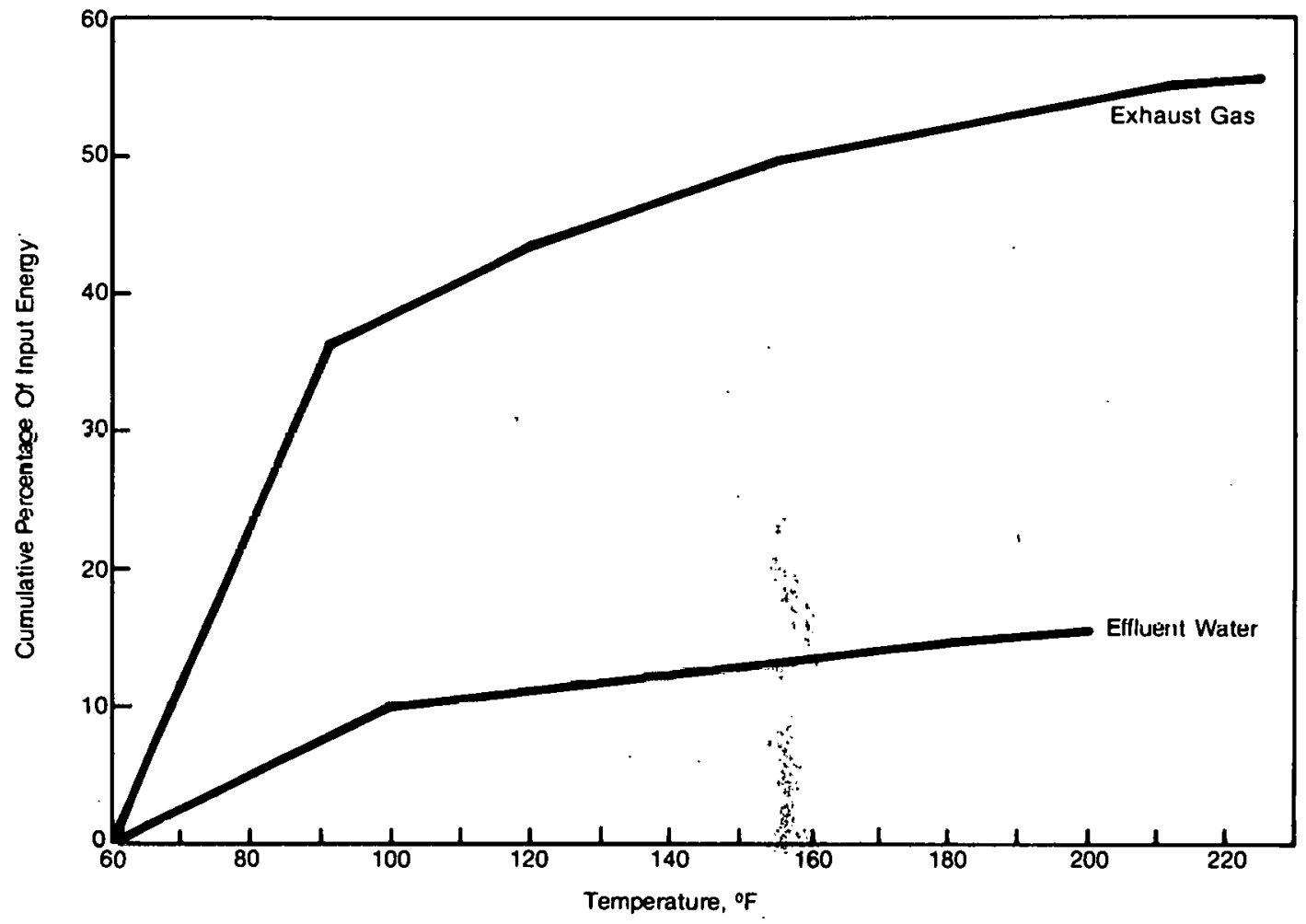

Figure 7-3. Estimated Energy Content (as \% of Total $15.2 \mathrm{GJ} / \mathrm{h}$ Input) Versus Temperature

First, supplying the various loads of the existing process with solar energy was investigated. These results are summarized in Table 7-2. Norre of these direct solar applications are economically attractive, as shown by the payback periods longer than the 20-year life of the solar system, and negative present worth values.

The payback period and present worth values were calculated in accordance with Dickinson and Brown (1979). The 1979 figures represent a solar system installed in 1979 with current collector/equipment costs, current fuel prices, and the economic factors listed in Table 7-3. The 1985 figures are based on an assumed solar system installation in 1985 with technological advances and economics of scale assumed to keep collector costs nominally the same as in 1979 (i.e., $6 \%$ reduction per year), fuel prices escalated at $5 \%$ per year, and equipment and labor rates inflated at $6 \%$ per year.

Because direct application of solar heating was not attractive, use of solar energy to preheat water to various temperature levels was examined. These results are summarized in Table 7-4. Once again, none of these applications is economically attractive given the economic circumstances prevailing in 1979. When a solar system startup of 1985 is considered, solar preheat to $38^{\circ} \mathrm{C}$ or $54^{\circ} \mathrm{C}$ results in payback periods nearly equal to the system lif etime of 20 years. 
Table 7-2. RESULTS OF SOLAR APPLICATIONS TO EXISTING PROCESS REQUIREMENTS

\begin{tabular}{|c|c|c|c|c|c|c|c|c|c|c|}
\hline & \multirow[b]{2}{*}{ Application } & \multirow[b]{2}{*}{ System $^{b}$} & \multicolumn{2}{|c|}{ Process Temperature } & \multirow{2}{*}{$\begin{array}{c}\text { Energy } \\
\text { Supplied } \\
\text { by Solar } \\
\text { (TJ/yr) }\end{array}$} & \multirow{2}{*}{$\begin{array}{l}\text { Capacity } \\
\text { Cost } \\
(\$ / \mathrm{GJ} / \mathrm{yr})\end{array}$} & \multicolumn{2}{|c|}{$\begin{array}{l}\text { Present Wor th } \\
\left(10^{6} \$\right)\end{array}$} & \multicolumn{2}{|c|}{$\begin{array}{c}\text { Payback Period } \\
\text { (years) }\end{array}$} \\
\hline & & & ${ }^{\circ} \mathrm{C}$ & ${ }^{\circ} \mathrm{F}$ & & & 1979 & 1985 & 1979 & 1985 \\
\hline 1. & $\begin{array}{l}\text { Hot Air to } \\
\text { Ovens }\end{array}$ & $\begin{array}{l}\text { Hot Air } \\
\text { Direct }\end{array}$ & 232 & 450 & 25.0 & 100 & -1.5 & -1.1 & -- & $20+$ \\
\hline 2. & $\begin{array}{l}\text { All Hot } \\
\text { Water }\end{array}$ & $\begin{array}{l}\text { Hot Water } \\
\text { Direct }\end{array}$ & 82 & 180 & 13.5 & 84 & -0.49 & -0.21 & $20+$ & $20+$ \\
\hline 3. & $\begin{array}{l}\text { Sugar } \\
\text { Room Heating }\end{array}$ & $\begin{array}{l}\text { Hot Water } \\
\text { Exchange }\end{array}$ & 66 & 150 & 5.4 & 98 & -0.26 & -0.16 & $20+$ & $20+$ \\
\hline 4. & $\begin{array}{l}\text { Basket } \\
\text { Wash Water }\end{array}$ & $\begin{array}{l}\text { Hot Water } \\
\text { Exchange }\end{array}$ & 82 & 180 & 2.4 & 88 & -0.09 & -0.05 & $20+$ & $20+$ \\
\hline 5. & $\begin{array}{l}\text { Clean-up } \\
\text { Water }\end{array}$ & $\begin{array}{l}\text { Hot Water } \\
\text { Direct }\end{array}$ & 71 & 160 & 5.8 & 77 & -0.18 & -0.06 & $20+$ & $20+$ \\
\hline
\end{tabular}

${ }^{a}$ Value of displaced fuel $=\$ 1.63 / \mathrm{GJ}$ (\$1.72/MBtu) in 1979 dollars.

bee Appendix B for schematics of solar systems. 
Table 7-3. ECONOMIC PARAMETERS USED IN ECONMAT LIFB-CYCLE ANALYSIS

\begin{tabular}{lc}
\hline Rate of Return & $12 \%$ \\
General Inflation Rate & $6 \%$ \\
Real Fuel Escalation Rate & $5 \%$ \\
Operation, Maintenance, Property Tax, & \\
$\quad$ and Insuränce as a Fraction & \\
$\quad$ of Investment & $2 \%$ \\
Corporate Tax Rate & $50 \%$ \\
System Lif etime & 20 years \\
Depreciation Period (Straight-Line) & 20 years \\
Solar 'l'ax Credit & $20 \%$ \\
Interest During Cunstiuctiụ! (Natural ras) & $4 \%$ \\
Conventional Fuel Cost 1979 (Natri & $\$ 1.72 / 10^{6}$ Btu \\
Labor Rate & $\$ 19 / \mathrm{h}$ \\
\hline
\end{tabular}

Table 7-4. RESULTS OF SOLAR APPLICATIONS TO PREHEATING BAKERY WATER STREAMS

\begin{tabular}{|c|c|c|c|c|c|c|c|}
\hline \multirow[b]{2}{*}{ Application } & \multirow[b]{2}{*}{ System $^{b, c}$} & \multirow{2}{*}{$\begin{array}{l}\text { Energy } \\
\text { Supplied } \\
\text { by Solar } \\
\text { (TJ/yr) }\end{array}$} & \multirow{2}{*}{$\begin{array}{l}\text { Capacity } \\
\text { Cost } \\
(\$ / G J / y r)\end{array}$} & \multicolumn{2}{|c|}{$\begin{array}{l}\text { Present } \\
\text { Worth } \\
\left(10^{6} \$\right)\end{array}$} & \multicolumn{2}{|c|}{$\begin{array}{c}\text { Payback } \\
\text { Period } \\
\text { (years) }\end{array}$} \\
\hline & & & & 1979 & 1985 & 1979 & 1985 \\
\hline $\begin{array}{l}\text { Preheat } \\
\text { Water to } \\
38^{\circ} \mathrm{C}\left(100^{\circ} \mathrm{F}\right)\end{array}$ & HWD & 5.9 & 56 & -0.1 & +0.03 & $20+$ & 20 \\
\hline $\begin{array}{l}\text { Preheat } \\
\text { Water to } \\
54^{\circ} \mathrm{C}\left(130^{\circ} \mathrm{F}\right)\end{array}$ & HWD & 10.0 & 63 & -0.2 & -0.01 & $20+$ & 20 \\
\hline $\begin{array}{l}\text { Preheat } \\
\text { Water to } \\
71^{\circ} \mathrm{C}\left(160^{\circ} \mathrm{F}\right)\end{array}$ & HWD & 13.5 & 71 & -0.1 & -0.11 & 201 & $20+$ \\
\hline
\end{tabular}

a Value of displaced fuel $=\$ 1.63 / \mathrm{GJ}(\$ 1.72 / \mathrm{MBtu})$ in 1979 dollars.

$\mathrm{h}_{\text {Sev Apperidix B. }}$

$c_{\text {Hot water direct. }}$

The possibility of heat exchanging incoming water with exiting streams and then preheating the result with solar energy was also examined. The exchange would heat the incoming water to about $31^{\circ} \mathrm{C}\left(88^{\circ} \mathrm{F}\right)$. Preheating from this temperature to $100^{\circ}, 130^{\circ}$, and $160^{\circ} \mathrm{F}$ with solar energy was studied. Figure 7-4 is a schematic flow diagram for this type of process. The fuel savings from the heat exchange were credited to the solar system, and the results are summarized in Table 7-5. This form of low-temperature solar 


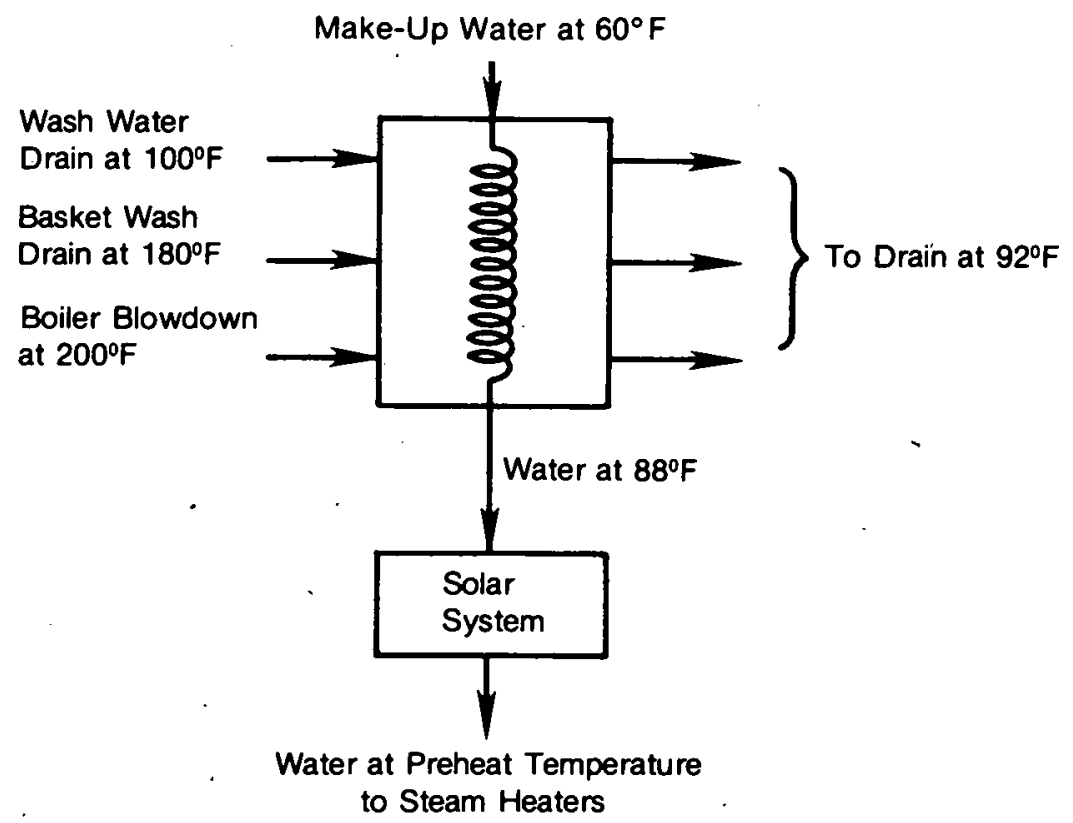

Figure 7-4. Schematic Diagram of Heat Recovery and Solar Preheat of Bakery Water

Table 7-5. RESULTS OF HEAT RECOVERY AND SOLAR WATER PREHEATING

\begin{tabular}{|c|c|c|c|c|c|c|c|c|}
\hline \multirow[b]{2}{*}{ Application } & \multirow[b]{2}{*}{ System $^{b, c}$} & \multirow{2}{*}{$\begin{array}{l}\text { Energy } \\
\text { Supplied } \\
\text { by Solar } \\
\text { (TJ/yr) }\end{array}$} & \multirow{2}{*}{$\begin{array}{l}\text { Energy } \\
\text { Displaced } \\
\text { (TJ/yr) }\end{array}$} & \multirow{2}{*}{$\begin{array}{l}\text { Capacity } \\
\text { Cost } \\
(\$ / G J / y r)\end{array}$} & \multicolumn{2}{|c|}{$\begin{array}{l}\text { Present } \\
\text { Worth } \\
\left(10^{6} \$\right)\end{array}$} & \multicolumn{2}{|c|}{$\begin{array}{c}\text { Payback } \\
\text { Period } \\
\text { (years) }\end{array}$} \\
\hline & & & & & 1979 & 1985 & 1979 & 1985 \\
\hline $\begin{array}{l}\text { Preheat } \\
\text { Water to } \\
38^{\circ} \mathrm{C}\left(100^{\circ} \mathrm{F}\right)\end{array}$ & HWD & 1.7 & 5.0 & 64 & +0.06 & +0.19 & 10 & 6 \\
\hline $\begin{array}{l}\text { Preheat } \\
\text { Water to } \\
54^{\circ} \mathrm{C}\left(130^{\circ} \mathrm{F}\right)\end{array}$ & HWD & 5.8 & 9.1 & 68 & -0.05 & +0.16 & $20+$ & 13 \\
\hline $\begin{array}{l}\text { Preheal } \\
\text { Water to } \\
71^{\circ} \mathrm{C}\left(160^{\circ} \mathrm{F}\right)\end{array}$ & HWD & 0.4 & 12.7 & 77 & -0.23 & +0.05 & $2 n+$ & 20 \\
\hline
\end{tabular}

${ }^{2}$ Value of displaced fuel $=\$ 1.63 / \mathrm{GJ}(\$ 1.72 / \mathrm{MBtu})$ in 1979 dollars.

${ }^{b}$ See Appendix B.

$c_{\text {Hot water direct. }}$ 
preheating, coupled with heat recovery, resulted in a positive present worth for one system in 1979 and for all three in 1985. The positive present worth indicates a discounted cash-flow rate of return greater than the $12 \%$ used in the economic analysis. The six-year payback period for $38^{\circ} \mathrm{C}$ solar preheat in 1985 is very nearly cost effective in terms of typical industrial investment criteria.

Finally, the partial recycling of hot exhaust gases from the ovens combined with solar preheat of the incoming air to $55^{\circ} \mathrm{C}$ or $232^{\circ} \mathrm{C}$ was considered. Gas recycle is feasible when solar energy is used because less fuel is burned, and, thus, less makeup oxygen is required. This configuration is illustrated in Fig. 7-5. The fraction of gas recycled was the calculated maximum possible, using the hottest available gas for the solar energy delivered. The results of this analysis are summarized in Table 7-6. None of the cases examined are economically attractive in 1979 , but solar preheat to $55^{\circ} \mathrm{C}$ showed a positive present value and a 12-year payback with a 1985 system installation.

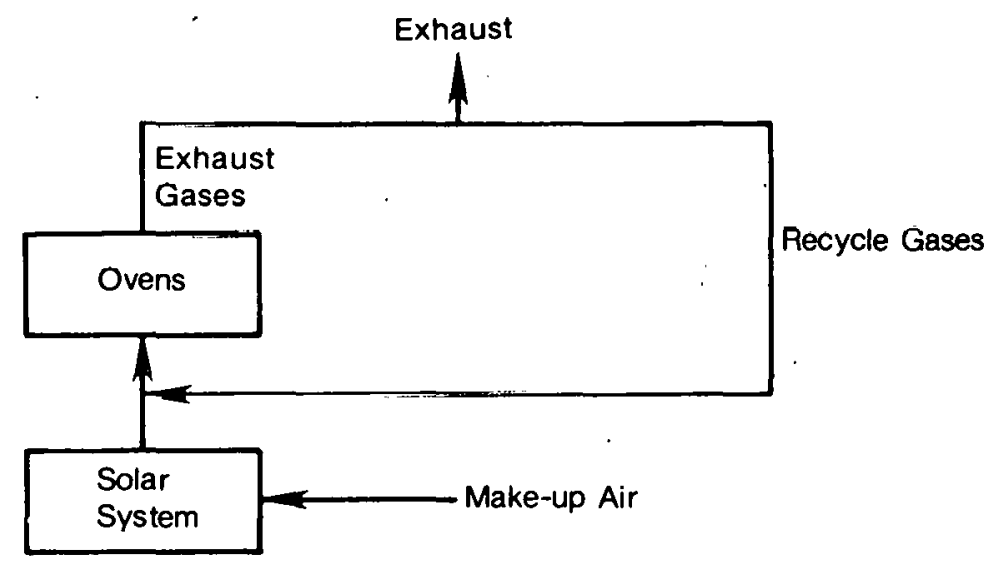

Figure 7-5. Schematic Diagram of Hot-Air Recycle and Solar Preheat of Make-Up Air

Table 7-6. RESULTS OF PARTIAL GAS RECYCLE AND SOLAR PREHEAT OF INCOMING AIR

\begin{tabular}{|c|c|c|c|c|c|c|c|}
\hline \multirow[b]{2}{*}{ Application } & \multirow{2}{*}{$\begin{array}{l}\text { Energy } \\
\text { Delivered } \\
\text { by Jolal: } \\
(\mathrm{TJ} / \mathrm{yr})\end{array}$} & \multirow{2}{*}{$\begin{array}{l}\text { Energy } \\
\text { Displucted } \\
\text { (TJ/yr) }\end{array}$} & \multirow{2}{*}{$\begin{array}{l}\text { Capacity } \\
\text { Cusl } \\
(\$ / \text { C.J } / y r)\end{array}$} & \multicolumn{2}{|c|}{$\begin{array}{l}\text { Present } \\
\text { Worth } \\
\left(10^{6} \$\right)\end{array}$} & \multicolumn{2}{|c|}{$\begin{array}{l}\text { Payback } \\
\text { Period } \\
\text { (years) }\end{array}$} \\
\hline & & & & 1979 & 1985 & 1979 & 1985 \\
\hline $\begin{array}{l}\text { Preheat } \\
\text { air to } \\
232^{\circ} \mathrm{C}\left(450^{\circ} \mathrm{F}\right)\end{array}$ & 21.5 & 25.0 & 100.0 & -1.2 & -0.74 & - & $20+$ \\
\hline $\begin{array}{l}\text { Preheat } \\
\text { air to } \\
55^{\circ} \mathrm{C}\left(131^{\circ} \mathrm{F}\right)\end{array}$ & 2.3 & 4.0 & 60.0 & -0.02 & +0.07 & $20+$ & 12 \\
\hline
\end{tabular}

${ }^{{ }^{Q}}$ Value of fuel displaced $=\$ 1.63 / \mathrm{GJ}(\$ 1.72 / \mathrm{MBtu})$ in 1979 dollars. 


\subsection{SUMMARY}

Heat conservation and recovery potentials have been identified for this bakery, and include the reduction of exhaust gas flow rates, heat recovery from warm effluent waters, and heat recovery by the recycle of hot exhaust gases.

F or the insolation conditions of Denver, Colo., and a fuel value of $\$ 1.63 / \mathrm{GJ}$ ( $\$ 1.72 / \mathrm{MBtu}$ ), direct substitution of solar energy for fossil fuel is not economically attractive for 1979 or 1985 solar system startups. This was found to be the case whether the solar system was designed to supply water or air at the required process temperature or to preheat to lower temperatures. It is worth noting that fuel prices escalated rapidly during 1979 and are likely to continue to do so, at least for the short term. Such price increases greatly enhance the economic viability of solar-supplied process heat.

Solar preheating of makeup water combined with heat recovery from effluent hot water streams can be cost effective if the value of the fuel displaced by effluent heat recovery is credited to the solar system. In particular, heat recovery combined with solar preheat to $38^{\circ} \mathrm{C}$ showed a six-year payback period with a 1985 system installation.

Solar preheating of makeup air to the ovens combined with partial recycle of the ovenexhaust gases was also examined. The fuel displaced by hot-gas recycling was credited to the solar system because more recycling is possible when solar heating is used than when it is not. This configuration was not economically attractive in 1979 , but a $55^{\circ} \mathrm{C}$ solar preheat system installed in 1985 yielded a 12-year payback period.

Thus, when energy conservation measures are combined with solar preheat systems, costeffective combinations can be postulated for a solar system installed in 1985 or later. Heat recovery combined with solar preheating of makeup water shows the most potential for this bakery. 


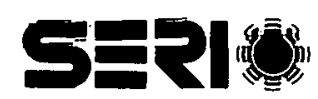




\section{SECTION 8.0}

\section{IPH CASE STUDY: MEAT PROCESSING}

A case study was performed on a meat processing plant in Denver, Colorado.

\subsection{PROCESS DESCRIPTION}

The męat processing plant is a flat-roofed building with floor space of approximately $9200 \mathrm{~m}^{2}\left(99,000 \mathrm{ft}^{2}\right)$. Adjacent is a truck washing facility that washes semitrailers for the meat processing plant as well as for other food processing plants in its vicinity.

Refrigerated carcasses are brought into the meat plant and processed into whole or ground meat products for retail distribution. No slaughtering operations are conducted. The plant operates two shifts per day, five days per week, on a year-round basis. The truck wash operates the same weekday schedule with an additional daytime shift on week ends.

The major process energy requirement is hot water for sanitary cleaning in both the meat plant and truck wash. The major sanitation load in the meat plant occurs from 8 p.m. to 4 a.m. Hot water in the meat plant is supplied from two hot water generators and one steam boiler. The truck wash has its own hot water heater. Natural gas, supplied through one meter, is the sole fuel source for the two hot water heaters and the truck wash heater. The primary fuel source for the steam boiler is also natural gas (supplied through a separate meter), with \#2 fuel oil and propane used as backup energy sources during natural gas cur tailments.

Although the primary load is from 8 p.m. to 4 a.m. five days per week, there is some load during daylight hours. This is in the form of hot water for a basket wash, and steam to heat water via shell-and-tube heat exchangers for use in prefab shrink tunnels (meat packaging). The steam boiler supplies most of the daytime load.

Detailed process and energy flow diagrams were not available for the plant. However, the following data were supplied by its staff:

- Natural gas use

- Gas use for the twुo meat plant hot water heaters plus the truck wash heater was $19,541,000 \mathrm{ft}^{3}$ for July 1978 to July 1979 (the average daily use was $50,000 \mathrm{ft}^{3}$ ); it was estimated that $17 \%$ of the energy went to the truck wash, and the remaining $83 \%$ was used by the meat plant.

- The meat plant steam boiler used 14,012,400 $\mathrm{ft}^{3}$ of natural gas, 11,717 gal of \#2 fuel oil, and 38,928 gal of propane during the same period.

- Boiler ratings

- Two meat plant hot water boilers

Rated input: $4,773,000 \mathrm{Btu} / \mathrm{h}$;

Rated output: $3,818,000 \mathrm{Btu} / \mathrm{h}$;

$80 \%$ efficiency. 
- Meat plant steam boiler

Rated 152 BHP;

- Designed to operate at 130 psig, but currently operating at 12 psig.

- Truck wash hot water heater

Rated input: 1.45 million Btu/h;

Stack gás temperature: $290^{\circ} \mathrm{F}$.

- Process temperatures

- Two meat plant hot water heaters supply $190-200^{\circ} \mathrm{F}$ water, which is tempered to $140^{\circ} \mathrm{F}$ as it passes into the system through a mixing valve.

- Meat plant steam boiler supplies 12-psig steam to the steam coil in the hot water tank; the water is maintained at $180^{\circ} \mathrm{F}$.

- Truck wash heater supplies water at $140^{\circ} \mathrm{F}$.

- Meat plant hot water load-during heavy sanitation period, total hot water load for all meat plant boilers was estimated to be $184 \mathrm{gpm}$.

- Truck wash operation

- 112 gal of water used per trailer;

- 400 trailers washed per week;

- 30 gal of water at $87^{\circ} \mathrm{F}$ recycled per truiler.

- City water supply temperature: $69^{\circ} \mathrm{F}$.

- Meat plant refrigeration system

- System \#1: 245-ton capacity; 600-gpm flow through cooling towers and condenser; water into condenser at $72^{\circ} \mathrm{F}$ and out at $77^{\circ} \mathrm{F}$.

- System \#2: 33b-ton capacity; 600-gpm flow through cooling tower and condenser; water into condenser at $80^{\circ} \mathrm{F}$ and out at $90^{\circ} \mathrm{F}$.

\subsection{ENERGY BALANCES}

The distribution of input energy to heat water for plant clean-up is shown in Fig. 8-1 for the two hot water boilers and the steam hoiler. The peresenteges are tho fraction of the total process energy input $\left(3.2 \times 10^{4} \mathrm{GJ} / \mathrm{yr}\right)$ contained in each stream. The energies were calculated with respect to $21^{\circ} \mathrm{C}\left(69^{\circ} \mathrm{F}\right)$, the input temperature of the makeup water from city mains. Figure 8-2 contains the same information for the truck wash hot water heatcr. In this case, the percentages ure with respect to the total truck wash energy input $\left(2.9 \times 10^{3} \mathrm{GJ} / \mathrm{yr}\right)$. The energy characteristics of the input and output streams for the meat processing plant and truck wash are summarized in Table 8-1. 

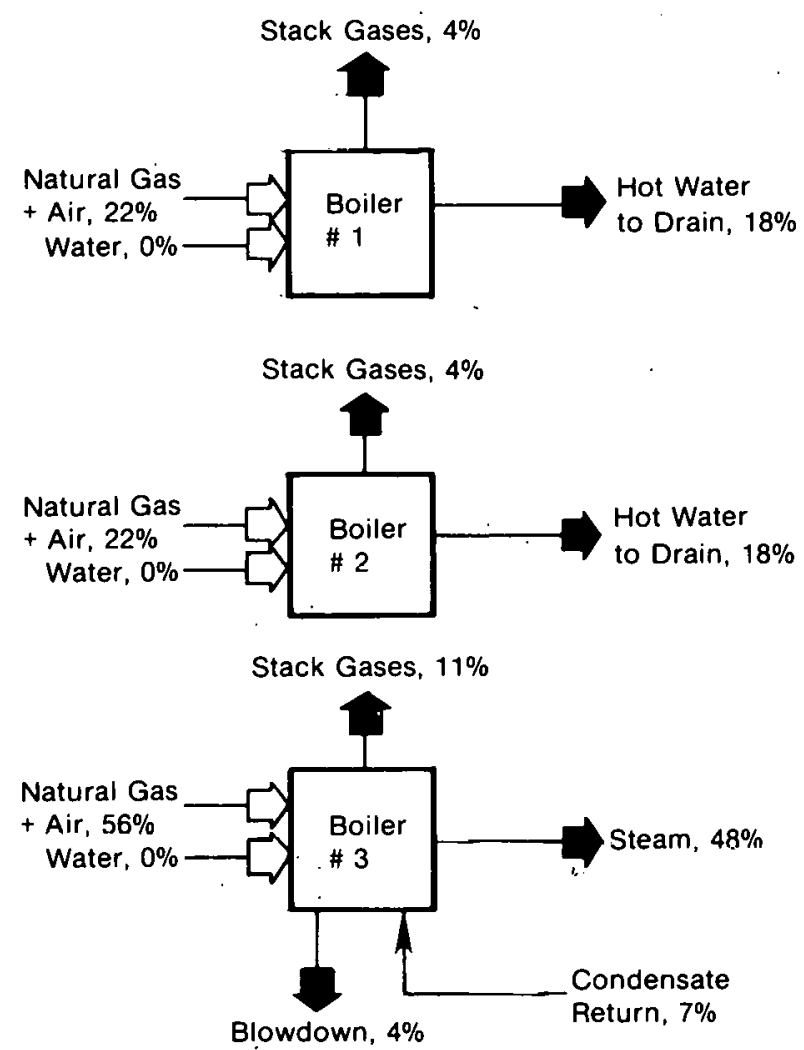

Figure 8-1. Meat Processing Plant Energy Flows: Percentages of Total Process Énergy Input (3.2 x 104 GJ/yr) Relative to $21^{\circ} \mathrm{C} \mid$ Contained in Each Stream.

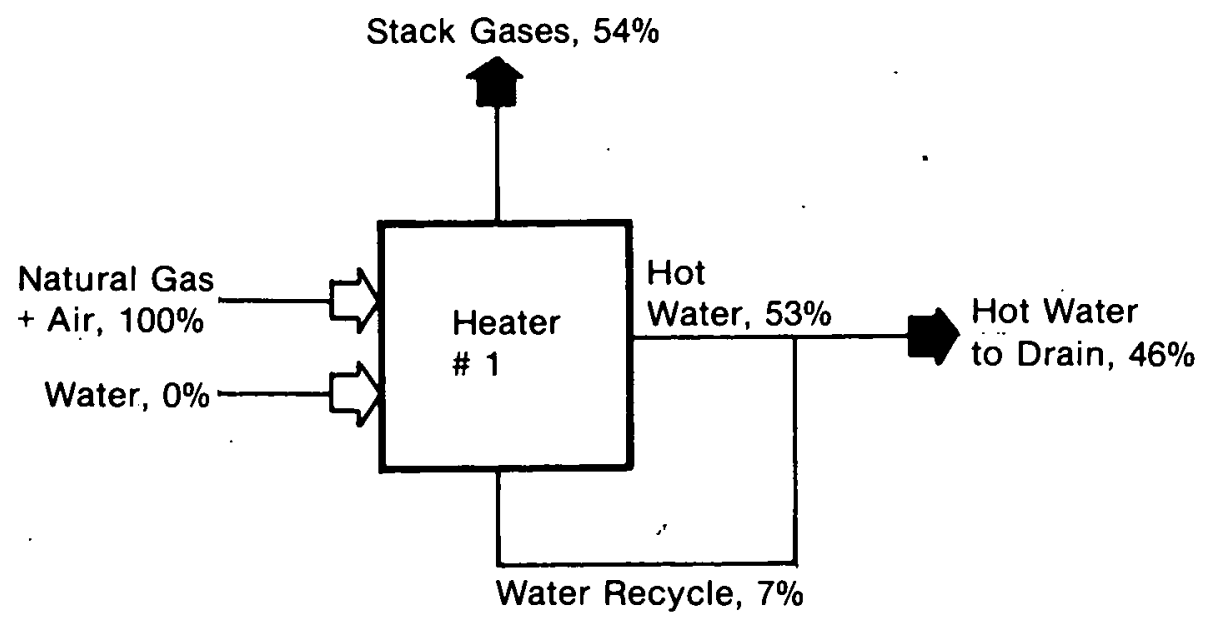

Figure 8-2. Truck Wash Energy Flows: Percentages of Total Energy Input $\left(2.9 \times 10^{3} \mathrm{GJ} / \mathrm{yr}\right)$ Relative to $21^{\circ} \mathrm{C}$ Contained in Each Stream 
Table 8-1. PROCESS INPUT AND OUTPUT ENERGY FOR MEAT PROCESSING PLAWT

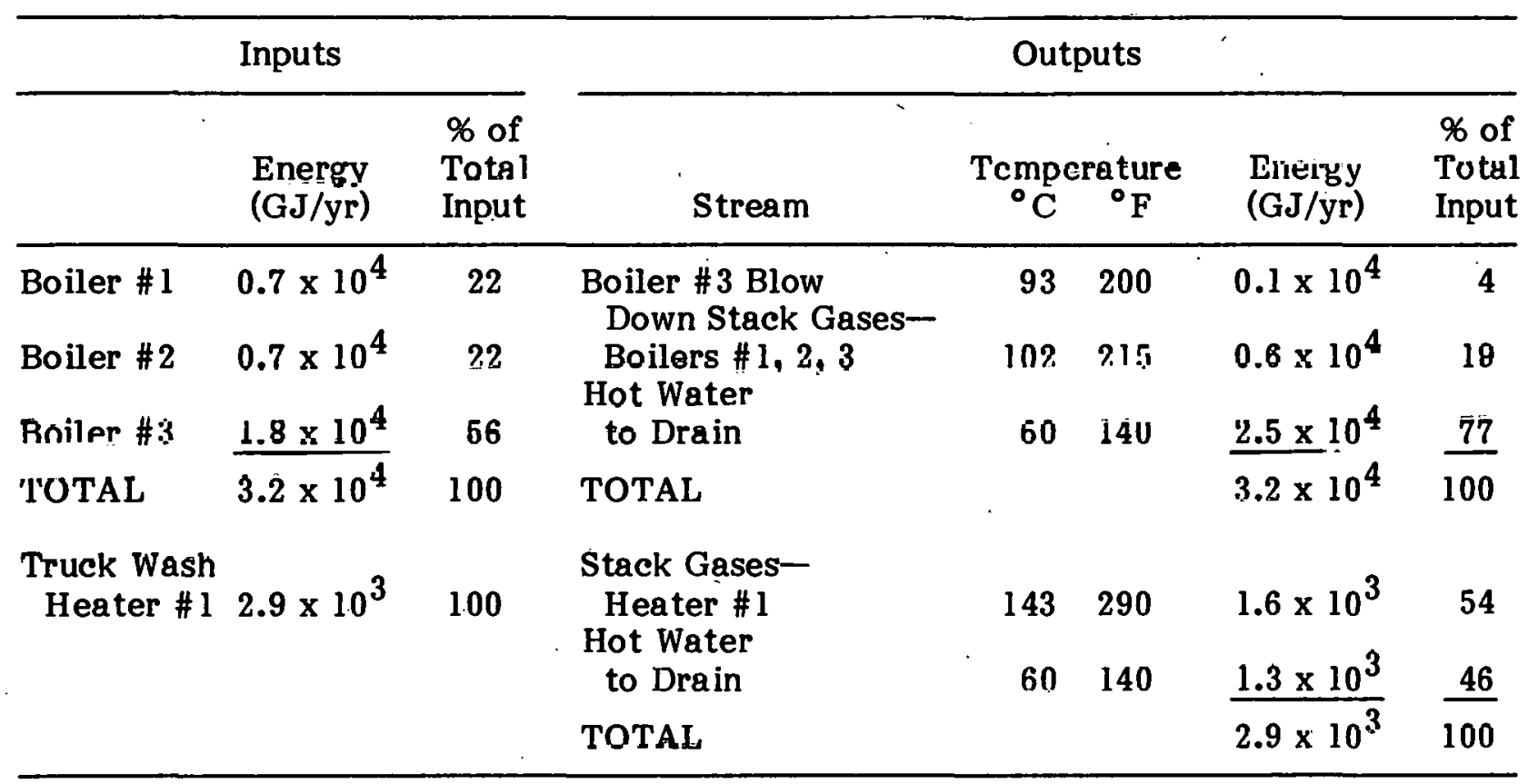

\subsection{ENERGY CONSERVATION POTENTIAL}

The exhaust streams from the meat processing plant and truck wash, including both the stack gases and hot water to the drain, offer potential for heat recovery. The following measures could be considered:

- Heul cuuld be exchanged between the makeup water and the hot water streams to the drain (i.e., boiler blowdown and used wash water). These exhaust streams contain about $81 \%$ and $46 \%$ of the input energy needed for the meat processing plant and truck wash, respertively, up to one-third of which could be recovered.

- Heat could be exchanger between incoming combustion air and sluck gascs for the three boilers and the truck wash heater (i.e., recuperation).

- The meat processing plant uses approximately 581 tons of refrigeration capacity, and the heat rejected from this system could be used as preheat for makeup water to the meat processing plant boilers or truck wash heater.

Detailed evaluations have not been made of the feasibility or economic attractiveness of these measures. However, it appears that perhaps one-third of the process heat input energy to the meat processing plant and truck wash could potentially be displaced through energy conservation measures. 


\subsection{SOLAR APPLCATIONS}

The PROSYS/ECONMAT simulation program, described in Appendix A, was used to evaluate possible solar applications for the meat processing plant and truck wash. Solar system installation dates of 1979 and 1985 were considered.

Although the temperature requirements and type of process heat load (hot water) are favorable for solar applications, the plant operating schedule is not. The greater part of the process heat load is for clean-up in the meat processing plant, which occurs from 8 p.m. to 4 a.m., five days per week. The truck wash schedule is more favorable, because it operates during daylight hours, seven days per week. However, the mismatch between the majority of the process heat load and the availability of solar energy means that thermal storage would be required to supply the meat processing plant.

Schematics are shown in Appendix B of solar systems that can typically deliver hot water for the clean-up processes. Collectors usable for this application include flat plates, parabolic troughs, Fresnel lens, etc. Although not indicated in the schematics, hot water storage tanks would be required for the meat processing plant clean-up water.

The solar applications analysis was performed for different components of the process heat load. In each case, the solar system was assumed to be augmented by the existing boilers and heater as needed to supply the total plant load. The results are shown in Table 8-2 for flat-plate solar collec tor systems.

The methods used in the ECONMAT program for determining the present worth values and payback period (gross, ignoring inflation and income tax) were in accordance with Dickinson and Brown (1979). The 1979 figures represent a solar system installed in 1979 with current collector costs, equipment costs, and fuel prices. The 1985 figures are based on an assumed solar system installation in 1985 with collector costs the same in nominal terms as in 1979 (i.e., assumed technological advances and economies of scale resulting in a $6 \%$ per year real reduction in cost), fuel prices escalated at $5 \%$ per year, and equipment costs and labor rates escalated at $6 \%$ per year. The values shown in Table 8-2 for the displaced fuels vary for different applications because multiple fuel sources were used for the steam boiler, whereas only natural gas was used for the hot water heaters.

As can be seen in Table 8-2, none of the solar energy applications were cost effective with a 1979 installation; i.e., the present worth values were negative and the payback periods greater than the 20 -year life of the solar system. For a solar system installation in 1985, the payback periods for three of the applications were less than 20 years, but longer than typically required by industry. The lowest payback period, 13 years for a flat plate solar system supplying the truck wash load, resulted primarily from the low efficiency of the truck wash heater $(\approx 50 \%)$ as compared to the other hot water heater and steam boiler efficiencies (75-80\%). In addition, the truck wash was most favorably suited for solar energy application, because it operated during the daylight hours seven days per week, thus eliminating the need for energy storage.

Any differences between the assumed economic parameters in this study and those actually occurring at the subject plant could significantly alter the results. In particular, fuel price increases in excess of the assumed $11 \%$ over the period 1979 to 1985 could reduce the payback periods, making one or more of the applications acceptable to industry. 
Table 8-2. RESULTS OF SOLAR APPLICATIONS

\begin{tabular}{|c|c|c|c|c|c|c|c|c|c|c|c|c|}
\hline \multirow{2}{*}{\multicolumn{2}{|c|}{ Application }} & \multirow[b]{2}{*}{ System } & \multicolumn{2}{|c|}{$\begin{array}{l}\text { Process } \\
\text { Temperature }\end{array}$} & \multirow{2}{*}{$\begin{array}{l}\text { Energy } \\
\text { supplied } \\
\text { by Solar } \\
\text { (TJ/yr) }\end{array}$} & \multirow{2}{*}{$\begin{array}{c}\text { Capacity } \\
\text { Cost }^{a} \\
(\$ / G J / y r)\end{array}$} & \multicolumn{2}{|c|}{$\begin{array}{l}\text { Present Wonth } \\
\left(10^{6} \$\right)\end{array}$} & \multicolumn{2}{|c|}{$\begin{array}{c}\text { Payback Period } \\
\text { (years) }\end{array}$} & \multicolumn{2}{|c|}{$\begin{array}{c}\text { Value of } \\
\text { Displaced Fuel }^{\mathrm{a}}\end{array}$} \\
\hline & & & ב & ${ }^{\circ} \mathrm{F}$ & & & 1979 & 1985 & 1979 & 1985 & $(\$ / G J)$ & (\$/MBtu) \\
\hline 1 . & $\begin{array}{l}\text { Total Meat } \\
\text { Processing } \\
\text { Plant and } \\
\text { Truck Wiash } \\
\text { Load }\end{array}$ & $\begin{array}{l}\text { Hot Water } \\
\text { Direct }\end{array}$ & 60 & 140 & 36.2 & 67 & -0.71 & +0.29 & $29+$ & 18 & 1.97 & 2.08 \\
\hline 2. & $\begin{array}{l}\text { Meat Process- } \\
\text { ing Plart } \\
\text { Steam Boiler } \\
\text { Load }\end{array}$ & $\begin{array}{l}\text { Hot hater } \\
\text { Direc: }\end{array}$ & 60 & 140 & 21.2 & 67 & -0.37 & +0.25 & $20+$ & 16 & 2.11 & 2.23 \\
\hline 3. & $\begin{array}{l}\text { Meat Process- } \\
\text { ing Plant } \\
\text { Hot Water } \\
\text { Heaters } \\
\text { Load }\end{array}$ & $\begin{array}{l}\text { Hot Water } \\
\text { Direct }\end{array}$ & 60 & 140 & 142 & 67 & -0.34 & 0.00 & $20+$ & $20+$ & 1.77 & 1.87 \\
\hline & $\begin{array}{l}\text { Truck Wash } \\
\text { Load }\end{array}$ & $\begin{array}{l}\text { Hot Water } \\
\text { Direct }\end{array}$ & 60 & 140 & 0.9 & 78 & -0.01 & +0.03 & $20 \div$ & 13 & 1.77 & 1.87 \\
\hline
\end{tabular}

a 1979 dollars. 


\section{SECTION 9.0}

\section{CONCLUSIONS}

The industrial case study program has been very useful in helping to identify the potential of solar technologies to supply industrial process heat. Only by examining specific cases of solar IPH applications through a detailed analytical approach can the unique problems and requirements of solar energy be identified. Although SERI has performed relatively few case studies to date, some important conclusions about the use of solar energy for IPH have been reached. Factors favoring the application of solar IPH systems are listed in Table 9-1, and the most important of these are discussed below.

Except for some possible unique instances, solar energy will most likely first become economically viable in the southwestern United States. On a unit area basis, collectors in the Southwest can deliver at least twice as much energy as collectors located in New England or the Pacific Northwest. Consequently, most of the following arguments apply to installations in the Southwest.

Conventional fuel sources available to industry, particularly coal, natural gas, and heavy fuel oil, are still inexpensive enough to render solar energy noncompetitive. Solar energy appears, on paper at least, to be presently competitive with electric heating, provided power demand charges can be avoided. Electricity from new plants costs about 4-5 $\notin / \mathrm{kWh}\left(\$ 11.72-14.65 / 10^{6} \mathrm{Btu}\right)$.

The federal deregulation of natural gas will not be complete before 1987, whereas crude oil controls expire on October 1,1981 (OGJ 1980a). This deregulation process, together with the increased cost of imported crude petroleum, has produced a dramatic rise in fuel costs, which tends to favor the introduction of solar technology. When domestic crude prices reach marginal world price levels (up to $\$ 40 /$ barrel in the spring of 1980 ), the price of distillate is liable to rise from about $\$ 1.10 / \mathrm{gal}\left(\$ 7.90 / 10^{6} \mathrm{Btu}\right)$ to perhaps $\$ 1.80 / \mathrm{gal}$ $\left(\$ 13.00 / 10^{6} \mathrm{Btu}\right)$. The price of residual fuel oil is less because of its poor quality and difficulty of use. The tendency now is for the price of fuels (oil and natural gas) to better reflect their energy content. Thus, in January 1980, Canada raised the price of natural gas imported to the United States to $\$ 4.47 / 10^{6}$ Btu (OGJ 1980b). Energy deregulation is likely to have another effect: present variation in fuel prices throughout the United States is likely to diminish and will reflect only distribution costs and local taxution, rather than differences in regulation. An exception is the price of coal, which is much more sensitive to transportation costs. Prior to 1980, the high price of fuel in New England was a significant reason to consider solar applications as important in that area as in the Southwest, despite very low insolation. With a dimunition in regional fuel variation throughout the remainder of this century, this relative advantage will disappear.

Probably more than any other factor, the increased cost of alternative fuels will provide the greatest economic motivation for investment in solar technology. While the uncertain availability of domestic and imported fossil fuels has also been mentioned as a strong motivation to consider solar energy, this factor is less likely to provide consistent and long-term advantages to solar energy, since both domestic and international political situations may strongly enhance or detract from fuel availability.

Despite the rising cost of alternative fuels, solar technology will penetrate the energy market only if solar energy costs rise at a lower rate. The level of success at achieving 
Table 9-1. FACTORS FAVORING THE APPLICATION OF SOLAR IPH SYSTEMS

Environmental Faetors

- High insolation levels-either total or direct, depending on the solar technology proposed

- High ambient temperatimes-to rodueo thormal lasses (particularly for nonconcentrating collectors) and to allow the use of water as a heat transfer fluid

- A pollution-free microclimate-so as not to dirty or corrode collector surfaces

- A polluted macroclimate or area with strict air pollution regulations-where no additional air pollution emissions are allowed and where such controls are a restraint on levels of production

\section{Proeses Paotoro}

- Low-temperature process-so that the cheapest type of collector, operating at a high efficiency, can be employed

- Continuous, steady operations ( $24 \mathrm{~h} / \mathrm{day}, 7$ days/week) where exact temperature control is not critical

- Liquid heating application as apposed to air or steam heating

- Built-in process storage-which helps even out fluctuations in the thermal output of the collectors, and which can act as a reservoir of heat produced by the solar system (during the weekend, or long summer evenings)

- Easy retrofit of the the solar system-so as to minimize costs

- Inefficient fuel usage, not easily rectified-so that energy delivered from the solar system replaces more than the equivalent Btu content of fossil fuel

\section{Ecoiomic Paetors}

- High and rapidly escalating fuel costs

- Uncertainties regarding fuel supplies-such as interruptible natural gas contracts

- Sufficient capital to finanoe investments in a solar energy system

- Long payback periods or demand for low rates of return on energy investments

- High federal, state, or local tax incentives for solar investments

- Energy-intensive industrial operation and energy costs representing a large fraction of value added

- All cconomical energy cunservation meäsures already incorporated

- Cheap land or a strong roof available close to the delivery point of the required energy; salt available at little or no cost, if a salt pond is a solar option

- Low labor costs - because solar installations are labor intensive

- New plant-allowing a solar system to be incorporated from the beginning

\section{Company Paetors}

- Desire to install a solar system and an enthusiastic work force from top management down

- A skilled maintenance and engineering work force-so that the solur system can be run and maintained at maximum efficiency

- Progressive management--which gives some recognition to the noneconomic but social values of solar energy, such as public relations, security of long-term supply, and reduced air pollution, leading perhaps to the application of less stringent payback criteria to investments in solar systems 
this goal will determine how quickly solar hardware is adopted by industry. Solar collectors and the required auxiliary equipment are material and labor intensive. Solar energy costs can therefore only be reduced below the general rate of inflation (which is lower than the rate of fuel price escalation) by a combination of improved performance, leading to higher operating efficiencies and increased reliability, mass production techniques, and through measures to reduce design and installation costs.

The government will greatly influence the development of the solar industry. This might be accomplished through restraints on importing fuel, through direct tax incentives, such as credits or the accelerated depreciation of solar hardware, through the direct or indirect provision of low-interest investment capital, or through a variety of other developmental, incentive, or regulatory mechanisms. Putting solar-derived energy on an equal footing with conventional fuels would exert a tremendous influence. Currently, the cost of fossil energy is tax deductible as a business operating expense. A similar number of Btu's derived from the sun or saved through conservation receive no such favorable treatment. The government could also increase funding levels of solar research and development. The IPH demonstration program will play a valuable role (if successful) in convincing skeptical industrialists of the technical and economic feasibility of solar technologies. Provided solar systems are shown to be viable technical options, it is clear that industry is most favorably influenced, and in fact will respond to, simple, direct economic incentives.

The above points are apparent to anyone familiar with the development of solar energy technology. Other factors that enhance the practicability of solar systems in the existing economic environment have been evoked by the case study program. The first of these was graphically illustrated by the case study investigation of crude oil dewatering. The propane used as a heat source was expensive and was used extremely inefficiently. Solar heat could be delivered to the process to displace several times the equivalent Btu potential of the propane. Assuming that retrofit of the existing heating system to upgrade its propane efficiency was uneconomical, this seemed a cost-effective solar application.

A similar multiplying effect can be achieved for direct-fired drying processes that involve an excess of combustion air. Hot exhaust gases can be partially reheated using solar energy and recycled to the burner. However, the economics of this scheme, which involves several fans and elaborate control, needs to be measured against alternatives. Other methods could involve, for instance, the solar preheat of combustion air already preheated by heat exchange with exhaust air.

Another means of using solar energy at an efficiency much greater than that achievable by conventional fuels is drying via direct solar radiation. Conventional drying generally involves large quantities of air. Depending on the temperature, drying can consume from two to five times the theoretical quantity of heat required simply to evaporate the water from the material being dried (due to heat leaving in the exit air stream). Moving this air also consumcs a considerable amount of electricity. On the other hand, drying material (such as gluten feed or coal) exposed under glass to direct solar radiation would require a thermal input only slightly greater than theoretical requirements. Air flow rates would be small, being only sufficient to control humidity in the exhaust air. Obviously, these benefits would be at the expense of increased drying time and at a rate dependent on insolation.

The analysis of the case study program suggests that measures to reduce energy consumption can enhance the prospect of solar energy application. Conservation projects 
must overcome the same institutional barriers and low fuel cost competition that solar technologies face. We are in a period of high interest rates, and both technologies require high front-end investments, the benefits of which are only fully apparent through life-cycle cost accounting techniques, rather than the usual industrial practice of applying required payback periods. The implementation of solar and conservation technologies in industries that would benefit most from their use is of ten hindered by the lack of information and engineering personnel. Conservation and solar technologies can greatly complicate what was once, in an era of cheap fuel, the simple process of generating energy. A forced-draft heater with recuperator and economizer is more complicated than a natural-draft heater without either., Both technologies involve considerable electricity for motors that save fossil fuel. This is probably a favorable energy trade-off, because the future cost of electrical power, being largely dependent on the cost of coal, should repeat historical trends in that its price is likely to rise much less quickly than that of natural gas or fuel oil. The similarity of problems facing the implementation of conservation and solar technologies means that actions such as the dissemination of information or the granting of tax benefits, taken to assist one technology, could favorably affect the other.

One important goal of technological development is to reduce energy inputs to industrial processes by lowering operating temperatures. For example, this has been done by developing more efficient catalytic processes and detergents that function effectively in warm rather than hot water. This trend is favorable to the marketability of solar systems, because the cost of a system increases significantly with temperature for a given quantity of energy. Another development, described in Appendix E, concerns the change from steam to high-temperature water (HTW) energy transportation systems. While this change alone is unlikely to reduce the temperature to which the water must be heated, liquid-based solar systems, compared to steam generators, are much cheaper and more efficient.

Thus, the trend towards increased energy conservation could foster solar energy installations. Solar energy and conservation technologies also present similar research and development requirements, such as the need to develop inexpensive heat exchangers to transfer heat efficiently at small temperature differences. Obviously, conservation should be the first means of saving energy at any industrial plant, and a great deal of this remains to be done; but once this potential is exhausted, solar energy is one of the few alternatives available that actually produces energy.

The case study program has also shown that more development of air collector systems and thermal energy storage is needed to extend the potential of solar IPH. Hot air is widely used in many industrial operations for baking and drying. However, solar air systems at present do not function efficiently at temperatures muoh greater than those re quired for space heating. Considerable benefits would ensue if efficient solar-heated air systems operating at small pressure drops (i.e., low parasitic power consumption) were developed. Similarly, reliable and inexpensive thermal storage systems would enhance the application of solar technologies to noncontinuous industrial operations.

Land availability is clearly a key issue in applying solar technology. Lack of space can preclude even the most favorable application. Such considerations highlight the advantage of building future industrial installations to include the option of adding a solar system. This could entail dedicating land adjacent to the plant or building a stronger roof with collector attachment points incorporated. 
The PROSYS/ECONMAT computer codes proved to be very useful for analyzing a wide range of solar IPH applications. Their flexibility, ease of data input, and speed were particular assets. Feedback from the case study program resulted in several changes and improvements in the codes. Continued development of the codes is warranted, and their distribution to the public would allow industry to perform its own initial screening of IPH projects for solar energy applications.

The case study program appears to have been successful in meeting its objectives. To further clarify some of the issues that have been raised, a continuation of the program is recommended. Focusing on favorable applications directed to SERI by industry could help speed up the identification of near-term applications and the actual installation of solar systems. For example, the food industry is a logical choice, based on its use of large quantities of hot water and its location in every region of the United States. Drying has been identified as a particularly suitable solar application. Additional economic studies would help set goals for solar IPH capital cost reductions and the required level of government incentives. With the potential role of solar energy for optimum IPH applications better defined, it is hoped that incentives could then be made available to stimulate the earliest possible use of solar energy by industry. 


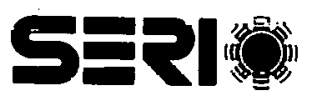




\section{SECTION 10.0}

\section{REFEKENCES}

Brenner, K. D. Director of Public Affairs, Corn Refiners Association, Inc. Modern Feed Manufacturing-Versatility with Corn.

Brown, K. C.; Hooker, D. W.; Rabl, A.; Stadjuhar, S. A.; West, R. E. 1980 (Jan.). End Use Matching for Solar Industrial Process Heat. SERI/TR-34-091. Golden, CO: Solar Energy Research Institute.

Casper, M. E., ed. 1977. Energy Saving Techniques for the Food Industry. Park Ridge, NJ: Noyes Data Corp.

Cinquemani, V.; Owenby, J. R.; Baldwin, R. G. 1978 (Nov.). Input Data for Solar Systems. Prepared by U.S. Department of Commerce for U.S. Department of Energy. Asheville, NC: USCOMME-NOAA.

Collares-Pereira, M.; Rabl, A. 1979a. "Simple Procedure for Predicting Long Term Average Performance of Nonconcentrating and of Concentrating Solar Collectors." Solar Energy. Vol. 23 (No. 7).

Collares-Pereira, M.; Rabl, A. 1979b. "Derivation of Method for Predicting Long Term Average Energy Delivery of Solar Collectors." Solar Energy. Vol. 23 (No. 7).

Dickinson, W. C.; Freeman, H. J. 1977 (June). An Economic Methodology for Solar Assisted Industrial Process Heat Systems: The Effects of Government Incentives. UCRL-52254. Liverm ore, CA: Lawrence Livermore Laboratory.

Dickinson, W. C.; Brown, K. C. 1979 (Aug.) Economic Analysis of Solar Industrial Process Heat Systems: A Methodology to Determine Annual Required Revenue and Internal Rate of Return. UCRL-52814. Livermore, CA: - Lawrence Livermore Laboratory.

Drexel University. 1976 (Dec.). Industrial Waste Energy Data Base/Technology Evaluation. CONS/2862. United Technologies Research Center, Mathematica, Inc.

Dudley, V. E. 1978 (May). Summary Report: Concentrating Solar Collector Test Results, Collector Modular Test Facility. SAND 78-0815. Albuquerque, NM: Sandia Laboratories.

Guthrie, K. M. 1969 (March 24). "Capital Cost Estimating." Chemical Engineering. Vúl. 76 (Nu. 6): pp. 114-142.

Hottel, H. C.; Whillier, A. 1955. "Evaluation of Flat-Plate Solar Collector Performance." Transactions of the Conference on the Use of Solar Energy: The Scientific Basis. Vol. II, Part I, Section A, pp. 74-104.

Johns-Manville Corp. 1976 (Nov.). A Study of Energy Conservation Potential in the Baking Industry. FEA/D-76/290. Denver, CO, for the Federal Energy Administration. 
Liu, B. Y. H.; Jordan, R. C. 1963. "A Rational Procedure for Predicting the Long Term Average Performance of Flat-Plate Solar Energy Collectors." Solar Energy. Vol. 7 (No. 53).

McCabe, W. L.; Smith, J. C. 1976. Unit Operations of Chemical Engineering. 3rd Edition. New York: McGraw-Hill, Inc.

Oil and Gas Journal (OGJ). 1980a (Jan. 14). "News."

OGJ. 1980b (Feb. 25). "News Item."

Perry, J. H.; Chilton, C. H. 1973. Chemical Engineer's Handbook. 5th Edition. New Y ork: McGraw-Hill Book Company.

Peters, M. S.; Timmerhaus, K. D. 1968. Plant Design and Economics for Chemical Engineers. 2nd Edition. Ncw Y̌ orks MoGraw-Hill Book Company.

Teller, W. H., et al. 1976 (June 21). "Conserving Fuel by Heating with Hot Water Instead of Steam." Chemical Engineering. pp. 185-190.

U.S. Dept. of Commerce, Bureau of Census. 1978 (June). Annual Survey of Manufacturers 1976-Industry Profiles. M 76 (4S)-7. 


\title{
APPENDIX A
}

\section{A SUMMARY OF THE PROSYS/ECONMAT COMPUTER CODE}

\begin{abstract}
An analytical method for assessing the feasibility of solar industrial process heat applications has been developed and implemented in a flexible, fast-calculating computer code-PROSYS/ECONMAT. The performance model PROSYS predicts long-term annual energy output for several collector types, including flat-plate, nontracking concentrator, one-axis tracking concentrator, and two-axis tracking concentrator. Solar equipment cost estimates, annual energy capacity cost, and optional net present worth analysis are provided by ECONMAT. User input consists of detailed industrial process information and optional economic parameters. Internal program data includes meteorological information for 248 U.S. sites, characteristics of more than 20 commercially available collectors representing several generic collector types, and defaults for economic parameters. Because a full-scale conventional back-up fuel system is assumed, storage is not essential and is not included in the model. Although the software is neither a dynamic simulation nor a detailed design tool, it yields the advantages of speed and flexibility and provides a method for uniform comparison of diverse solar equipment, IPH applications, and locations. Recent updates in performance calculations, the collector array sizing algorithm, and system cost estimates have improved the accuracy of the PROSYS/ ECONMAT evaluation. Efforts in IPH model comparison and PROSYS/ECONMAT validation have been initiated. The PROSYS/ECONMAT code has been used in a variety of the case studies, in-depth applications analyses, and generic system studies.
\end{abstract}

\section{EVALUATION PROCEDURE}

Software developed for the analysis of solar IPH applications includes the performance model PROSYS, the economic evaluation ECONMAT, and several attendant data bases. The main features of the PROSYS/ECONMAT code are summarized in Table A-1 and expanded in the following sections.

\section{DATA BASES}

Characterization and analysis of solar IPH applications require site-specific meteorological data, detailed industrial process information, solar equipment performance and cost data, and appropriate economic parameters. This information resides in four data bases-METDAT, IPHDB, COLDAT, and ECONMAT.

The meteorological data base (METDAT) specifies the quantity and quality of the available solar radiation at 248 U.S. locations as determined by availability of SOLMET and ERSATZ data (Cinquemani et al. 1978). Values are given for a typical day each month and include long-term average daily total radiation on a horizontal surface, clearness number, daytime ambient average temperature, and cloudiness index $\mathrm{K}_{\mathrm{T}}$ for each location. 
Table A-1. FEATURES OF THE PROSYS/ECONMAT CODE

\begin{tabular}{|c|c|}
\hline Purpose: & Provide a method to assess feasibility of solar IPH applications. \\
\hline User Inputs: & $\begin{array}{l}\text { Detailed industrial process information and optional economic } \\
\text { parameters. }\end{array}$ \\
\hline $\begin{array}{l}\text { Internal } \\
\text { Data: }\end{array}$ & $\begin{array}{l}\text { Meteorological inf ormation for } 248 \text { U.S. sites. } \\
\text { Characteristics of several generic collector types. } \\
\text { Defaults for economic parameters. }\end{array}$ \\
\hline $\begin{array}{l}\text { Progralin } \\
\text { Outputs: }\end{array}$ & $\begin{array}{l}\text { Long-term average performance prediction for cach collcctor procese } \\
\text { combination. } \\
\text { Estimate of sólar system cost and annurl energy cupucily cusl. } \\
\text { Optional present worth analysis. }\end{array}$ \\
\hline Advantages: & $\begin{array}{l}\text { Flexible, high-speed evaluation. } \\
\text { Uniform comparison of diverse solar equipment, IPH applications, and } \\
\text { locations. }\end{array}$ \\
\hline Restrictions: & $\begin{array}{l}\text { Nondyna mic analysis. } \\
\text { Not a detailed design tool. } \\
\text { Conventional fuel backup assumed, no consideration of storage. }\end{array}$ \\
\hline
\end{tabular}

The industrial process heat data base (IPHDB) is composed of entries for specific processes and contains for each of them: temperature, heat rate, and flow rate requirements; conventional fuel. source and efficiency; and appropriate system types in order of applicability (three of a possible six). Each entry is identified as a four-digit standard industrial classification (SIC) and an optional alphanumeric character if subprocesses are given.

At the present time, 20 collectors are represented in the collector data base (COLDAT). Of these, eight have performance data derived through tests at the facilities of Sandia Laboratory, Albuquerque (Dudley 1978). Both performance and cost information is given for each collector, including optical efflclency, concentrulion ratio, heat-loss coefficients, internal blocking and shading factors, FOB costs, auxiliary costs, and installation labor. Generic collector types represented in COLDAT include flatplate, compound parabolic concentrator, linear Fresnel lens, parabolic trough, line focus, and parabolic dish. Collector parameters for flat-plate and parabolic trough collectors are shown in Table A-2.

The economic data base (ECONDAT) contains site-specific information on labor rates and conventional fuel costs, Including coal, natural gas, fuel oil, electricity, and propane. Fuel costs often vary with the amount used, contract status (firms, interruptible, etc.), and use schedule. In cases where such detailed information is known, the data base values can be overridden through card input. 
Table A-2. COLLECTOR PARAMETERS USED IN PROSYS SIMULATIONS

\begin{tabular}{lcc}
\hline & $\begin{array}{c}\text { Flat-Plate } \\
\text { Collector }\end{array}$ & $\begin{array}{c}\text { Parabolic Trough } \\
\text { Collector }\end{array}$ \\
\hline Shading and Blockage Factor & 0.0 & 0.1 \\
Optical Efficiency & 0.77 & 0.72 \\
Tracking Efficiency (degrees) & 1.00 & 0.98 \\
Concentration Ratio & 1.00 & 25.0 \\
FOB Cost $\left(\$ / \mathrm{ft}^{2}\right.$ ) & 15.00 & 22.00 \\
Auxiliary Equipment Cost $\left(\$ / \mathrm{ft}^{2}\right)$ & 1.50 & 0.00 \\
Burdened Cost $\left(\$ / \mathrm{ft}^{2}\right)$ & 0.00 & 1.00 \\
Required Installation Labor $\left(\mathrm{h} / \mathrm{ft}^{2}\right)$ & 0.25 & 0.30 \\
Standard Collector Module Area $\left(\mathrm{ft}^{2}\right)$ & 24.0 & 170.0 \\
Heat Loss Coefficient & & 0.07 \\
(Btu/h $\left.\mathrm{ft}^{20} \mathrm{~F}\right)^{\mathrm{a}}$ & 0.81 & 0.07 \\
\hline
\end{tabular}

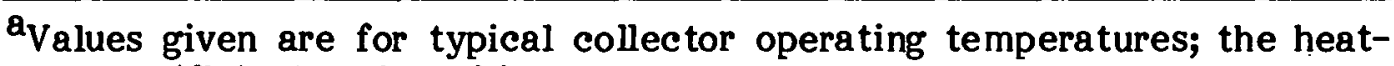
loss coefficient varies with collector temperature.

\section{PERFORMANCE MODEI. PROSYS}

To assess the feasibility of solar energy for a specific industrial process, it is first necessary to calculate the amount of energy that can be delivered by the available solar equipment while satisfying the process requirements. The analytical performance model applies a method developed by Rabl and Collares-Pereira that predicts the long-term average energy delivered by several generic collector types. This procedure is based on the classical utilizability concept originated by Hottel and Whillier (1955) and Liu and Jordan (1963) for flat-plate collectors. Rabl and Collares-Pereira (1979a, b) have generalized and simplified the method by including other collector types and defining the utilizability with respect to the day rather than the hour.

Collectors that are modeled include the two-axis tracking concentrator, single-axis concentrator, nontracking concentrator (compound parabolic concentrator), and flat-plate collector. The calculated deliverable energy per unit area for a single collector is adjusted to include losses normal to larger systems. Six system types are modeled, including direct hot water, fluid/water heat exchange, direct hot air, fluid/air heat exchange, flashed steam, and unfired steam generator.

The analytical model is implemented in the computer program PROSYS (Process Heat System Model) yielding a tool with which a variety of solar equipment configurations can be evaluated. PROSYS is neither a dynamic simulation nor a means of detailed system design, but instead a method of predicting long-term average performance. While the nondynamic nature of the model imposes some limitations, it yields the advantages of speed and flexibility. The model provides an efficient method for preliminary appraisal of solar energy for industrial applications, a standard procedure to compare generic collector types, and a rapid means of performing a large number of parametric studies. 


\section{ECONOMIC EVALUATION ECONMAT}

The basic calculation of the economic analysis is the estimation of the total solar equipment cost. To allow comparison of systems differing in size and annual energy output, an energy capacity cost [ $\$ /(\mathrm{GJ} / \mathrm{yr})]$ is calculated by dividing the total equipment cost by the annual delivered energy. Additional economic evaluation may include calculation of lifecycle levelized energy cost, net present value, payback period, and break-even fuel price (Dickinson et al. 1977, 1979). For the case study examples, gross payback periods (defined in Table A-3) were calculated.

\section{Table A-3. DEFINTION OF PAYBACK PERIOD}

For the case study examples, a gross payback period, ignoring inflation and income tax, was calculated, defined by the following equation:

$$
T=\frac{1-T C}{\frac{\mathrm{eE}_{\mathbf{s} \mathrm{P}_{\mathrm{fo}}}}{\mathrm{I}}-\mathrm{OMPI}_{\mathrm{o}}}
$$

$$
\begin{array}{ll}
\text { where } \mathrm{T} & =\text { gross payback period, years } \\
\mathrm{TC} & =\text { total investment tax credit } \\
\mathrm{e} & =\text { solar eff ectiveness factor = fuel energy saved by solar system divided } \\
& \text { by solar energy delivered } \\
& =\text { annual solar energy provided by solar system at point-of-use } \\
\mathrm{P}_{\mathrm{S}} & =\text { price of fuel in zero-year } \\
\mathrm{I} & =\text { total initial solar system investment in zero-year dollars. } \\
\mathrm{OMPI}_{\mathrm{O}}= & \text { average cost of operation, maintenance, property tax, and insurance, as } \\
& \text { fraction of total initial investment in zero-year dullars. }
\end{array}
$$

The computer program ECONMAT implements the analysis using the precalculated performance data from PERFDAT, the collector costs from COLDAT, and labor rates from ECONMAT. Given the process demand heat rate and the collector peak delivery rate, the collector array is sized such that all energy supplied by the solar system is used by the process and no excess energy is produced. Total solar equipment cost is estimated, including collector, auxiliary equipment, installation, and system costs.

The optional net present value analysis depends on economic factors that may vary from case to case. The software contains typical default values for economic parameters, such as $12 \%$ internal rate of return; $6 \%$ general inflation rate; $5 \%$ add-on fuel escalation rate; annual operation, maintenance, property tax, and insurance at $2 \%$ of initial investment; $50 \%$ corporate income tax rate; 20 -year system lifetime; and $20 \%$ tax credit. Appropriate local fuel price is obtained from ECONMAT. All default economic factors, including fuel price and labor rate, may be overridden by user input.

To allow system size variation for a specific process and to demonstrate the economy of scale effect, all calculations are shown for 10 incremental energy levels. A large number 
of computations are required to evaluate each process-system-collector combination at 10 energy increments, and a large output results. To facilitate analysis, an option is provided to print only the results for the most economical collector per system.

\section{ANALYTICAL RESULTS}

The analytical tools PROSYS/ECONMAT allow comparison of a variety of collectors for diverse process requirements and quick selection of the solar equipment most suitable in both cost and performance for a specific process. The software can be used for many types of analysis merely by varying the information in the data bases. A ranking of solar IPH applications for a given location can be generated by using an IPHDB containing average parameter values for many "typical" industrial plants. Conversely, actual case studies that provide detailed process breakdown, preheat potential, and/or process reconfiguration can be analyzed with an IPHDB containing specific process data. 


\section{APPENDIX B}

\section{SOLAR SYSTEM SCHEMATICS}

The ECONMAT costing routines are based upon the simplified schematics shown below. Heat is generally transferred to an industrial process as either hot air, hot water (or another liquid), or. steam. Transfer can be either direct (with the process fluid passing through the collector field), or a heat exchanger can be used to transfer heat from a heat transfer fluid, circulating through the collectors, to the process fluid. The figures also document a brief discussion of the relative advantages of each approach. 


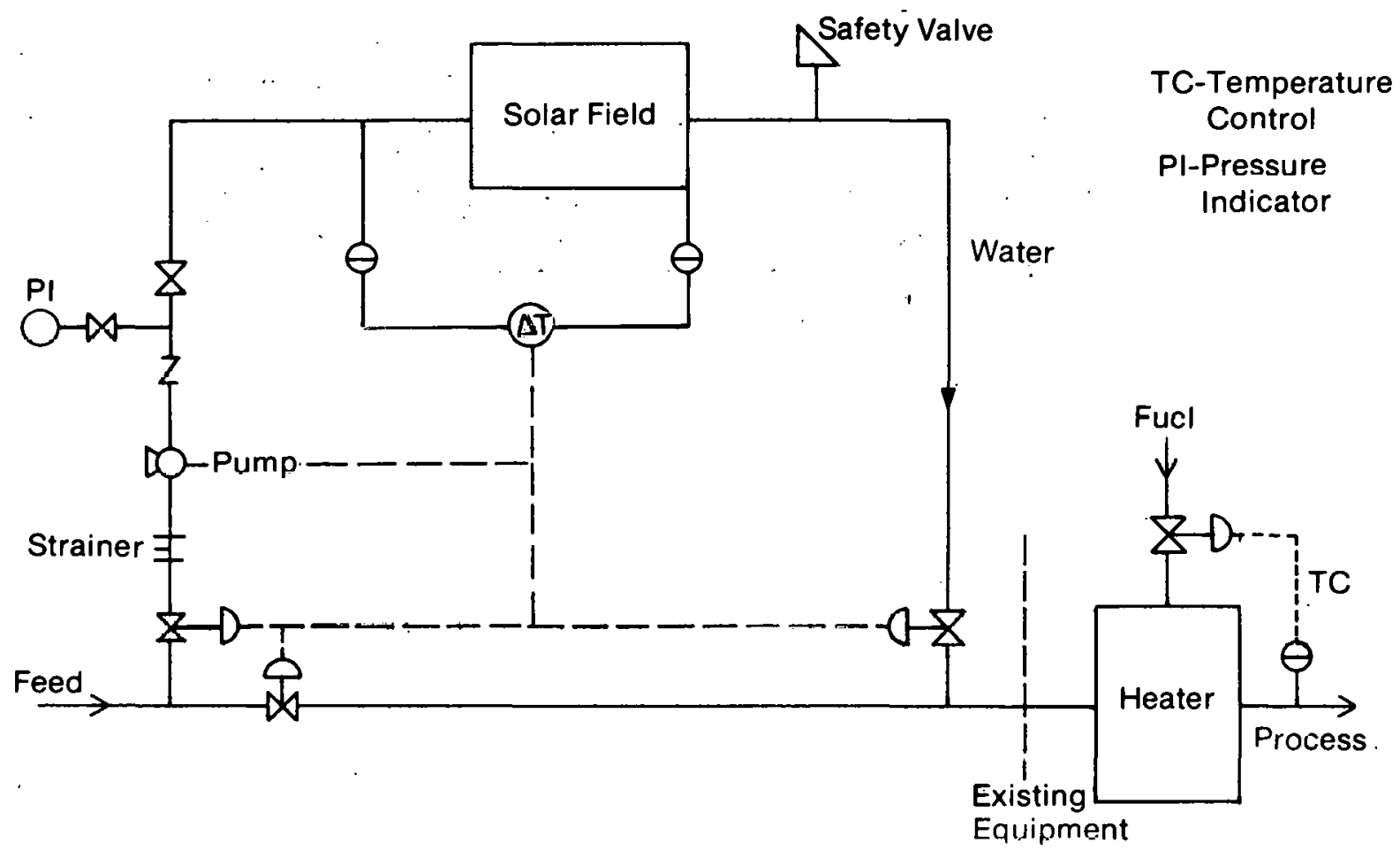

Advantages

1. Collectors at maximum efficiency

2. Minimum equipment

3. No contamination problems
Disadvantages

1. Control valves required

2. Freeze protection needed in adverse climates by:

a. Heat Tracing-steam or electrical

b. Circulation-must avoid dead spots

c. Draindown Not Feasible for Large TC Systems-admitting air causes corrosion problems; system must be liquid full before pump starts; process flow must not be interrupted during filling; possible stagnation problems with flatplatucollectors

3. Solids built up in collector lines

Figure B-1. Simplified Schematic of Hot Water Direct Solar System 


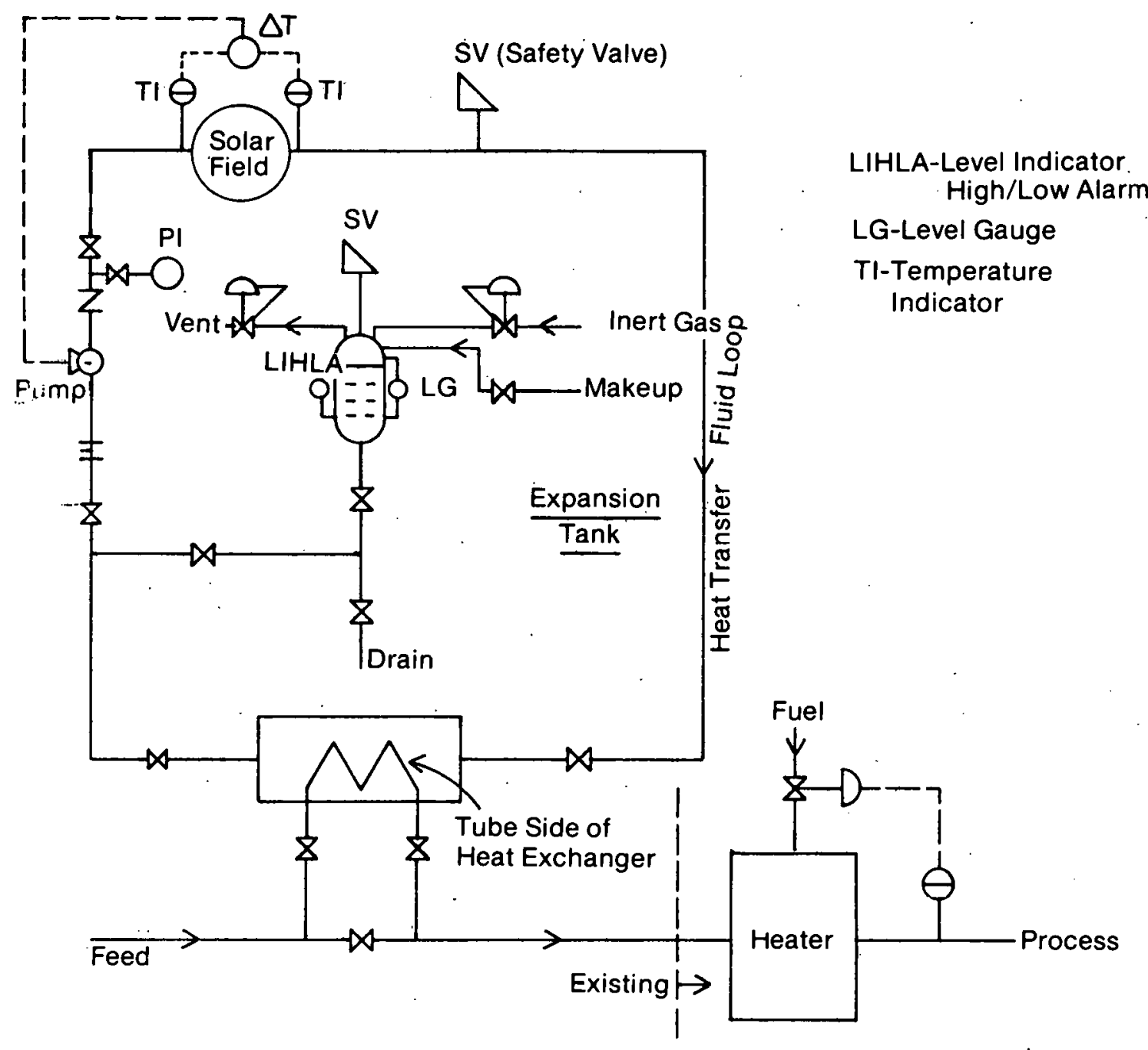

Advantages

1. No freezing problems

2. Simple Controls-no control valves. $\Delta T$ turns pump on and off. Supply always flows through heat exchanger
Disadvantages

1. Higher collector temperature

2. Possible contamination of water stream if leakage of heat transfer fluid

3. More equipment

Figure B-2. Simplified Schematic of Hot Water Indirect Solar System 


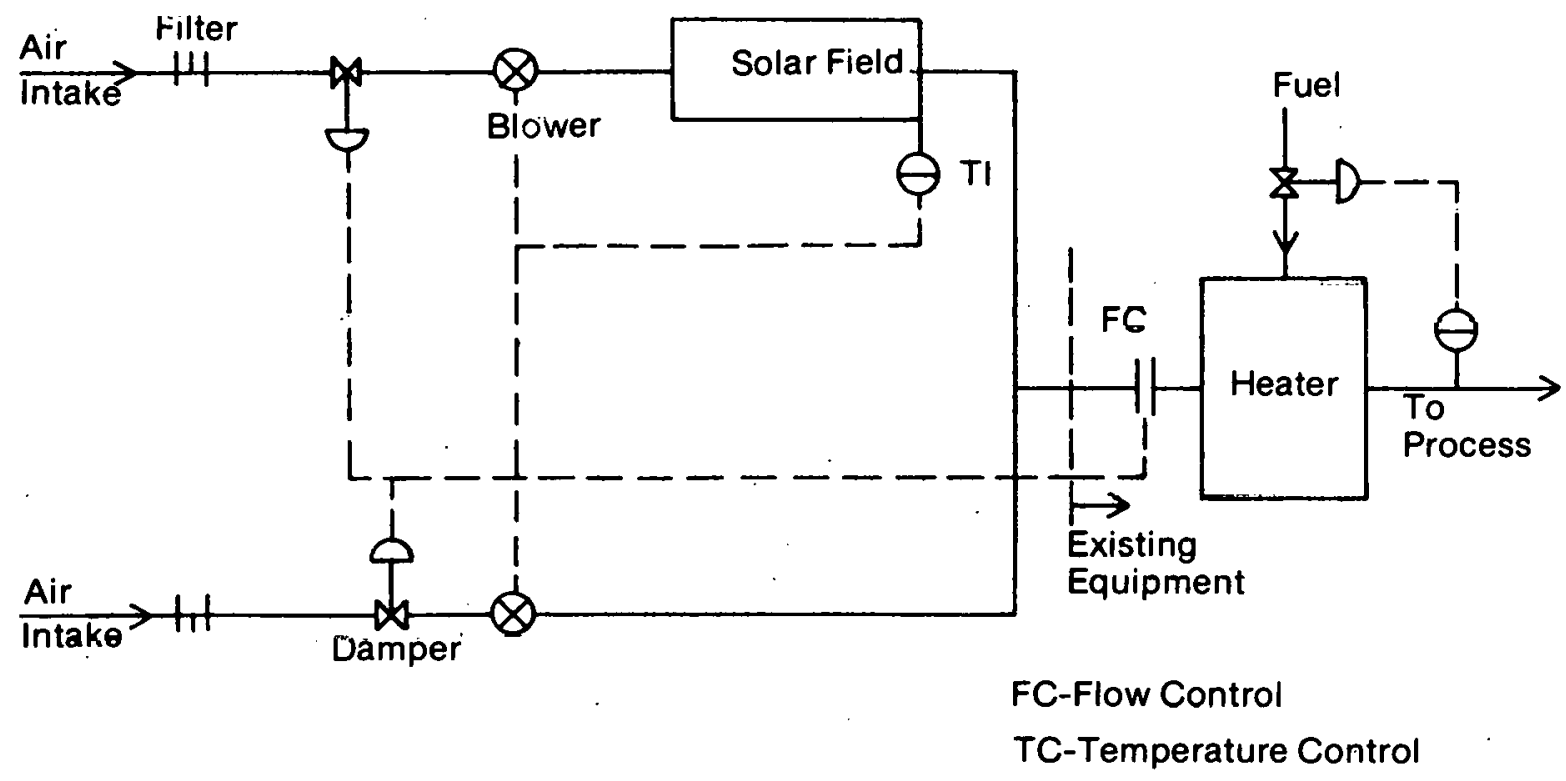

Advantages

1. No hoat cxohange, hence lower collectüi temperatures

2. No freezing problems

\section{Disadvantages}

1. Air is puu lieal lrarssler fluld. Collector efficiencies very!low at elevated temperatures

2. Collector internals exposed to contaminants in ambient air

3. High parasitice

Figure B-3. Simplified Schematic of Hot Air Direct Solar System 
Configuration exactly the same as hot-water indirect system. Cost is increased due to use of liquid-to-air heat exchanger.

Advantages

1. Best absorber working fluid can be chosen

2. Energy could be transferred from more remote location

3. Lower power consumption
Disadvantages

1. Higher collector temperatures

2. Heat exchange required and air film heat transfer coefficients tend to be low

Figure B-4. Solar Hot Air Indirect System 


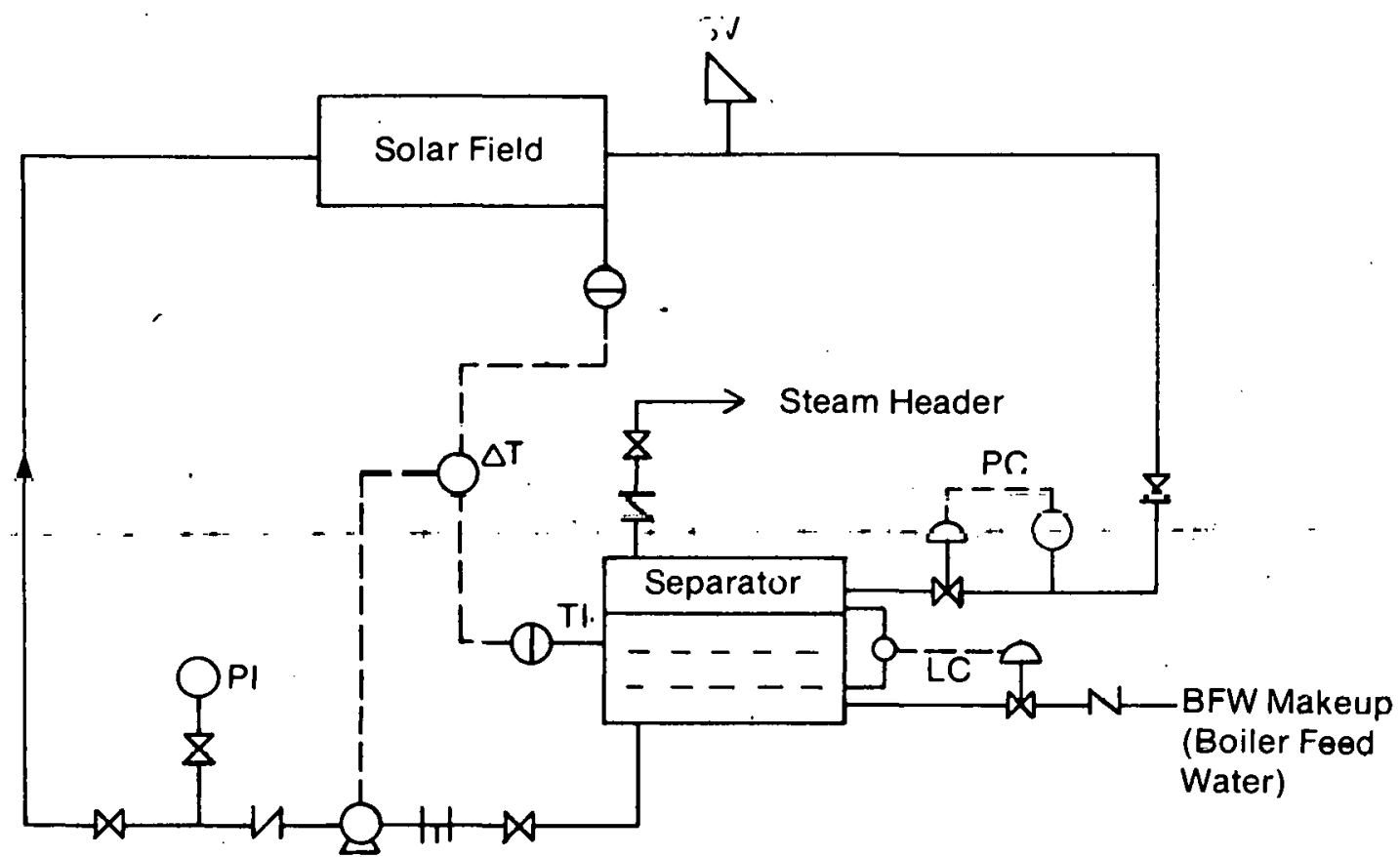

Advantages

1. Simple system

2. No expensive HTF and inert gas blanketing system

3. Low coollector temperatures
Dlsadvantages

1. Freeze protection required by tracing or circulation

2. High-pressure system, increasing cost and rating of equipment

$\begin{array}{llc}\text { Sat. Steam } & \text { Temp., }^{\circ} \mathrm{F} & \text { Press., psig } \\ & 250 & 15 \\ & 300 & 52 \\ & 400 & 232 \\ & 500 & 66 .\end{array}$

3. Pump head and power requirements increase drastically above $300^{\circ} \mathrm{F}$

Figure B-5. Simplified Schematic of Water Flash Steam Generating System 


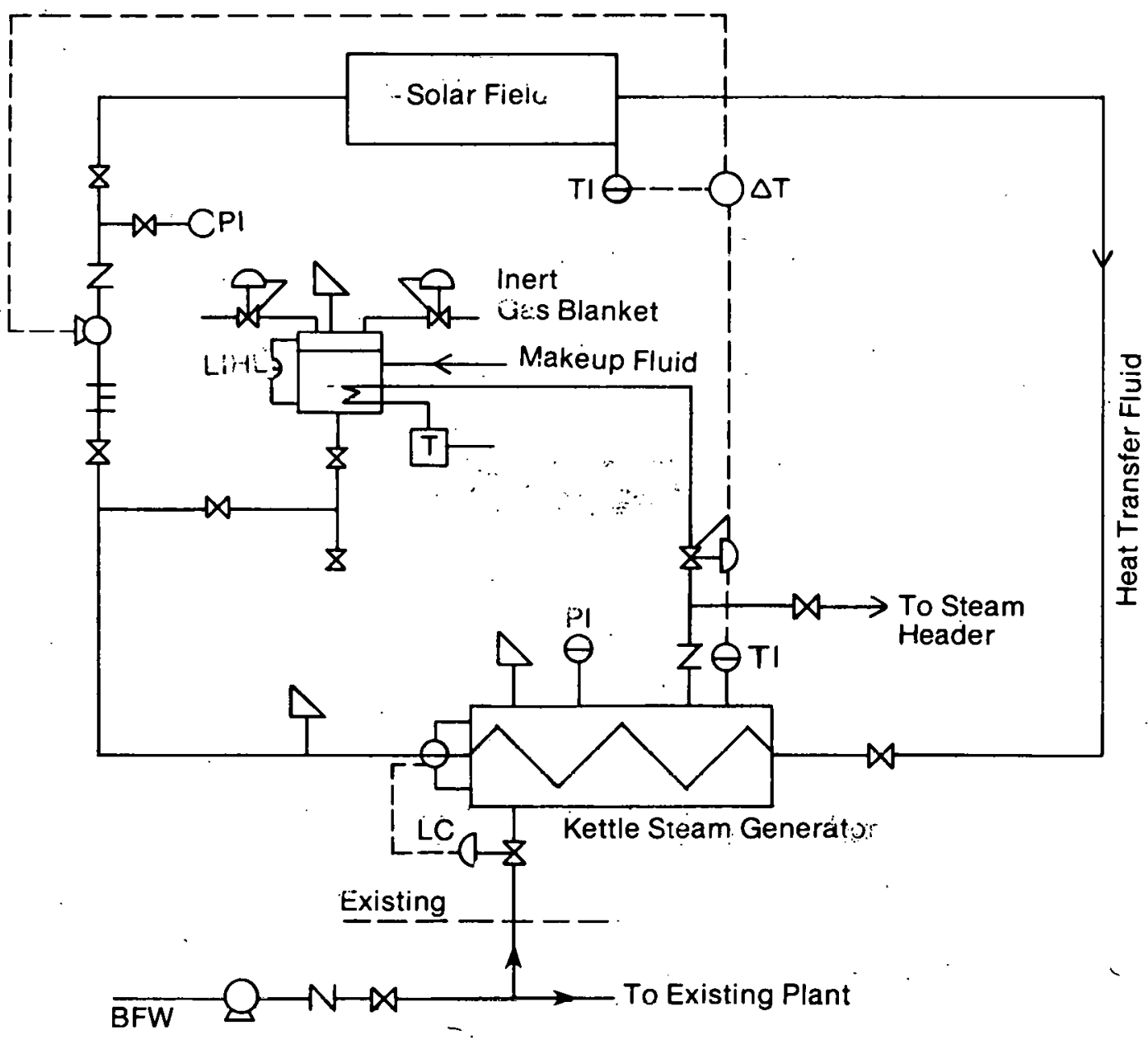

Advantages

1. Low-pressure, low-head, hot oil system

2. No freeze protection required except tracing on boiler

3. Lower pumping power to produce highpressure stẹam

4. Steam could be superheated
Disadvantages

1. Highier collector temperature

2. Heat transfer fluids costly, possibility of fire, if leakage

3. Larger flow rate

4. Higher parasitics to produce low-pressure steam

Figure B-6. Simplified Schematic of Indirect Steam Generating System 


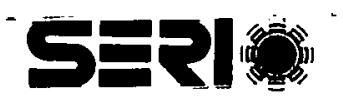




\section{APPENDIX C}

\section{INSOLATION MAPS OF THE UNITED STATES}

Figure C-1 illustrates the average daily global solar radiation on a horizontal surface. This is equivalent to the sum of the direct and diffuse components of solar radiation. Figure C-2 illustrates average daily direct normal solar radiation. This is radiation incident on a surface facing directly into the sun. Figures $\mathrm{C}-1$ and $\mathrm{C}-2$ are computer maps derived from data obtained at the SOLMET and ERSATZ collection sites. The list below illustrates values of solar radiation in different units:

$$
\begin{array}{ccc}
\mathrm{kJ} / \mathrm{m}^{2}-\mathrm{dy} & \mathrm{kWh} / \mathrm{m}^{2}-\mathrm{dy} & \mathrm{Btu} / \mathrm{ft}^{2}-\mathrm{dy} \\
26,000 & 7.2 & 2290 \\
10,000 & 2.8 & 881
\end{array}
$$

The thermal output of a solar collector is greatly influenced by levels of insolation, but factors such as ambient temperature, orientation, the type of solar collector, and the type of solar radiation must also be taken into account. In areas where diffuse radiation is a large fraction of total radiation, nonconcentrating collectors are capable of collecting more energy at temperatures less than $.93^{\circ} \mathrm{C}\left(200^{\circ} \mathrm{F}\right)$ than highly concentrating collectors, such as parabolic troughs and dishes. 


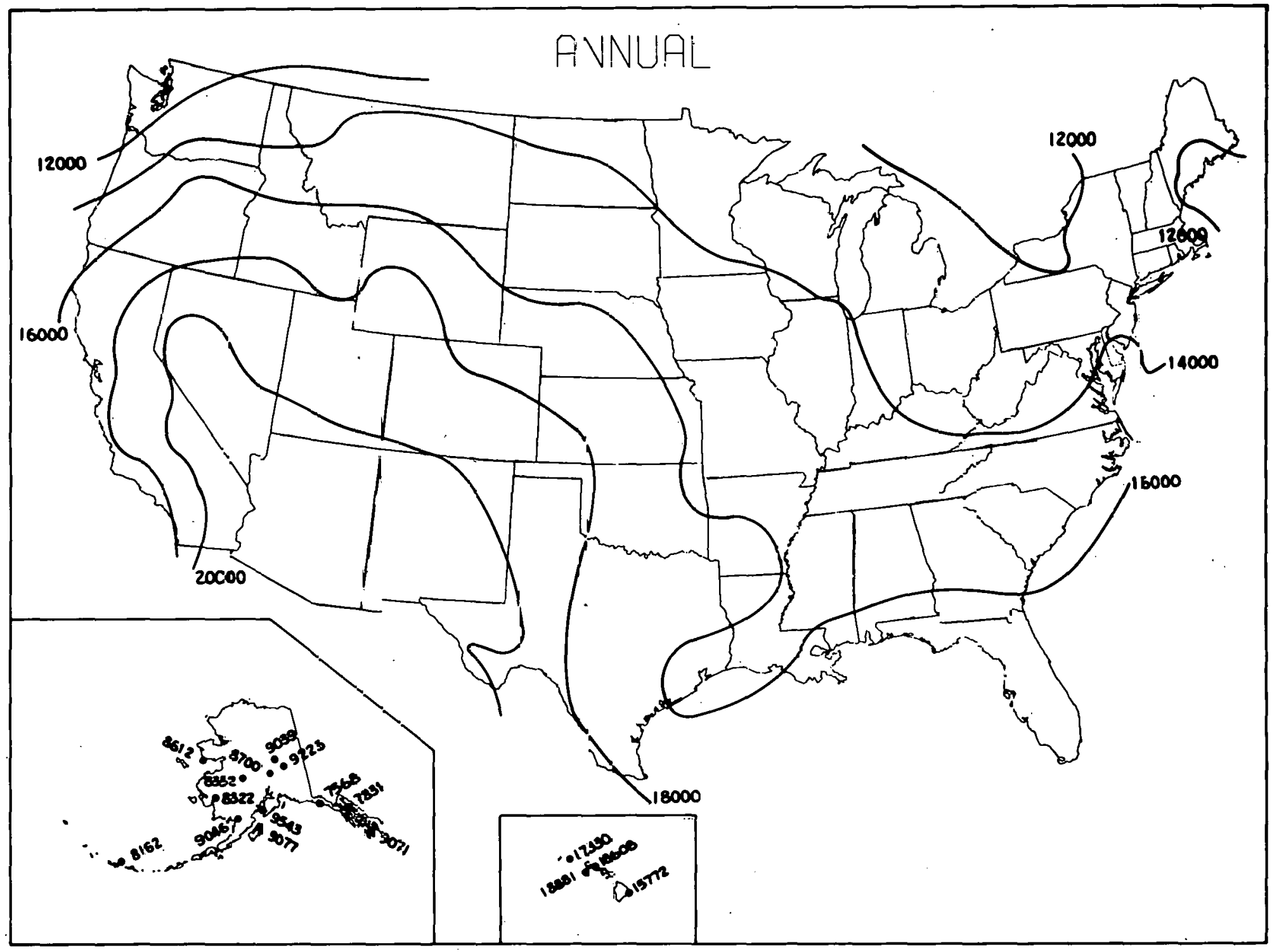

Figure C-1. Average Daily Global Solar Radiation on a Horizontal Surface $\left(\mathrm{kJ} / \mathrm{m}^{2}\right)$ 


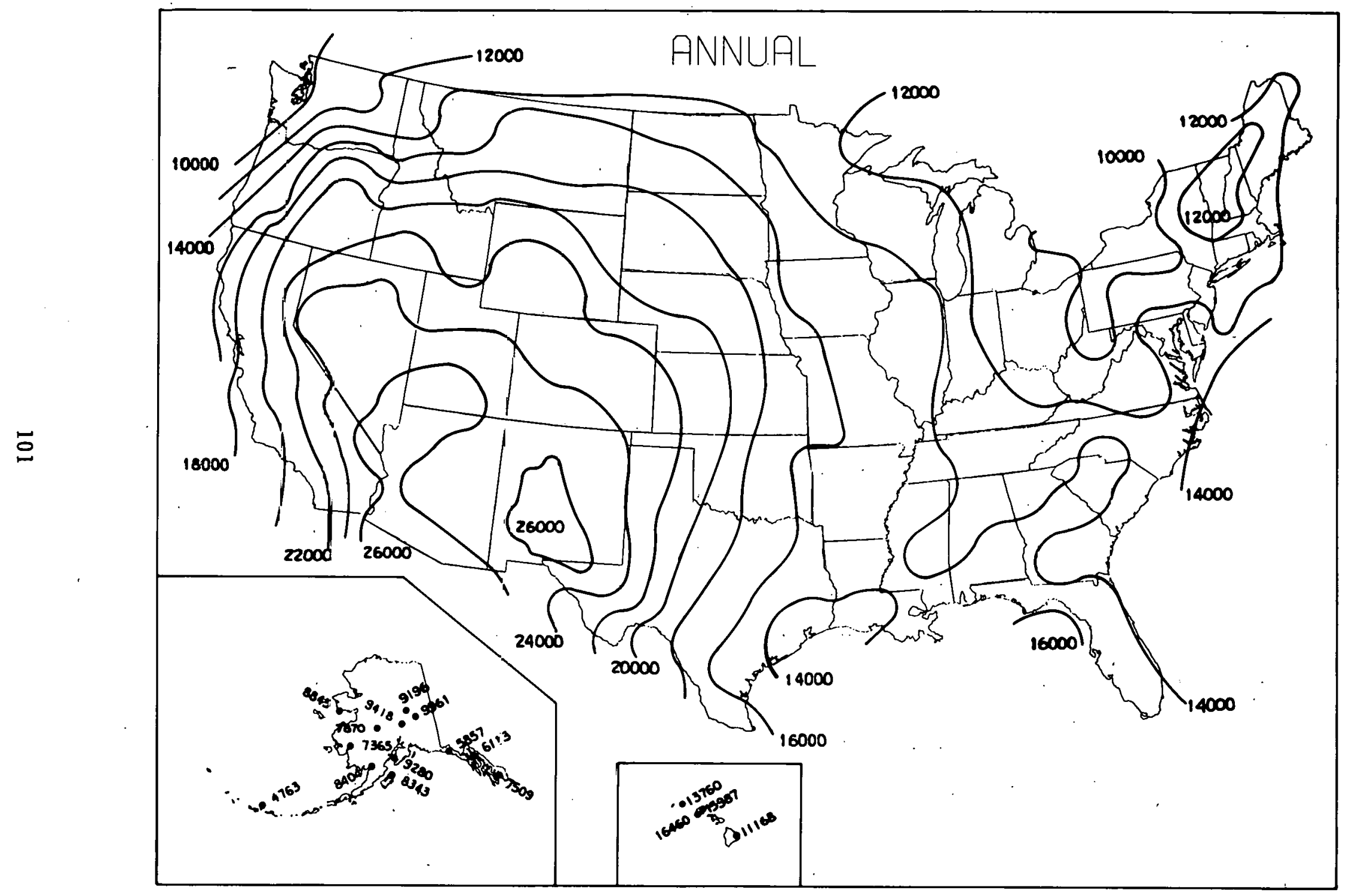

Figure C-2. Average Daily Direct Normal Solar Radiation (kJ/m²) 


\begin{abstract}
APPENDDX D
Figures D-1 and D-2 are examples of the PROSYS simulation carried out for various collectors at representative sites (El Paso, Tex. and Charleston, S.C.). The graphs illustrate a great deal, notably:

- The performance of point-focus collectors is almost independent of temperature, resembling the performance of a conventional heater. This results because the small area of the concentrating receiver greatly reduces thermal losses. Nonconcentrating collectors are most affected by thermal losses due to their large area, and thus their performance falls drastically with increased temperature. The maximum delivery temperature of flat-plate collectors is about $160-180^{\circ} \mathrm{F}$. The performance of line-focus collectors, such as parabolic troughs, is dependent on temperature to an extent somewhere between flat-plate and point-focus concentrators.
\end{abstract}

- Concentrating collectors can only collect the direct component of solar radiation. Consequently, their performance suffers greatly in environments that are cloudy or subject to high humidity. Thus, at low operating temperatures in locations such as Charleston, a flat-plate can outperfor $m$ a point-focus collector.

- The performance of point-focus collectors; for highly sunny climates, exceeds all other types because the two-axis tracking mechanism allows greater efficiency of collection and because the design reduces thermal losses. The output of a two-axis tracking collector is basically constant when the sun is shining. This is of particular benefit for IPH applications, where the desire is to service a constant load. Single-axis (e.g., parabolic troughs) or nontracking collectors (e.g., flat plates) exhibit output characteristics, which gradually rise and fall around solar noon. Such collectors also exhibit large seasonal variations in solar output, partially the result of lower winter ambient temperatures, but more importantly because of geometric orientation. The output of a point-focus collector largely varies in proportion to the hours of sunshine. 


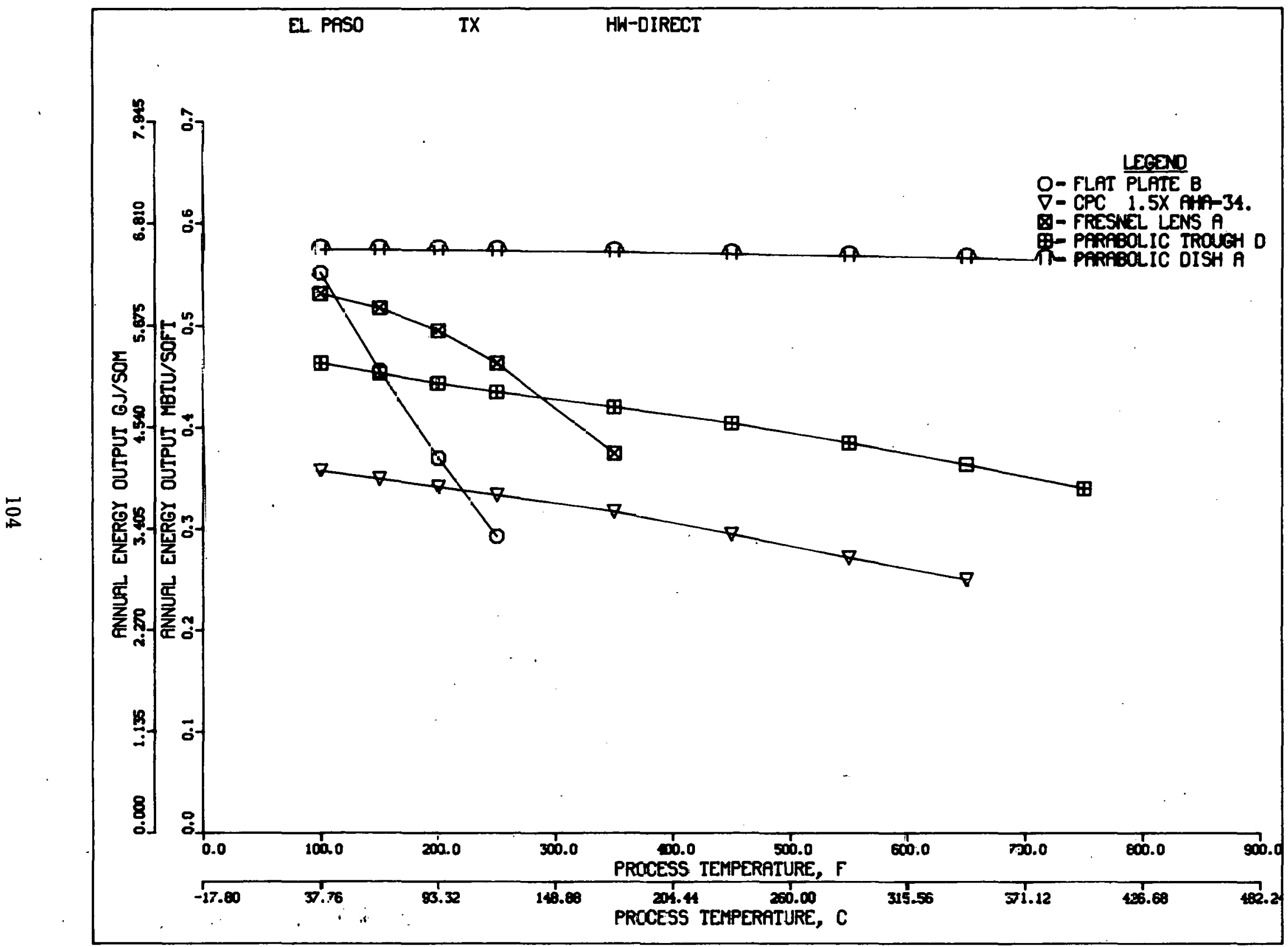

Figure D-1. Annual Energy Output of Several Collector Types over a Range of Temperatures for EI Paso 


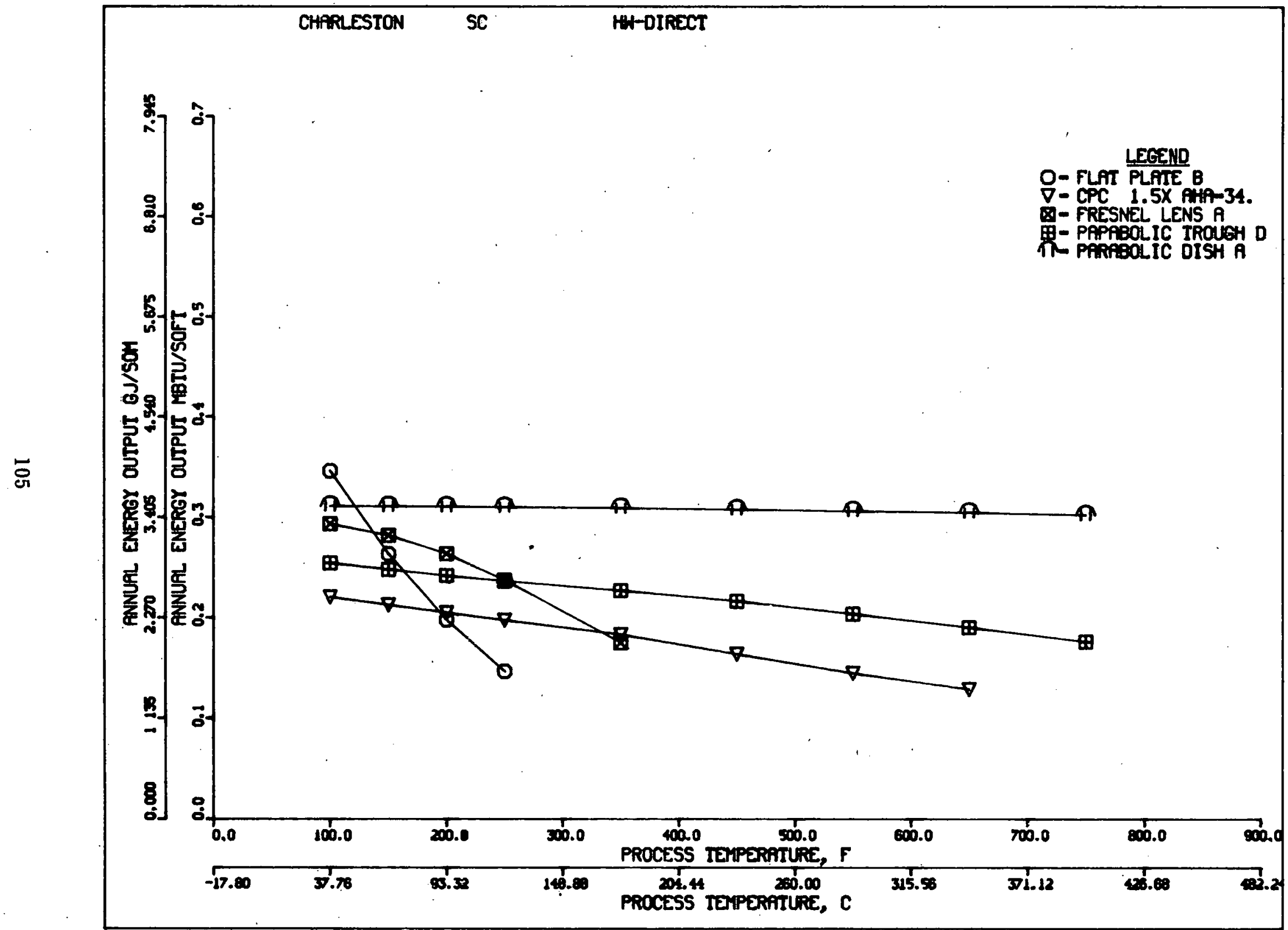

Figure D-2. Annual Energy Output of Several Collector Types over a Range of Temperatures for Charleston, S.C. 


\section{SERP}




\section{APPENDIX E}

\section{THE ADVANTAGES OF LIQUID OVER STEAM HEATING SYSTEMS FOR INDUSTRIAL PROCESS HEAT AND THE POTENTIAL FOR SOLAR ENERGY APPLICATIONS}

The use of package steam boilers to provide low-temperature process heat is a common industrial practice. This is true regardless of process temperature requirements. Steam boilers are widely used in industries such as dairying and meat-packing, even though almost the entire process heat load could be supplied using hot water.

Package steam boilers are available "off the shelf" to provide a wide variety of process heat requirements. They are compact and rapid in response. Pumping power requirements are low, and the pump runs at a low temperature. The condensation process allows large quantities of heat to be transferred for a low mass flow rate-a particular advantage for direct process heating. However, there is a body of trade literature advocating that the package steam boiler is a relic of the low-fuel-cost economy, and that considerable savings can be realized by heating with liquids instead of steam.

Process heating using high-temperature water (HTW) is feasible to about $400^{\circ} \mathrm{F}$. Above this temperature, the pressures required to keep water in a liquid state are too high to be practical. Makeup and treatment of water for a hot water system are minimal. Treatment of boiler feed water to a steam system is more extensive, and blow-down requirements result in considerable heat loss. Additional steam system heat losses result from leaks from the increased number of fittings, such as traps and pressure-reducing valves, and from vents on condensate receivers.

A forced water-circulating system can give more accurate process temperature control. Liquid flow rates can be selected to give very small sensible-heat temperature drops. Consequently, uniform heat transfer rates can be maintained throughout the heating coil. In contrast, steam condensing in a coil yields less uniform heat transfer due to variations in saturation temperature caused by pressure drop along the coil and to changes in condensing film thickness.

Though steam yields $800-960 \mathrm{Btu} / \mathrm{lb}$ when it condenses, while a hot water system can transfer only 100-150 Btu/lb, the heat capacity of a liquid system is typically about 40 times that of the equivalent steam system (Teller et al. 1976). This inherent heat storage in a liquid system reduces fluctuations in hea ter output, improving hea ter efficiency and reducing wear. However, high heat capacity is a disadvantage for discontinuous operations due to the inertia related to bringing the system back on-line. For a solar system, high heat capacity can mean high thermal losses when the system is not in operation.

Operation and maintenance costs of a steam system are higher than those of a water system because oxygen dissolved in condensate can cause pipe corrosion; because there is the possibility of scale formation in boiler tubes; and because there are more fittings:

Teller et al. (1976) claims a high-temperature water system substituted for a steam system can result in fuel savings of 20-50\%. Systems in the range of 5 to $15 \mathrm{million} \mathrm{Btu} / \mathrm{h}$ (1.5 to $4.4 \mathrm{MW}$ ) are regarded as only marginally more economical than steam systems, but are often preferred due to more accura te and uniform temperature control. 
Above about $400^{\circ} \mathrm{F}\left(204^{\circ} \mathrm{C}\right)$, process heating needs of ten are supplied using superhea ted steam. However, the relative advantages of liquid heating still hold at higher temperatures when water is replaced by commercially available heat transfer fluids. These systems have the advantage of operating at low pressure; but compared to water, heat transfer fluids have higher viscosities, lower specific heats, and are of ten flammable..

Liquid-based solar systems are more developed, cheaper, and more efficient than solar systems generating steam. It is an easy matter to heat a liquid pumped through a solar collector. A system generating steam is much more complex. The use of a liquid heating system reduces the difference between required collector temperature and process temperature. Because of freezing problems, heat transfer fluids will of ten be used in solar collectors for industrial applications. The problems of retrofitting solar installations are greatly diminished if the industrial heat delivery system is already liquid based. Overall, the economic conversion from steam to liquid process heating greatly inereases the potential for solar energy applications. 


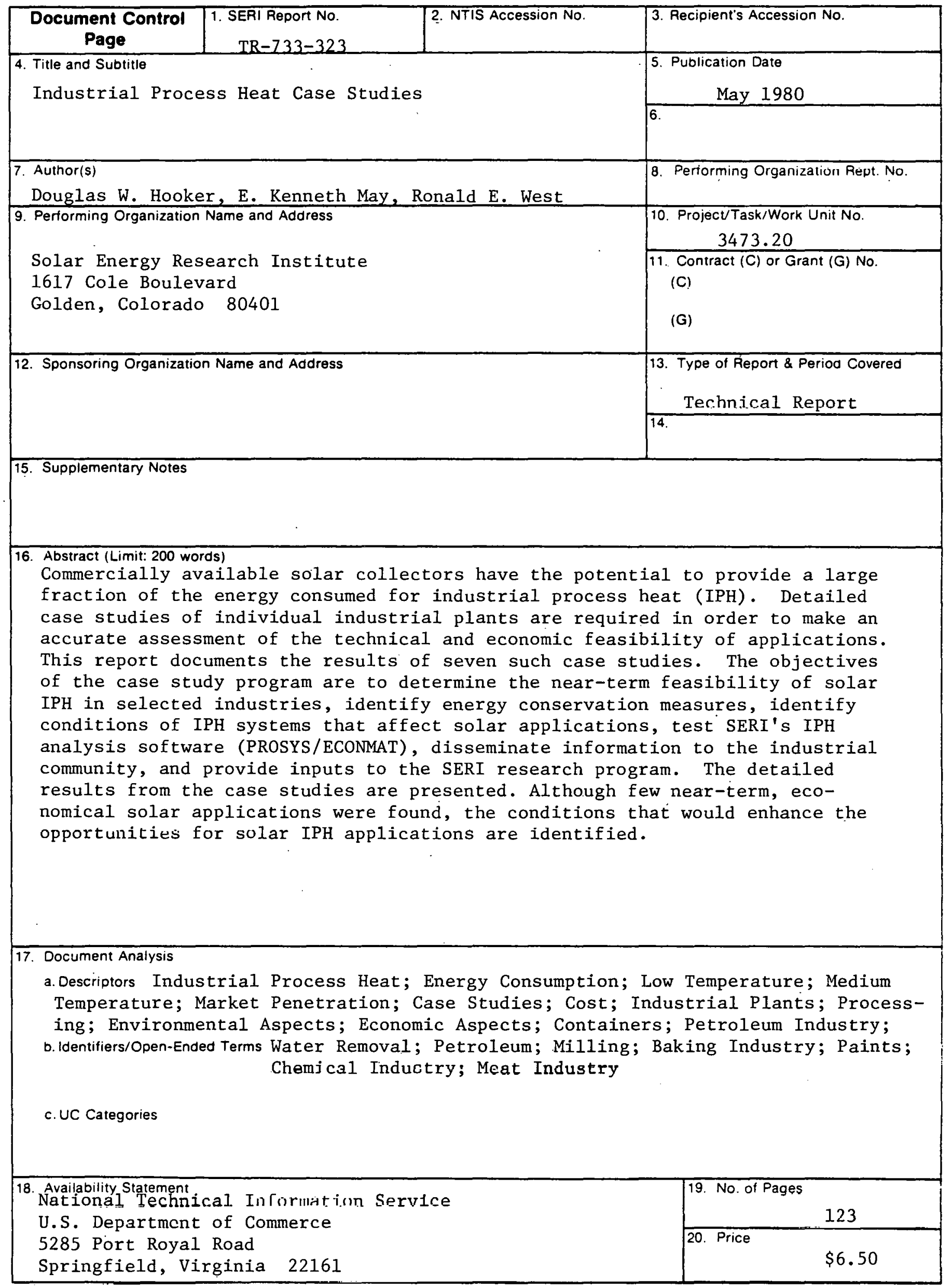

